\author{
Universidade de São Paulo \\ Faculdade de Saúde Pública
}

Análise da configuração da agenda de revisão da Política Nacional de Atenção Básica de 2017: contexto, problemas e alternativas

Américo Yuiti Mori

São Paulo

2019 


\title{
Análise da configuração da agenda de revisão da Política Nacional de Atenção Básica de 2017: contexto, problemas e alternativas
}

\author{
Américo Yuiti Mori
}

Dissertação apresentada ao Programa de PósGraduação em Saúde Pública para obtenção do título de Mestre em Ciências da Saúde

Área de Concentração: Saúde Pública

Orientadora: Prof ${ }^{\mathrm{a}} . \mathrm{Dr}^{\mathrm{a}}$ Cleide Lavieri Martins Coorientadora: Prof ${ }^{a}$. Dr ${ }^{\mathrm{a}}$ Aylene Emilia Moraes Bousquat

\author{
Versão Original \\ São Paulo \\ 2019
}


Autorizo a reprodução e divulgação total ou parcial deste trabalho, por qualquer meio convencional ou eletrônico, para fins de estudo e pesquisa, desde que citada a fonte. 


\section{AGRADECIMENTOS}

A minha família, em especial aos meus pais, que garantiram as condições para que eu pudesse estudar. A minha mãe, que mesmo com dificuldade de ler o que diziam os livros, não deixou que faltassem.

A minha filha Lia Harumi, primavera que mudou a minha vida e me faz querer mudar o mundo para fazê-la sorrir.

Ao meu filho Martim Akira, que nasceu junto com o projeto de mestrado e me ensina sobre o propósito das coisas a partir da sua própria natureza.

A Cau, minha companheira da vida, agradeço a compreensão, a empolgação, as reflexões, as crises e conclusões sobre o mundo e a nossa vida. Agradeço o companheirismo nas madrugadas de estudo, por me incentivar em cada nova etapa e principalmente por acreditar em mim.

A Liu, que de forma despretensiosa me convenceu a realizar a seleção do mestrado e de uma forma ou de outra faz parte dessa história.

Aos amigos do tempo da Residência de São Carlos, encontros de São Bernardo e tempos contemporâneos de São Paulo, eterna fonte de afeto, debates, discussões e inspirações.

A família do Grito Lara, Lari, Mari, Lucas... e todas e todos que passaram por ali, a acolhida de vocês foi fundamental nesse novo tempo em São Paulo. Além disso, me deram fatos, livros e textos para ler, contribuições e reflexões que estão presentes na dissertação.

As minhas orientadoras, professoras Cleide e Aylene, obrigado pela oportunidade de aprendizado e pela serenidade nas orientações. Vocês me deixaram muito à vontade e contribuíram para que o mestrado fosse um processo prazeroso.

Aos professores Cristiani Vieira Machado, Lígia Giovanella e Luiz Augusto Facchini pela disposição e suas valiosas considerações sobre o desenvolvimento do trabalho.

A Faculdade de Saúde Pública e Universidade de São Paulo que proporcionaram infinitas possibilidades de aprendizado e total condição para o desenvolvimento da pesquisa. A universidade pública não só resiste como é motivo de orgulho.

Finalmente, agradeço aos trabalhadores e trabalhadoras do SUS que estão cotidianamente construindo o sistema de saúde, incluindo aqueles que aceitaram contribuir com essa pesquisa. 


\section{RESUMO}

MORI, A.Y. Análise da configuração da agenda de revisão da política nacional de atenção básica de 2017: contexto, problemas e alternativas. [Dissertação] Programa de PósGraduação em Saúde Pública da Faculdade de Saúde Pública da Universidade de São Paulo, 2019.

Em 2017, a Política Nacional de Atenção Básica (PNAB) passou por um processo de revisão permeado por uma intensa disputa política, que resultou em mudanças significativas em suas diretrizes. Considerando questões provocadas pelo campo da análise de políticas públicas, o estudo buscou observar "por que" e "como" a proposta de mudanças nas diretrizes para a composição da equipe de Atenção Básica entrou na agenda de governo. Analisa o processo decisório sobre a configuração da agenda, levando em consideração as motivações técnicas e políticas, a participação dos atores, o processo de negociação para a sua aprovação e as possíveis repercussões das mudanças para o sistema de saúde. No percurso metodológico foi realizada análise das atas do Conselho Nacional de Saúde (CNS) e dos resumos executivos das reuniões da Comissão Intergestores Tripartite do período de 2015 a 2017. Também foram realizadas 10 entrevistas, envolvendo atores dos 3 níveis de gestão, representantes do segmento dos trabalhadores e da comunidade científica no CNS, pesquisador da área de Saúde Coletiva e representante dos Agentes de Saúde. Os entrevistados foram selecionados a partir da análise documental, que propiciou a identificação de sujeitos que participaram ativamente do processo de elaboração ou discussão da proposta de revisão. Os dados coletados foram categorizados e analisados em contexto político, problemas e alternativas de soluções, elementos do modelo de análise dos múltiplos fluxos. Como resultado, evidenciouse que os elementos constitutivos da formação da agenda de mudança nas diretrizes da PNAB estão relacionados, principalmente, a conflitos oriundos da gestão do trabalho e do financiamento para a manutenção do Agente Comunitário de Saúde. Esses problemas derivam da regulamentação da carreira e do piso salarial conquistados pela categoria, assim como das mudanças econômicas e políticas ocorridas no Brasil a partir de 2015, determinantes na janela de oportunidades para a formação da agenda. Outro dado importante identificado foi a acomodação de diferentes interesses ao flexibilizar a carga horária dos profissionais da equipe, dada principalmente pela dificuldade de provimento e atração de médicos para atuação na Atenção Primária à Saúde (APS). Destaca-se que, embora tenha sido consumada a revisão da PNAB 2017, parte do esforço para o bloqueio da agenda obteve sucesso, haja vista que a Estratégia de Saúde da Família segue enquanto modelo prioritário na APS. Por fim, a discussão de arranjos e diretrizes para a composição de equipe e o escopo de práticas atrelado ao financiamento são questões em aberto e centrais no debate sobre o modelo tecnoassistencial, observando-se como forte tendência para o debate sobre APS nos próximos anos.

Palavras-chave: Atenção Primária à Saúde; Agenda de Prioridades em Saúde; Política de Saúde; Políticas Públicas; Agente Comunitário de Saúde. 


\begin{abstract}
MORI, A.Y. Analysis of the agenda setting of 2017 National Primary Health Care Policy: context, problems and alternatives. [Dissertation] Postgraduate Program in Public Health, School of Public Health, University of São Paulo, 2019.

In 2017, the National Primary Health Care Policy (NPHCP) underwent a review process allowed by an intense political dispute, which resulted in significant changes in its guidelines. Considering issues raised by the field of public policy analysis, the study sought to observe "why" and "how" the proposed changes in the guidelines for the composition of the Primary Care team entered the government agenda. It analyzes the decision-making process on the agenda setting, taking into account the technical and political motivations, the participation of the actors, the negotiation process for its approval and the possible repercussions of changes for the health system. During the methodological analysis, the minutes of the National Health Council (NHC) and the executive summaries of the Tripartite Inter-Managers Committee meetings from 2015 to 2017 were analyzed. Ten interviews were also conducted, involving actors from the 3 levels of management, representatives of the workers' segment and the scientific community at NHC, researcher in the area of Collective Health and representative of Health Agents. The interviewees were selected from the documentary analysis, which allowed the identification of subjects who actively participated in the process of elaboration or discussion of the review proposal. The collected data were categorized and analyzed according to the political context, problems and alternative solutions, elements of the Multiple Flow analysis model. As a result, it was evidenced that the constitutive elements of the formation of NPHCP guidelines change agenda are mainly related to conflicts arising from work management and financing for the maintenance of the Community Health Agent. These problems derive from the career regulation and the salary level achieved by the category, as well as the economic and political changes that occurred in Brazil since 2015, determining the window of opportunity for the formation of this agenda. Another important data identified was the accommodation of different interests about easing the workload of team professionals, mainly due to the difficulty of providing and attracting doctors to work in Primary Health Care (PHC).

It is noteworthy that, although the 2017 NPHCP review has been completed, part of the effort to block the agenda was successful, given that the Family Health Strategy remains a priority model in PHC. Finally, the discussion of arrangements and guidelines for team composition and the scope of practices linked to funding are open and central issues in the debate on the techno-care model, and it is a strong tendency for the PHC debate in the coming years.
\end{abstract}

Keywords: Primary Health Care; Health Priority Agenda; Health policy; Public policy; Community Health Agent. 


\section{SUMÁRIO}

1 INTRODUÇÃO

1.1 A ATENÇÃO PRIMÁRIA NA ORDEM DO DIA DA AGENDA POLÍTICA DA SAÚDE

1.2 DESENVOLVIMENTO DOS SISTEMAS DE SAÚDE E A CONCEPÇÃO DE APS 20

1.3 A REFORMA SANITÁRIA BRASILEIRA E O PAPEL DA APS NA CONSTITUIÇÃO DO SISTEMA ÚNICO DE SAÚDE ............................................2 25

1.4 AVANÇOS E DESAFIOS DA PNAB PARA O DESENVOLVIMENTO DA APS .... 30

1.5 O CENÁRIO DA POLÍTICA DE SAÚDE E A APS NA AGENDA DE GOVERNO: O

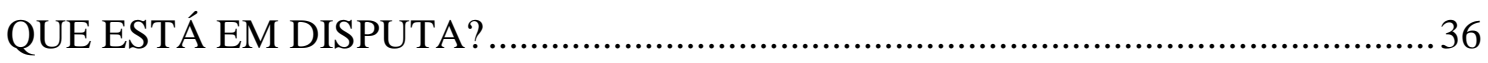

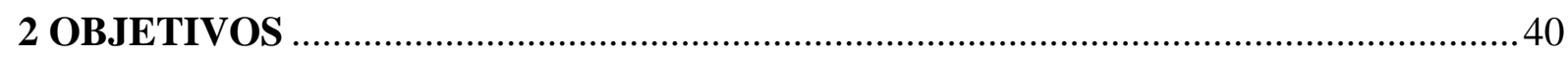

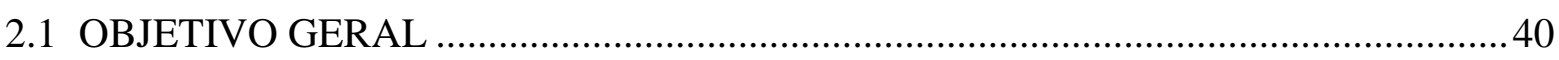

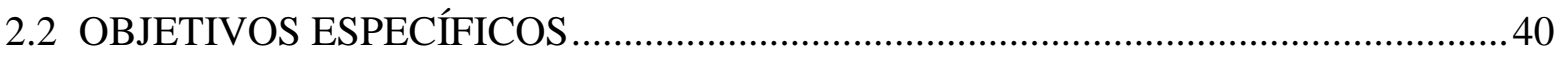

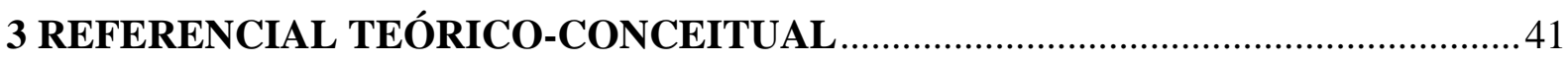

3.1 ALGUNS CONCEITOS DO CAMPO DE POLÍTICAS PÚBLICAS COMO PONTO

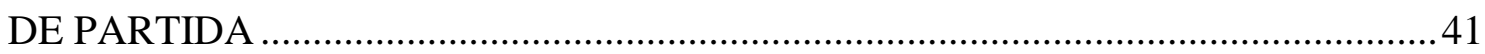

3.2 A ABORDAGEM SOBRE A CONFIGURAÇÃO DA AGENDA ...............................44

3.3 A ABORDAGEM DA CONFIGURAÇÃO DA AGENDA E A ESCOLHA DE ALTERNATIVAS SEGUNDO A DINÂMICA DOS MÚLTIPLOS FLUXOS ............ 46

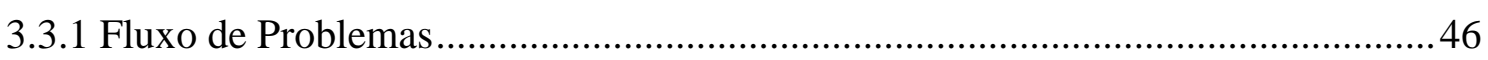

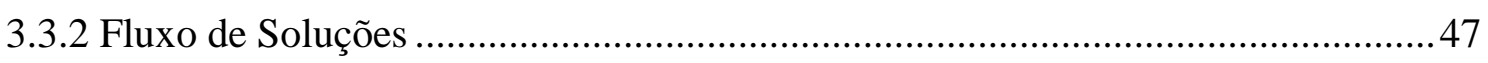

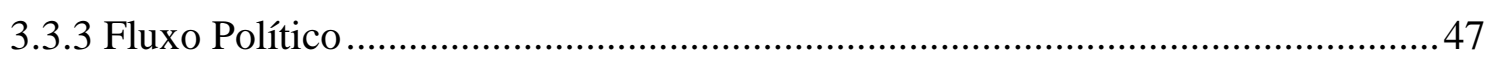

3.3.4 Atores Políticos e sua Influência na Configuração da Agenda ............................. 49

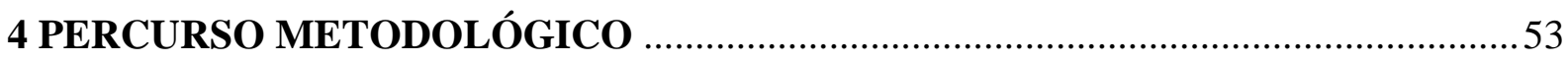

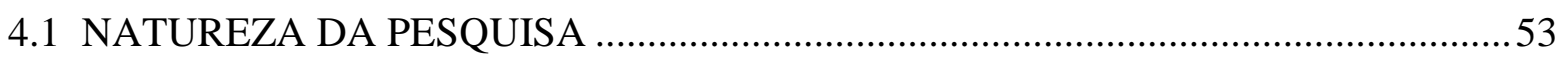

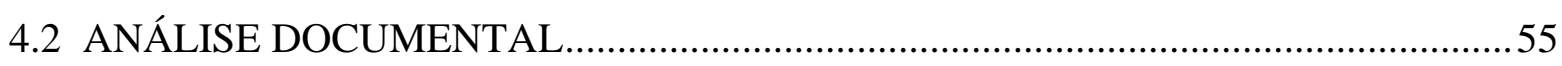

4.2.1 Documentos e Fonte de Coleta de Dados ............................................................55

4.2.2 Análise Documental - Procedimentos Adotados para o Tratamento dos Dados ... 56

4.3 ENTREVISTAS - COLETA E TRATAMENTO DOS DADOS …............................58

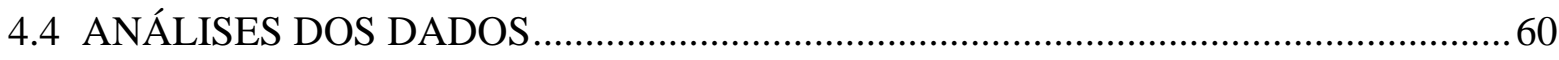

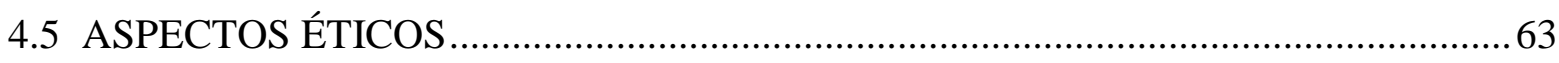

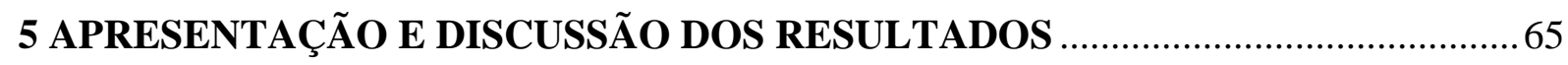

5.1 FLUXO POLÍTICO: O CONTEXTO DA AGENDA DE REVISÃO DA PNAB ......... 70 


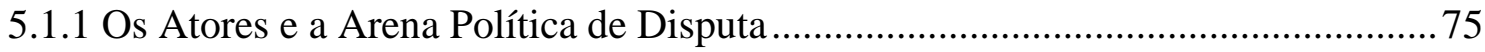

5.1.2 A Atuação dos Atores e as Forças Políticas Organizadas ...................................... 80

5.2 O ADENSAMENTO DE PROBLEMAS E A ESCOLHA DE PROPOSTAS DE

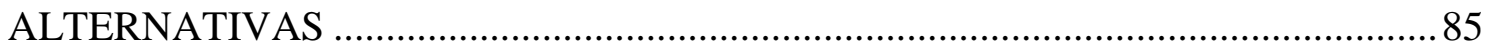

5.2.1 Arboviroses, Baixa Cobertura Vacinal e Integração entre a Vigilância em Saúde e

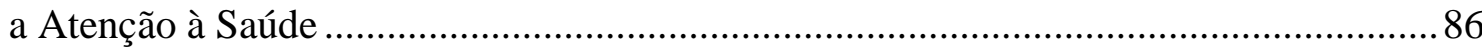

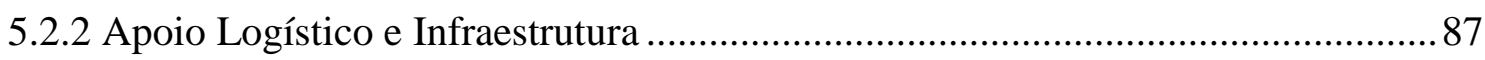

5.2.3 Expansão da Cobertura, Provimento e Formação Médica ...................................... 88

5.2.4 Acesso, PMAQ e Padrões Essenciais e Ampliados .............................................. 90

5.2.5 A Disputa de Modelo de Atenção Expressa na Proposta de Plano de Saúde Acessível e a Discussão de Arranjo de Equipe ................................................................92

5.2.6 Mudanças no Modelo de Atenção e o Trabalho do ACS...................................... 104

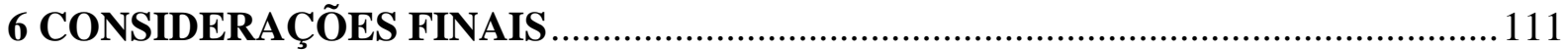

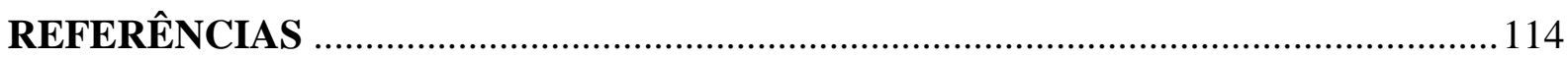

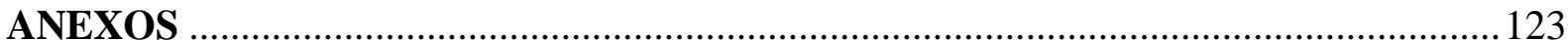

Anexo 1 - Termo de Consentimento Livre e Esclarecido....................................................... 123

Anexo 2 - Consentimento para Gravação de Voz .................................................................. 124 


\section{LISTA DE SIGLAS}

$\mathrm{AB}$ - Atenção Básica

ABRASCO - Associação Brasileira de Saúde Coletiva

$\mathrm{ACE}$ - Agentes de Combate às Endemias

ACS - Agente Comunitário de Saúde

APS - Atenção Primária à Saúde

CEBES - Centro Brasileiro de Estudos em Saúde

CGPNI - Coordenação Geral do Programa Nacional de Imunização

CIT - Comissão Intergestores Tripartite

CNES - Cadastro Nacional de Estabelecimentos de Saúde

CNS - Conselho Nacional de Saúde

CONACS - Confederação Nacional dos Agentes Comunitários de Saúde e Combate às Endemias

CONASEMS - Conselho Nacional de Secretarias Municipais de Saúde

CONASS - Conselho Nacional de Secretários de Saúde

DAB - Departamento de Atenção Básica

eAB - equipe de Atenção Básica

eAP - equipe de Atenção Primária

EC - Emenda Constitucional

ENSP - Escola Nacional de Saúde Pública

EPJV - Escola Politécnica Joaquim Venâncio

eSF - equipe de Saúde da Família

ESF - Estratégia de Saúde da Família

FENAM - Federação Nacional dos Médicos

FENASCE - Federação Nacional dos Agentes Comunitários de Saúde e Combate às Endemias

FIOCRUZ - Fundação Oswaldo Cruz

FSP-USP - Faculdade de Saúde Pública da Universidade de São Paulo

GT - Grupo de Trabalho

MDB - Movimento Democrático Brasileiro 
MS - Ministério da Saúde

NASF - Núcleo de Apoio à Saúde da Família

NHS - National Health Service

NOB - Norma Operacional Básica

OMS - Organização Mundial de Saúde

OPAS - Organização Pan-Americana de Saúde

PAB - Piso da Atenção Básica

PACS - Programa de Agentes Comunitários de Saúde

PEC - Prontuário Eletrônico do Cidadão

PIASS - Programa de Interiorização das Ações de Saúde e Saneamento

PIB - Produto Interno Bruto

PMAQ - Programa de Melhoria do Acesso e da Qualidade

PMDB - Partido do Movimento Democrático Brasileiro

PNAB - Política Nacional de Atenção Básica

PNI - Programa Nacional de Imunização

PROESF - Projeto de Expansão e Consolidação da Saúde da Família

PROVAB - Programa de Valorização do Profissional da Atenção Básica

PSDB - Partido da Social Democracia Brasileira

PSF - Programa de Saúde da Família

RAS - Rede de Atenção à Saúde

SAPS - Secretaria de Atenção Primária à Saúde

SGTES - Secretaria de Gestão do Trabalho e da Educação na Saúde

SESP - Serviço Especial de Saúde Pública

SILOS - Sistemas Locais de Saúde

SUS - Sistema Único de Saúde

SVS - Secretaria de Vigilância em Saúde

TCLE - Termo de Consentimento Livre Esclarecido

UBS - Unidade Básica de Saúde

UNICEF - Fundo das Nações Unidas para a Infância

UNICAMP - Universidade de Campinas 
UFSCar - Universidade Federal de São Carlos

UNIFESP - Universidade Federal de São Paulo

UPA - Unidade de Pronto Atendimento 


\section{LISTA DE QUADROS}

Quadro 1- Abordagens da Atenção Primária à Saúde.

Quadro 2 - Descrição das categorias e dos elementos do modelo de análise dos múltiplos fluxos. 51

Quadro 3 - Base do roteiro das entrevistas. 58

Quadro 4 - Relação de entidades e instituições com posicionamento relativo à proposta de revisão da Política Nacional de Atenção Básica 2017. 76

Quadro 5 - Relação de notícias na mídia sobre a revisão da Política Nacional de Atenção Básica. 


\section{LISTA DE TABELAS}

Tabela 1 - Número de reuniões e documentos analisados da Comissão Intergestores

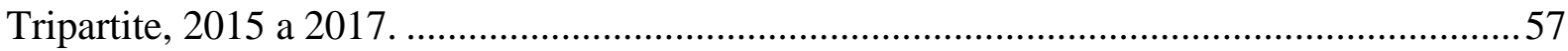

Tabela 2 - Número de reuniões e documentos analisados do Conselho Nacional de Saúde, 2015 a 2017. 57

Tabela 3 - Quantidade de documentos e códigos que fizeram parte da análise dos dados, por tipo de fonte. 60

Tabela 4 - Temas identificados e frequência, por tipo de documento. 61

Tabela 5 - Dados de cobertura de Atenção Básica no Brasil, 2007 a 2019. 100 


\section{LISTA DE GRÁFICOS}

Gráfico 1 - Número de equipes de Saúde da Família implantadas no Brasil, 1998 a 2017.... 33

Gráfico 2 - Cobertura de Atenção Básica estimada no Brasil, 2007 a 2019......................... 100

Gráfico 3 - Quantidade de Agentes Comunitários de Saúde, Brasil, 2007 a 2019............... 103 


\section{LISTA DE FIGURAS}

Figura 1 - Modelo dos Múltiplos Fluxos de Kingdon.

Figura 2 - Elementos relacionados ao desenvolvimento da Atenção Primária à Saúde no

Brasil, 1991 a 2014. 66

Figura 3 - Elementos do processo de revisão da Política Nacional de Atenção Básica, 2015 a 2017. 67

Figura 4 - Rede de temas da análise da configuração da agenda de revisão da PNAB 2017. 69

Figura 5 - Múltiplos fluxos da configuração da Agenda de revisão da Política Nacional de Atenção Básica de 2017. 


\section{SOBRE A IMPLICAÇÃO DO PESQUISADOR E O INTERESSE PELO TEMA DE PESQUISA}

Eu recebi o nome Américo Yuiti Mori. Filho de imigrantes japoneses, nasci e fui criado na grande São Paulo, mas logo rompi minhas fronteiras, estabelecendo contato com diferentes realidades de outros estados brasileiros, a partir do movimento estudantil. Ingressei na área da saúde, inicialmente, como técnico de enfermagem, trabalho que garantiu as condições para que me formasse como enfermeiro, em 2004, pela Universidade Federal de São Paulo (UNIFESP).

A partir dos projetos de extensão em comunidade e das experiências no movimento estudantil, comecei a me interessar pela atuação na Atenção Primária. Dessa forma, segui o meu itinerário de formação (formal), cursando Residência em Saúde da Família na Universidade Federal de São Carlos (UFSCar), em 2009, e especialização em Apoio em Saúde pela Universidade de Campinas (UNICAMP), em 2013. Ingressei no mestrado do Programa de Pós-Graduação em Saúde Pública, da Faculdade de Saúde Pública da Universidade de São Paulo (FSP-USP), em 2017, com a intenção de pesquisar o tema da Atenção Primária à Saúde no campo da Gestão e da Política de Saúde.

A intenção em aprofundar o estudo nesse tema corresponde a inquietações suscitadas na minha trajetória profissional. Dessa trajetória, destaco a experiência como enfermeiro de equipe de Saúde da Família (eSF) na Cidade Tiradentes, Zona Leste da cidade de São Paulo, entre os anos de 2004 a 2007. Nessa experiência atuei antes mesmo da inauguração da unidade de saúde, contribuindo na territorialização, na seleção e no treinamento de agentes comunitários de saúde (ACS) e auxiliares de enfermagem.

Posteriormente, senti os efeitos de um modelo de gestão pautado pelo gerencialismo, os quais produziram diversos atravessamentos sobre o processo de trabalho da equipe. Naquele momento, acentuava-se a implantação do modelo de gestão com as Organizações Sociais de Saúde e o contrato de gestão baseado no cumprimento de metas, que recaia sobre a equipe como uma cobrança do cumprimento da "meta de produção".

Aliado aos limites da minha prática centrada em uma formação biomédica, fiquei ainda mais provocado a questionar os limites da capacidade e da prática clínica, o que me impulsionou a buscar a Residência Multiprofissional em Saúde da Família e Comunidade da UFSCar. 
A Residência oportunizou cenários que também estimularam o debate sobre a formação e a gestão na saúde. O município de São Carlos, São Paulo, naquele momento vivia um processo de reorganização da Rede de Atenção à Saúde (RAS) em articulação com a UFSCar. Por sua vez, a Universidade vivia um processo de intensa mudança na formação dos cursos de saúde.

Essas experiências levaram-me à gestão da Atenção Básica e à formação em serviço entre os anos de 2009 e 2016. Nesse período, atuei como técnico na Diretoria de Atenção Básica da Secretaria Estadual de Saúde da Bahia, exercendo atividades de tutoria e facilitação em cursos e processos de formação, e nos últimos anos trabalhei no Departamento de Atenção Básica, à época, e nos Departamentos de Planejamento e Regulação da Provisão de Profissionais da Saúde e de Gestão da Educação na Saúde do Ministério da Saúde, concentrando minhas atividades na perspectiva da melhoria do acesso à saúde e da qualificação da Atenção Primária no Sistema Único de Saúde (SUS).

Acredito ter vivido intensas experiências no campo da saúde pública ao trabalhar na assistência, formação e gestão em diversas esferas do SUS. Os questionamentos advindos da minha prática no mundo do trabalho e o atual contexto da política de saúde no Brasil instigam-me para a investigação sobre os aspectos dessa política pública e a implementação do SUS.

Dentre as questões que me motivam, destaco as contribuições do campo das políticas públicas e o contexto de revisão da Política Nacional de Atenção Básica. Acredito que vivenciamos um complexo e crítico momento da sociedade brasileira, em que a conjuntura de crises econômica e política tem impactado na dinâmica da relação entre a sociedade e o Estado. Sugere-se que as consequências desse processo têm afetado profundamente o desenvolvimento das políticas sociais.

Embora possa parecer prematuro antecipar as consequências da atual conjuntura sobre a política de saúde brasileira, parece-me fundamental investigar a relação desse contexto com os problemas e as alternativas de soluções eleitas, como também o impacto dessas definições sobre o sistema de saúde. Penso que a implicação com este estudo é coerente com a perspectiva da minha trajetória enquanto trabalhador do SUS. 


\section{INTRODUÇÃO}

\subsection{A ATENÇÃO PRIMÁRIA NA ORDEM DO DIA DA AGENDA POLÍTICA DA SAÚDE}

A Atenção Primária à Saúde (APS) tem sido tema de destaque no setor saúde nas últimas décadas. No Brasil, aparece na agenda de governo como uma política prioritária a partir da década de 1990, principalmente com a Estratégia de Saúde da Família (ESF), com o objetivo de promover o acesso à saúde e a reorganização do modelo de atenção. Em 1996, a partir da Norma Operacional Básica (NOB-96) do SUS, é destinado financiamento específico para o incentivo à implantação da ESF (BRASIL, 1997; SECRETARIA DE POLÍTICAS DE SAÚDE, 2000).

Em trabalho de análise da política federal para a Atenção Básica no Brasil, CASTRO e MACHADO (2012, p. 501) evidenciam a sua expressiva presença na agenda de prioridades do governo. Os autores destacam a presença de elementos de continuidade ao longo da primeira década dos anos 2000 em comparação com a década anterior, que corresponde a períodos de distintos governos, e afirmam que, apesar de ter havido alterações nas regras e diretrizes desde sua implantação, as mudanças propostas “[...] procuraram dar respostas a limitações que vinham sendo identificadas na implementação da política de atenção básica, sem colidir com suas bases institucionais prévias".

A designação do termo Atenção Básica refere-se a como a APS foi designada no Brasil, principalmente após a cristalização do termo com o seu emprego nos documentos normativos e institucionais. Embora a literatura não apresente precisão sobre os motivos da adoção do termo, há registros de que o seu emprego objetivou demarcar uma diferenciação do entendimento de uma Atenção Primária restrita e focalizada, indicada por organismos internacionais, como o Banco Mundial. A diferenciação em Atenção Básica buscou reforçar uma concepção mais ampliada, remetendo a uma forma de orientação da organização do sistema de saúde e não apenas para caracterizar o nível primário de atenção (MELLO et al., 2009).

Segundo CECÍLIO e REIS (2018), a opção pelo uso do termo Atenção Básica demarca o posicionamento de entidades de representação dos gestores municipais e estaduais, bem como do próprio Conselho Nacional de Saúde (CNS) e está associada ao processo 
político que encontra suas raízes na própria história do movimento da Reforma Sanitária brasileira, que vislumbrava a construção de um sistema de saúde público e universal.

Neste sentido, a Política Nacional de Atenção Básica (PNAB) tem um importante papel na condução de esforços para a garantia do acesso à saúde e para a organização do modelo de atenção à saúde no Brasil. Possui uma base social e política composta por diferentes grupos de interesse que, apesar das contradições entre si, sustentam-na enquanto política pública para a implementação do SUS. Obviamente, essa base não é homogênea e agrega diferentes interesses e concepções, o que resulta em disputas e contradições no seu processo de implementação (CECÍLIO e REIS, 2018).

Neste trabalho, assim como especificado no texto da PNAB (BRASIL, 2012), utilizam-se os termos Atenção Primária à Saúde e Atenção Básica como sinônimos, sendo que este aparece mais associado aos elementos da política de atenção básica normatizados pelo Ministério da Saúde (MS).

Em 2017, a PNAB passou por um processo de revisão permeado por uma intensa disputa política, sendo finalmente reeditada por meio da Portaria $\mathrm{n}^{\circ} 2.436$, de 21 de setembro de 2017, que estabelece a revisão de diretrizes para a organização da Atenção Básica, no âmbito do SUS. Posteriormente, a Normativa foi incorporada à Portaria de Consolidação no 2, de 28 de setembro de 2017, Anexo XXII.

Durante esse processo, diferentes grupos posicionaram-se quanto à nova proposta, a qual foi elaborada por um grupo técnico tripartite entre os gestores e apresentada na reunião da Comissão Intergestores Tripartite (CIT) ${ }^{1}$ do dia 27 de julho de 2017.

Embora a proposta tenha sido pactuada no dia 31 de agosto de 2017 pelo colegiado de gestores que compõem a CIT, parte da base social que sustenta a ideia do sistema de saúde orientado pela APS seguiu insistindo nos questionamentos sobre os efeitos da PNAB 2017 e

\footnotetext{
${ }^{1}$ A Comissão Intergestores Tripartite (CIT) constitui-se como foros permanentes de negociação, articulação e decisão entre os gestores nos aspectos operacionais e na construção de pactos nacionais, estaduais e regionais no Sistema Único de Saúde (SUS). Desta forma, fortalece a governança nestes espaços e prioriza a responsabilização dos entes de modo que a tomada de decisão na gestão tenha transparência, buscando o acesso integral a assistência à Saúde. A Comissão Intergestores Tripartite (CIT), teve seu início nos primeiros anos da década de 90, após promulgação da Constituição Federal (CF), quando da instituição do Sistema Unificado e Descentralizado de Saúde (SUDS) como um colegiado intergovernamental. Para atender as determinações da Lei $\mathrm{n}^{\circ}$ 8.080, de 10 de setembro de 1990, e a Lei $\mathrm{n}^{\circ}$ 8.142, de 28 de dezembro de 1990, bem como as recomendações da Resolução $n^{\circ} 02$ do Conselho Nacional de Saúde e a necessidade de articulação e coordenação entre os gestores governamentais do SUS, foi instituída por meio da Portaria n $^{\circ} 1.180$, de 22 de julho de 1991, a Comissão Técnica em âmbito nacional, posteriormente denominada Comissão Intergestores Tripartite (BRASIL, 2019).
} 
mantendo vivo o processo de debate sobre a condução da Política, assumindo posição contrária às mudanças propostas pela revisão da PNAB 2017.

Para ilustrar a dimensão que esse processo ganhou, entidades que protagonizaram a Reforma Sanitária que deu origem ao SUS, como a Associação Brasileira de Saúde Coletiva (ABRASCO) e o Centro Brasileiro de Estudos em Saúde (CEBES), lançaram nota conjunta com a Escola Nacional de Saúde Pública Sérgio Arouca (ENSP/FIOCRUZ) posicionando-se contrárias à reformulação da PNAB (ABRASCO, 2017). Em outubro de 2017, após mobilização da Confederação Nacional dos Agentes Comunitários de Saúde e Combate às Endemias (CONACS), cerca de 20 Deputados, de diferentes partidos, protocolaram um projeto de Decreto Legislativo que objetiva anular os efeitos da Portaria da PNAB 2017, proposta pelo Ministério da Saúde (VIOMUNDO, 2017).

Destaca-se que o conjunto dos atores que nos últimos anos reforçaram a Saúde da Família enquanto estratégia prioritária para a reorganização do modelo de atenção, apesar da sua composição heterogênea e de suas contradições, sempre mostrou-se muito coeso na defesa de uma APS abrangente ou integral. Entendida como uma estratégia de organização do sistema de saúde e com um importante papel na garantia do acesso universal e da sustentabilidade do próprio SUS (OPAS/OMS, 2007; BOUSQUAT et al., 2017). Contudo, essa base de apoio que tem influência sobre a PNAB tem apresentado importantes dissonâncias sobre o seu processo de condução no atual contexto.

Para entender o processo em disputa e os elementos que levaram à proposta da agenda de revisão da $\mathrm{PNAB}$, definidores no processo de condução da política, é fundamental considerar as contribuições do campo de estudo da análise das políticas públicas. A tradição desse campo é imprescindível na análise do processo de formulação e implementação no âmbito da gestão pública, pois lança luz sobre os elementos que deram origem à política, o que mudou nesse processo de revisão e por que as mudanças ocorreram (MATTOS e BAPTISTA, 2015).

A presente pesquisa buscou responder a questões provocadas pelo campo de análise das políticas públicas: "por que" e "como" as mudanças das diretrizes da PNAB 2017 entraram na agenda do governo? Propôs-se analisar o processo decisório sobre as alterações nas diretrizes para a composição da equipe de Atenção Básica (eAB), a qual tem importante papel sobre a organização do modelo tecnoassistencial, bem como as motivações políticas e técnicas, a atuação dos atores, os conflitos desse processo e as possíveis repercussões na organização do sistema de saúde. 


\subsection{DESENVOLVIMENTO DOS SISTEMAS DE SAÚdE E A CONCEPÇÃO DE APS}

Para uma análise sobre a PNAB é necessário retomar, inicialmente, as diferentes concepções de APS e o seu papel ao longo da história na constituição dos sistemas de saúde.

A APS é entendida como uma estratégia de organização da atenção à saúde, sendo também o nível de atenção ou a abordagem em que deve haver, preferencialmente, o primeiro contato da população com um conjunto de ações e serviços ofertados pelo sistema de saúde. É atribuída a ela a capacidade de resolver a maioria dos problemas de saúde mais comuns da comunidade ou da base territorial sob sua responsabilidade, articulando ações de promoção, prevenção, tratamento e reabilitação (STARFIELD, 2002; CONILL, 2008; LAVRAS, 2011).

Caracteriza-se por uma conformação de serviços organizados em uma atenção clínicoambulatorial, e, no geral, apresenta recursos de baixa densidade tecnológica, embora o objeto de sua intervenção seja determinado por problemas e necessidades de ordem social, sendo, portanto, carreada por múltiplos fatores e com diversos graus de complexidade (STARFIELD, 2002; CONILL, 2008; LAVRAS, 2011).

A delimitação do escopo e dos objetivos da APS foi desenvolvida ao longo da história e de acordo com as características de cada sistema de saúde no qual foi implementada. Um importante elemento na análise dessas definições diz respeito à busca da racionalização do sistema de saúde para a maximização dos resultados e sustentabilidade dos custos. Barbara STARFIELD (2002), que desenvolveu importante trabalho no sentido de avaliar comparativamente a capacidade e o desempenho dos sistemas de saúde em diversos países, baseando-se nos pressupostos de Alma-Ata, deu origem ao que se convencionou chamar de atributos essenciais e derivados, característicos da organização e necessários para um bom desempenho da APS.

De acordo com STARFIELD (2002), os atributos essenciais são sistematizados em: Atenção no primeiro contato, ou a APS como primeira referência do usuário para a resolução dos seus problemas de saúde, a porta de entrada do sistema, à medida que a população a identifica como serviço preferencial e capaz de responder as suas necessidades. Essa relação é determinada pelo acesso ao serviço, o qual é definido por elementos geográficos, organizacionais, socioeconômicos e culturais. Longitudinalidade, que implica em uma relação em que está presente a disponibilidade de um atendimento regular e o seu uso ao longo do tempo, mediado pelo vínculo interpessoal entre o profissional de saúde e a pessoa ou a 
população em que é estabelecido um processo de cooperação mútua. Integralidade, que parte do reconhecimento da complexidade das necessidades e dos problemas de saúde, ou seja, da compreensão de que o processo saúde-doença é determinado socialmente e por múltiplos fatores e que, portanto, carece de uma abordagem ampliada por parte da equipe de saúde, bem como de recursos que extrapolam a própria APS, demandando acesso e outros níveis de atenção, os quais devem ser organizados em uma rede de serviços e recursos terapêuticos. Coordenação da atenção, é o elemento integrador essencial para a articulação dos outros três atributos anteriormente destacados. Por meio da coordenação da atenção são estabelecidos mecanismos para o reconhecimento de informações relativas às ações e aos atendimentos prévios, a necessidade de acesso a outros níveis de atenção e seus resultados e o monitoramento para a garantia da continuidade do cuidado.

Por seu turno, os atributos derivados são: Orientação comunitária, que visa o conhecimento das necessidades da comunidade e o envolvimento do serviço de saúde com a comunidade e vice-versa; Centrado na família para abordagem sistêmica; e a Competência cultural, que visa conhecer e tomar providências para atender as necessidades especiais associadas às características culturais e ao modo de vida da população adstrita.

Os estudos de Barbara STARFIELD tornaram-se referência e contribuíram para o levantamento de evidências quanto à maior eficiência e eficácia dos sistemas de saúde orientados pela APS. Esses atributos, frequentemente, são adotados como orientadores na organização e avaliação de sistemas de saúde. No Brasil, pode-se observar, inclusive, a sua incorporação no texto das diretrizes da própria PNAB (PRATES et al., 2017).

Obviamente, esse processo de incorporação tem relação com o caminho percorrido no Brasil em seu processo de Reforma Sanitária e constituição do SUS. O sistema brasileiro teve inspiração em outros sistemas universais de saúde que, por sua vez, apresentam uma forte orientação para a APS. Por outro lado, é necessário ponderar que, no caso brasileiro, o sistema de saúde é permeado por uma complexa relação entre o público e o privado, além de existir uma grande desigualdade socioespacial na oferta dos serviços (MAAS et al., 2019).

Como destacado acima, o processo de desenvolvimento da APS está intimamente ligado ao desenvolvimento de sistemas de saúde e o seu contexto. Um sistema é definido como um conjunto de partes integrantes e interdependentes que formam um todo unitário e efetuam determinada função ou objetivo. No caso dos sistemas de saúde, tratam-se de sistemas abertos, ou seja, há interação com outros sistemas e com um conjunto de relações produzidas interna e externamente (OLIVEIRA,1998). 
Por exemplo, um sistema de saúde é determinado ou pode ser afetado de acordo com as mudanças no sistema econômico ou político. GIOVANELLA e LOBATO (2012, p. 109), acerca dos sistemas de saúde, afirmam que representam uma “[...] arena política de disputa de poder e recursos, na qual ocorrem conflitos distributivos (distribui dinheiro, prestígio e empregos), envolvendo inúmeros atores sociais [...]”.

A função dos sistemas de saúde é a prevenção de doenças e a oferta de serviços de assistência à saúde, bem como a regulamentação de produtos que afetam a saúde da população e o controle do meio ambiente. Essa ideia de sistema de saúde, que se tornou comum na forma como o concebemos hoje, consolida-se apenas em meados do século XX e guarda relação com o desenvolvimento dos modelos de proteção social, que tratam da forma com que o Estado organiza e intervém sobre a área social, incluídas, além da saúde, a assistência e a previdência social (GIOVANELLA e LOBATO, 2012).

$\mathrm{O}$ contexto histórico do início do século XX nos países industrializados, pós Revolução Industrial, foi caracterizado pela crescente incorporação tecnológica e concentração da população nos centros urbanos. Estruturou-se nesses países, juntamente com o sistema de proteção social, o conjunto de serviços para a garantia do acesso a cuidados médicos. No setor, consequentemente, os crescentes gastos e a necessidade de estruturação de serviços de saúde mais eficientes para toda a população foram dando contorno ao desenvolvimento dos sistemas de saúde.

De acordo com a Organização Pan-Americana de Saúde da Organização Mundial da Saúde (OPAS/OMS), recomendações internacionais apontam que:

[...] países com sistemas de saúde fortemente orientados à APS têm maior probabilidade de apresentar resultados em saúde melhores e mais equitativos, serem mais eficientes, terem menores custos na atenção à saúde e alcançarem melhor satisfação do usuário do que aqueles cujos sistemas de saúde têm apenas uma fraca orientação à APS (OPAS/OMS, 2007, p. 15).

Em 1920, o Relatório Dawson, encomendado pelo Ministério da Saúde do Reino Unido, foi um dos primeiros documentos a conceber a estruturação do sistema de saúde a partir da organização local. O documento consistiu na elaboração de uma proposta para a organização da provisão de serviços médicos à população de uma determinada área definida. Sua concepção tinha por base a integração das ações preventivas e curativas e a organização dos serviços a partir das necessidades de saúde da população, a qual seria delimitada por território definido e vinculada a um centro de saúde. Estes serviços comporiam o nível de atenção primária e estariam vinculados aos demais serviços de apoio diagnóstico (centro de saúde secundário) e tratamento (hospitais e serviços especiais terciários), que seriam 
distribuídos de forma hierarquizada (níveis de atenção), integrados em uma base regional de funcionamento complementar e coordenados por uma única autoridade sanitária. Atribui-se a Dawson a base da concepção de rede de atenção, ao propor esta conformação para a organização do sistema de saúde (OPAS/OMS, 1964; STARFIELD, 2002; KUSCHNIR e CHORNY, 2010).

Embora o Relatório tenha sido imediatamente recusado na época, mais adiante suas ideias tiveram forte influência na criação do sistema nacional de saúde britânico, o National Health Service (NHS), em 1948, que passou a influenciar a organização de diversos sistemas universais, principalmente na Europa (LAVRAS, 2011).

Um conceito mais amplo de cuidados primários e sua importância na conformação dos sistemas de saúde consolidaram-se a partir da Conferência de Alma-Ata, realizada em 1978, pela OMS e pelo Fundo das Nações Unidas para a Infância (UNICEF). A declaração da primeira Conferência Internacional sobre Cuidados Primários de Saúde, conhecida como Declaração de Alma-Ata, firmou o que posteriormente chamaríamos de APS como fundamental para o alcance da meta estabelecida "Saúde Para Todos no ano 2000". Em seu texto, cuidados primários são definidos como:

Os cuidados primários de saúde são cuidados essenciais de saúde baseados em métodos e tecnologias práticas, cientificamente bem fundamentadas e socialmente aceitáveis, colocadas ao alcance universal de indivíduos e famílias da comunidade, mediante sua plena participação e a um custo que a comunidade e o país possam manter em cada fase de seu desenvolvimento, no espírito de autoconfiança e automedicação. Fazem parte integrante tanto do sistema de saúde do país, do qual constituem a função central e o foco principal, quanto do desenvolvimento social e econômico global da comunidade. Representam o primeiro nível de contato dos indivíduos, da família e da comunidade com o sistema nacional de saúde, pelo qual os cuidados de saúde são levados o mais proximamente possível aos lugares onde pessoas vivem e trabalham, e constituem o primeiro elemento de um continuado processo de assistência à saúde (OMS, 1978, p. 3).

Apesar da centralidade atribuída à APS no alcance da meta "Saúde Para Todos no ano 2000”, com entendimento ampliado da APS enquanto modelo orientador da organização do sistema de saúde, a partir dos anos 80, quando se observa os efeitos de um ciclo de crise do capitalismo, marcado pela crise do petróleo, em 1979, e redução da taxa de crescimento econômico, são retomadas as ideias liberais e a aplicação de um conjunto de medidas nomeadas como reforma do Estado, que visavam o enxugamento do aparato estatal e da sua participação na vida social. Essas medidas caracterizaram-se pelos cortes no financiamento das políticas sociais; intervenção para a manutenção do mercado, e privatizações e concessões à iniciativa privada (CAMPOS et al., 2015). 
Esse processo de crise do capitalismo motivou uma série de medidas econômicas, como a imposição de mecanismos de mercado em setores fundamentais para a garantia do bem-estar social. No caso de países da Europa com sistemas de saúde universais, como o NHS, o caminho foi conferir maior capacidade para o exercício da coordenação do cuidado pela APS, sendo atribuídas funções gerenciais ao profissional médico generalista, ficando ele responsável pela a racionalização do acesso a outros níveis de atenção e a gestão dos recursos. Assim, deu-se início a uma série de reformas nos sistemas universais de saúde, que tiveram como objetivo lidar com as mudanças demográficas e epidemiológicas (envelhecimento da população e advento de doenças crônicas não transmissíveis) e os crescentes gastos com a saúde (GIOVANELLA, 2006).

Já nos países da América Latina, a partir dos anos 90, com a implementação da chamada agenda neoliberal, a reforma do Estado teve como princípio a redução do seu papel na garantia e regulação dos direitos sociais, estabelecendo a mercantilização de direitos sociais como a saúde e a educação. A partir daí são desenvolvidas mais fortemente propostas de APS com caráter seletivo, caracterizada por um conjunto de ações (cesta básica de ações de saúde) voltadas às populações específicas e/ou pobres. Conjuntamente, também há a redução de investimento ou a transferência dos recursos à iniciativa privada, para o investimento em políticas sociais. Nesse contexto, há uma focalização de programas a populações ou grupos sociais específicos, justificada por uma retórica de equidade descolada dos princípios de igualdade e universalidade, gerando, assim, distorção na concepção de justiça social (CAMPOS et al., 2015).

Assim, observam-se diferentes abordagens de APS no desenvolvimento dos sistemas de saúde, estando relacionadas a mudanças ao longo da história dos sistemas político e econômico. Essas diferentes concepções não se apresentam de forma isolada, coexistindo em diferentes momentos na história ou em um mesmo sistema de saúde, e orientam os diversos atores políticos e grupos de influência no processo de produção e condução da política de saúde (MENDES, 2015). A sistematização do Quadro 1 ajuda no reconhecimento dessas diferentes concepções. 
Quadro 1- Abordagens da Atenção Primária à Saúde.

\begin{tabular}{|l|l|l|}
\hline \multicolumn{1}{|c|}{ Abordagem } & \multicolumn{1}{|c|}{ Concepção } & \multicolumn{1}{c|}{ Enfoque } \\
\hline APS seletiva & $\begin{array}{l}\text { Conjunto circunscrito de ações e } \\
\text { serviços de saúde direcionados às } \\
\text { populações específicas e que tenham } \\
\text { alto impacto no enfrentamento dos } \\
\text { problemas de saúde mais prevalentes. }\end{array}$ & $\begin{array}{l}\text { O enfrentamento dos problemas de } \\
\text { saúde é limitado pelos custos } \\
\text { assumidos como toleráveis pelas } \\
\text { autoridades. Geralmente empregado } \\
\text { em modelos dirigidos a populações } \\
\text { pobres. }\end{array}$ \\
\hline $\begin{array}{l}\text { APS integral ou } \\
\text { abrangente }\end{array}$ & $\begin{array}{l}\text { Remete ao conceito de Alma-Ata de } \\
\text { cuidados primários de saúde ampliado, } \\
\text { concebendo a APS como estratégia de } \\
\text { organização do sistema de saúde. Desta } \\
\text { forma, deve garantir acesso universal e } \\
\text { integralidade, a partir da articulação } \\
\text { com o conjunto do sistema de saúde. }\end{array}$ & $\begin{array}{l}\text { Direcionada ao enfrentamento dos } \\
\text { determinantes sociais da saúde, ao } \\
\text { social, à ação intersetorial, ao uso de } \\
\text { tecnologias apropriadas e recursos de } \\
\text { forma eficiente. }\end{array}$ \\
\hline $\begin{array}{l}\text { APS como } \\
\text { primeiro nível de } \\
\text { atenção }\end{array}$ & $\begin{array}{l}\text { Nível de atenção do sistema de saúde. } \\
\text { Encarado como a porta de entrada, } \\
\text { onde deve ser atendida a maior parte } \\
\text { das pessoas que necessitam de } \\
\text { cuidados contínuos. }\end{array}$ & $\begin{array}{l}\text { Em sua abordagem mais estreita, está } \\
\text { relacionada à oferta de serviços } \\
\text { primários de saúde, centrados em } \\
\text { médicos generalistas ou especialistas } \\
\text { em medicina de família. }\end{array}$ \\
\hline $\begin{array}{l}\text { APS com enfoque } \\
\text { em saúde e direitos } \\
\text { humanos }\end{array}$ & $\begin{array}{l}\text { Parte da compreensão da saúde como } \\
\text { direito humano, devendo ser abordados } \\
\text { os determinantes sociais e políticos da } \\
\text { saúde. Defende que a política de saúde } \\
\text { deve compreender os compromissos } \\
\text { financeiro e legislativo. }\end{array}$ & $\begin{array}{l}\text { Enfoque em saúde e direitos humanos } \\
\text { namerspectiva dos processos } \\
\text { emancipatórios. }\end{array}$ \\
\hline
\end{tabular}

Fonte: Adaptado de VUORI, 1986; OPAS/OMS, 2007; BOUSQUAT et al., 2017.

\subsection{A REFORMA SANITÁRIA BRASILEIRA E O PAPEL DA APS NA CONSTITUIÇÃO DO SISTEMA ÚNICO DE SAÚDE}

A introdução da APS no Brasil está associada ao desenvolvimento da rede de serviços básicos de saúde e ações de saúde pública. Essas últimas são entendidas como ações governamentais de saneamento, educação, higiene e prevenção de doenças que afetavam o pleno desenvolvimento econômico, principalmente, nos grandes centros urbanos e nas áreas exploradas pelo extrativismo, como foi o caso da borracha na Região Norte do País (CAMPOS, 2007).

Por isso, até início do século passado, as ações de saúde pública eram direcionadas ao controle do ambiente, dos agentes infecciosos e da coletividade, com vistas à fiscalização das condições sanitárias. As medidas de saneamento, higiene e profilaxia e controle dos portos vão evoluindo na perspectiva da educação sanitária e do combate das doenças endêmicas, como a malária, a ancilostomose e a tuberculose. Os primeiros estabelecimentos públicos de 
saúde, voltados ao atendimento de uma população em base territorial permanente, foram os postos de higiene e profilaxia rural (CAMPOS et al., 2016).

Essas ações e estabelecimentos de saúde requereram a formação de pessoal qualificado, notadamente os chamados médicos sanitaristas e enfermeiras visitadoras, processo que teve forte influência da Fundação Rockfeller (CAMPOS et al., 2016).

Com os avanços científico e tecnológico do início do século XX e o desenvolvimento econômico do Brasil, a partir da década de 20, algumas cidades polo passaram por um processo de modernização. São desenvolvidas experiências de organização da rede de serviços básicos que tentavam superar o modelo campanhista. Nesse processo, houve a introdução dos centros de saúde e respectivos distritos sanitários, desenvolvidos com institutos e faculdades de saúde, o que representa a introdução da noção de Atenção Primária no Brasil.

Em São Paulo, o médico Geraldo de Paula Souza foi o pioneiro na criação de postos de atendimento com forte orientação para a prevenção e a educação sanitária. Da mesma forma, Clementino Fraga, sucessor de Carlos Chagas, e seus adeptos, chamados de "novos turcos", foram os responsáveis por esse processo no Rio de Janeiro (TEIXEIRA, 2006; CAMPOS et al., 2016, p. 1.355).

Em 1942, fruto de uma cooperação bilateral entre o Brasil e os Estados Unidos, foi criado o Serviço Especial de Saúde Pública (SESP), influenciado pela medicina preventiva norte-americana e cujo objetivo era realizar ações de saneamento, campanhas e atendimento médico hospitalar e ambulatorial.

Já a partir dos anos 70, alguns municípios, com o apoio de universidades e influenciados pelo movimento de Reforma Sanitária, desenvolveram experiências de centros de saúde com base na medicina comunitária (LAVRAS, 2011).

Na mesma época, em 1976, foi desenvolvido o Programa de Interiorização das Ações de Saúde e Saneamento (PIASS), o qual se caracterizava pela ênfase no combate às doenças transmissíveis e nos encaminhamentos de doentes, no desenvolvimento de ações de saúde de baixo custo e na instalação de postos de atendimento. Destaca-se que o Programa tinha como diretriz a utilização de pessoal de nível auxiliar, recrutado nas próprias comunidades a serem beneficiadas (BRASIL, 1976).

A característica de engajamento comunitário no recrutamento de pessoal auxiliar do PIASS e a experiência de visitadores sanitários da SESP guardam similaridade com as 
características do Programa de Agentes Comunitários de Saúde (PACS), iniciado em 1987 no Ceará e adotado, posteriormente, pelo governo federal, em 1991 (MATHIAS, 2008).

Ainda na década de 80 , incentivado pela OPAS para a efetivação dos pressupostos da Alma-Ata, também foi desenvolvido o modelo técnico assistencial que tinha como eixos centrais o engajamento comunitário e o planejamento da organização dos serviços de saúde a partir da delimitação de uma base territorial (distritos sanitários) e suas características epidemiológicas. Foi uma experiência, conhecida como Sistemas Locais de Saúde (SILOS), que se estruturava a partir da descentralização e regionalização do sistema de saúde. O Brasil contou com experiências, principalmente, no Nordeste, que fizeram parte do processo de desenvolvimento e evolução de um sistema único e descentralizado de saúde (PAIM e ALMEIDA, 1998).

Intrínseca a essas experiências, forjou-se o movimento da Reforma Sanitária brasileira, fundamental na consagração do direito à saúde e da constituição do SUS. Nesse período, na América Latina e no Brasil, onde houve um desenvolvimento tardio do capitalismo, houve o acirramento das contradições e dos embates produzidos pela ditadura. No processo de redemocratização do Brasil, coexistiram os projetos liberal e nacionalista de desenvolvimentismo econômico que aprofundou as desigualdades sociais e os crescentes movimentos democráticos que buscavam por meio da Constituinte a garantia de direitos sociais, em alusão ao pleno exercício da cidadania e do bem-estar social (ALMEIDA, 2002; SILVEIRA, 2015).

O processo de redemocratização do Brasil vivenciado nos anos 80 culminou com a Constituição Federal de 1988 que, mesmo em meio a concessões e contradições na composição do seu texto, é forjada pelo processo de retomada da participação democrática no País e influenciada pela concepção de bem-estar social, reafirmando um Estado democrático de direito (GOUVEIA e PALMA, 2009; SILVEIRA, 2015).

Assumiu-se o ideal de uma sociedade igualitária, justa e solidária com o objetivo de promover o seu bem-estar. Nesse sentido, o capítulo da Seguridade Social descreve um conjunto de direitos a serem garantidos pelo Estado e constitui o sistema de Proteção Social, composto pela Saúde, Assistência e Previdência Social (BRASIL, 1988).

Por um lado o acesso à saúde passa a ser um direito universal, com a inclusão de uma parcela importante da população ora excluída, gerando a necessidade de um sistema de saúde capaz de atender as necessidades de toda a população. Por outro, contraditoriamente, a estruturação desse recém-criado sistema de saúde no Brasil não encontrou condições 
favoráveis para o seu desenvolvimento. PAIM (2006) aponta sérios entraves do SUS em seu ponto de partida, que sofreu com restrições estruturais em seu financiamento, dificuldades na provisão e formação dos recursos humanos, mecanismos de gestão ineficientes e falta de estruturação de rede assistencial pública, sendo obrigado a recorrer à iniciativa privada.

Desta forma, estabeleceram-se cláusulas pétreas na Constituição, destinadas a assegurar o exercício da cidadania por meio da garantia dos diretos sociais e individuais. Contraditoriamente, foram contemplados os interesses do setor privado, prevendo-se a complementariedade do sistema por meio da prestação de serviços pela iniciativa privada.

Os princípios do SUS reconhecidos na Constituição de 1988 e nas Leis Orgânicas da Saúde $\mathrm{n}^{\circ}$ 8.080, de 18 de setembro de 1990, e n 8.142, de 28 de dezembro de 1990, são frutos da $8^{\text {a }}$ Conferência Nacional de Saúde, conquistas do movimento brasileiro da Reforma Sanitária e estão ligados à ideia de democratização da saúde, direitos humanos e cidadania. Propõem um sistema de saúde pautado na universalidade do acesso, na participação social e na integralidade da atenção que caracterizam valores ligados ao direito de cidadania e em substituição a um sistema excludente e desigual (PAIM, 2006).

A saúde foi assumida como direito universal a ser assegurado pelo Estado mediante políticas econômicas e sociais. Estabeleceu-se que o conjunto de ações e serviços públicos que integram uma rede regionalizada e hierarquizada deve compor um sistema único de saúde, o qual deve se estruturar de acordo com as diretrizes da descentralização, do atendimento integral e da participação da comunidade (BRASIL, 1988).

Com a promulgação da Constituição de 88 , o processo de descentralização da responsabilidade sobre o acesso à saúde e a gestão dos serviços de saúde entram na agenda do governo federal, que passa a apoiar o processo de municipalização. Com a regulamentação do SUS, em 1990, por meio das Leis Orgânicas da Saúde e subsequentes NOB, que passaram a determinar a organização e o funcionamento do sistema de saúde, bem como a responsabilidade de cada ente da Federação, os municípios passaram a ter responsabilidade sanitária pelo seu território e passaram a intensificar as experiências de constituição de modelos de atenção para a organização do sistema de saúde e o provimento do direito à saúde.

A municipalização, que marcou o processo de descentralização, sofre críticas por ter ocorrido desarticulada da descentralização do poder e descolada da regionalização. Essa última, considerada hoje como fundamental para a eficiência do sistema, dada as características de organização entre os entes federativos e a baixa capacidade técnica e 
financeira da maioria dos municípios, além da questão da economia de escala e densidade tecnológica. Apesar da municipalização, continuou existindo uma grande centralidade do governo federal sobre a condução da política de saúde, exercida, principalmente, por sua concentração da capacidade financeira e normatização das políticas (SILVA, 2001).

O movimento da Reforma Sanitária e o florescimento do campo da Saúde Coletiva também tiveram papel fundamental na produção técnico-científica que influenciou a formulação da política de saúde. Uma das principais questões passou a ser a proposta de substituição do modelo médico-privatista, com a chamada inversão do modelo tecnoassistencial.

Tudo isso adensou o desenvolvimento, no Brasil, das experiências de sistemas locais de saúde, tendo a Atenção Primária como porta de entrada preferencial para o acesso à saúde e com uma forte orientação para a prevenção de doenças e a promoção da saúde.

Em 1991, o Ministério da Saúde adotou, nacionalmente, o PACS e, em 1994, o Programa Saúde da Família (PSF), assumido, posteriormente, em 1998, como estratégia de reorganização do modelo assistencial. Ambos os Programas são normatizados por portarias e com forte indução de recurso específico para a sua implantação e custeio. $O$ próprio Departamento de Atenção Básica do Ministério da Saúde (DAB/MS) foi criado em 1999 e a Estratégia Saúde da Família (ESF) teve papel de destaque no processo de formulação da PNAB.

O esforço para implementar a gestão plena da Atenção Básica e do sistema local pelos municípios foi desenvolvido concomitante com a indução da ESF. Diversos trabalhos chamam atenção para o forte papel de indução do governo federal, que formatou o modelo de atenção por meio da normatização associada a repasses financeiros (BAPTISTA, 2007).

BODSTEIN (2002) afirma que, embora o repasse financeiro intragovernamental tenha sido regulamentado pelas Leis Orgânicas da Saúde, o processo de descentralização foi intensificado apenas a partir de 1996, quando são implementadas medidas concretas para o repasse financeiro pelo governo federal, expressas, sobretudo, na NOB 1996, para que os municípios assumam a gestão da rede de serviços locais de saúde, e instituído o Piso da Atenção Básica (PAB), através da Portaria no 1.882, de 18 de dezembro de 1997, que prevê repasse financeiro do governo federal, diretamente aos municípios, inclusive recursos específicos para aqueles com Saúde da Família implantada.

O Pacto pela Saúde, instituído pela Portaria no 399, de 22 de fevereiro de 2006, que tratou de um esforço em atualizar e aprimorar os mecanismos de gestão do SUS entre os entes 
federados substituiu a habilitação da gestão dos municípios por adesão ao comprometimento com compromissos. Estabeleceu, ainda, o mecanismo do termo de compromisso de gestão para a formalização das prioridades e dos compromissos entre os gestores do SUS. Na dimensão do Pacto pela Vida definiu como prioridade o compromisso em "consolidar e qualificar a estratégia Saúde da Família como modelo de Atenção Básica e centro ordenador das redes de atenção à saúde no SUS” (BRASIL, 2006).

A PNAB, editada inicialmente por meio da Portaria $n^{\circ}$ 648, de 28 de março de 2006, consolidou a ESF como modelo prioritário de organização da Atenção Básica, bem como o conjunto de normas e diretrizes para a organização da Atenção Básica nos municípios a partir dos atributos da APS. Em 2011, passou por um primeiro processo de revisão das suas diretrizes com a publicação da Portaria $n^{\circ} 2.488$, de 21 de outubro de 2011. Em ambas, a Atenção Básica é caracterizada como:

[...] um conjunto de ações de saúde, no âmbito individual e coletivo, que abrange a promoção e a proteção da saúde, a prevenção de agravos, o diagnóstico, o tratamento, a reabilitação, a redução de danos e a manutenção da saúde com o objetivo de desenvolver uma atenção integral que impacte na situação de saúde e autonomia das pessoas e nos determinantes e condicionantes de saúde das coletividades. É desenvolvida por meio do exercício de práticas de cuidado e gestão, democráticas e participativas, sob forma de trabalho em equipe, dirigidas a populações de territórios definidos, pelas quais assume a responsabilidade sanitária, considerando a dinamicidade existente no território em que vivem essas populações (BRASIL, 2012, p. 19).

\subsection{AVANÇOS E DESAFIOS DA PNAB PARA O DESENVOLVIMENTO DA APS}

Com a indução financeira e a boa aceitação por parte da população, o PSF e o PACS foram se expandindo, tendo um crescimento mais perceptível em pequenos municípios. $\mathrm{O}$ desafio de expandir a cobertura da ESF e a sua consolidação como estratégia de inversão do modelo de atenção fez com que o Ministério da Saúde investisse no Projeto de Expansão e Consolidação da Saúde da Família (PROESF), que teve foco de investimento os municípios de grande porte (BODSTEIN et al., 2006).

Segundo o Ministério da Saúde, o PROESF é:

[...] uma iniciativa do Ministério da Saúde, apoiada pelo Banco Mundial - BIRD, voltada para a organização e o fortalecimento da Atenção Básica à Saúde no País. Visa contribuir para a implantação e consolidação da Estratégia de Saúde da Família em municípios com população acima de 100 mil habitantes e a elevação da qualificação do processo de trabalho e desempenho dos serviços (BRASIL, 2003). 
A primeira etapa do PROESF ocorreu entre os anos de 2002 e 2009 e contou com o volume total de U\$ 550 milhões, distribuídos dentre os componentes e as linhas de investimento do Projeto. Os três componentes técnicos foram: componente I - investimento na estruturação da ESF em municípios com mais de 100 mil habitantes; componente II investimento para formação, capacitação e educação permanente de recursos humanos; e componente III - apoio à estruturação e implementação de metodologias e instrumentos de monitoramento e avaliação de processo e desempenho no âmbito do SUS (BRASIL, 2003). As linhas de investimento do PROESF dão pistas da percepção institucional sobre os desafios para a ampliação e a consolidação da ESF, assim como as dimensões abordadas nas pesquisas de linha de base realizadas no âmbito do PROESF.

No documento publicado pelo Ministério da Saúde, Diretrizes Operacionais: pactos pela vida, em defesa do SUS e de gestão, o item Fortalecimento da Atenção Básica traz nove subitens, os quais seguem transcritos abaixo e foram incorporados integralmente no termo de compromisso de gestão (BRASIL, 2006).

Ao serem assumidos enquanto compromisso pelos gestores, os objetivos apontam para os desafios identificados como necessários de serem enfrentados para o fortalecimento da Atenção Básica:

a. Assumir a estratégia de Saúde da Família como estratégia prioritária para o fortalecimento da atenção básica, devendo seu desenvolvimento considerar as diferenças loco-regionais;

b. Desenvolver ações de qualificação dos profissionais da atenção básica por meio de estratégias de educação permanente e de oferta de cursos de especialização e residência multiprofissional e em medicina da família;

c. Consolidar e qualificar a estratégia de Saúde da Família nos pequenos e médios municípios;

d. Ampliar e qualificar a estratégia de Saúde da Família nos grandes centros urbanos;

e. Garantir a infraestrutura necessária ao funcionamento das Unidades Básicas de Saúde, dotando-as de recursos materiais, equipamentos e insumos suficientes para o conjunto de ações propostas para estes serviços;

f. Garantir o financiamento da Atenção Básica como responsabilidade das três esferas de gestão do SUS;

g. Aprimorar a inserção dos profissionais da Atenção Básica nas redes locais de saúde, por meio de vínculos de trabalho que favoreçam o provimento e fixação dos profissionais;

h. Implantar o processo de monitoramento e avaliação da Atenção Básica nas três esferas de governo, com vistas à qualificação da gestão descentralizada;

i. Apoiar diferentes modos de organização e fortalecimento da Atenção Básica que considere os princípios da estratégia de Saúde da Família, respeitando as especificidades loco-regionais (BRASIL, 2006, p. 13).

Nesse contexto, a publicação da Portaria $n^{\circ}$ 648, de 28 de março de 2006, que instituiu a PNAB, além de ratificar a Atenção Básica como fundamental para promover o acesso à saúde e a organização do sistema de saúde, caracterizou-se por definir a Saúde da Família 
como estratégia prioritária de organização do modelo de atenção. Estabeleceu princípios e diretrizes para a organização da Atenção Básica muito próximos com os próprios princípios e fundamentos do SUS, como também dos atributos da APS. De acordo com o texto de apresentação do próprio Ministério da Saúde, a PNAB de 2006:

[...] aponta para a redefinição dos princípios gerais, responsabilidades de cada esfera de governo, infraestrutura e recursos necessários, características do processo de trabalho, atribuições dos profissionais, e as regras de financiamento, incluindo as especificidades da estratégia Saúde da Família. (BRASIL, 2007, p. 3).

Na Portaria de publicação da PNAB 2006 destaca-se a definição de parâmetros para a organização e o funcionamento da Saúde da Família, com estabelecimento do número máximo de 4.000 pessoas a serem acompanhadas pela equipe e 750 pessoas para cada ACS, sendo em número suficiente para cobrir $100 \%$ das pessoas cadastradas e não ultrapassando o número de 12 ACS por equipe, bem como as 40 horas de carga horária semanal para todos os profissionais da equipe. Também incorporou a equipe de saúde bucal às eSF, proporcionando, em curto período de tempo, um aumento do número de equipes e o acesso à saúde bucal na Atenção Básica (BRASIL, 2007).

Entre a publicação da PNAB de 2006 e a versão de 2011, diversas portarias e normativas foram editadas com o intuito de incremento e desenvolvimento da Política. $\mathrm{Na}$ verdade, a PNAB de 2011, publicada por meio da Portaria $\mathrm{n}^{\circ} 2.488$, de 21 de outubro de 2011, manteve a essência da de 2006, incorporando as diversas novidades desenvolvidas nesse período (FONTANELLE, 2012).

Destaca-se o reconhecimento ou a proposição de uma maior diversidade de arranjos e ampliação de equipes, como equipes ribeirinhas e fluviais, Consultório na Rua, Núcleo de Apoio à Saúde da Família (NASF); a flexibilização da carga horária do médico na composição de equipe (20h, 30h e 40h); a incorporação da ideia desejável da APS como ordenadora da RAS e coordenadora do cuidado; e o aumento de forma significativa dos recursos da área, com a introdução de critérios de equidade no repasse do PAB fixo e o financiamento associado à avaliação de padrões de qualidade comparáveis, por meio do Programa de Melhoria do Acesso e da Qualidade (PMAQ). Destacam-se, ainda, no bojo da PNAB de 2011, os esforços para a melhoria da infraestrutura com o programa de construção e reforma de unidades básicas de saúde, bem como a sua informatização (BRASIL, 2012).

Apesar de avanços significativos da APS no Brasil ao longo dos últimos anos, observam-se esforços para abordar os desafios para a expansão da ESF e o acesso à saúde por meio da APS (CASTRO e MACHADO, 2012). De acordo com os registros administrativos 
da Secretaria de Atenção Primária à Saúde (SAPS) do Ministério da Saúde, embora a tendência de crescimento do número de eSF permaneça positiva no período, conforme demonstrado no Gráfico 1, percebe-se que entre os anos de 2006 e 2013 houve uma desaceleração da tendência de expansão ou maior dificuldade no aumento do número absoluto de eSF

Gráfico 1 - Número de equipes de Saúde da Família implantadas no Brasil, 1998 a 2017.

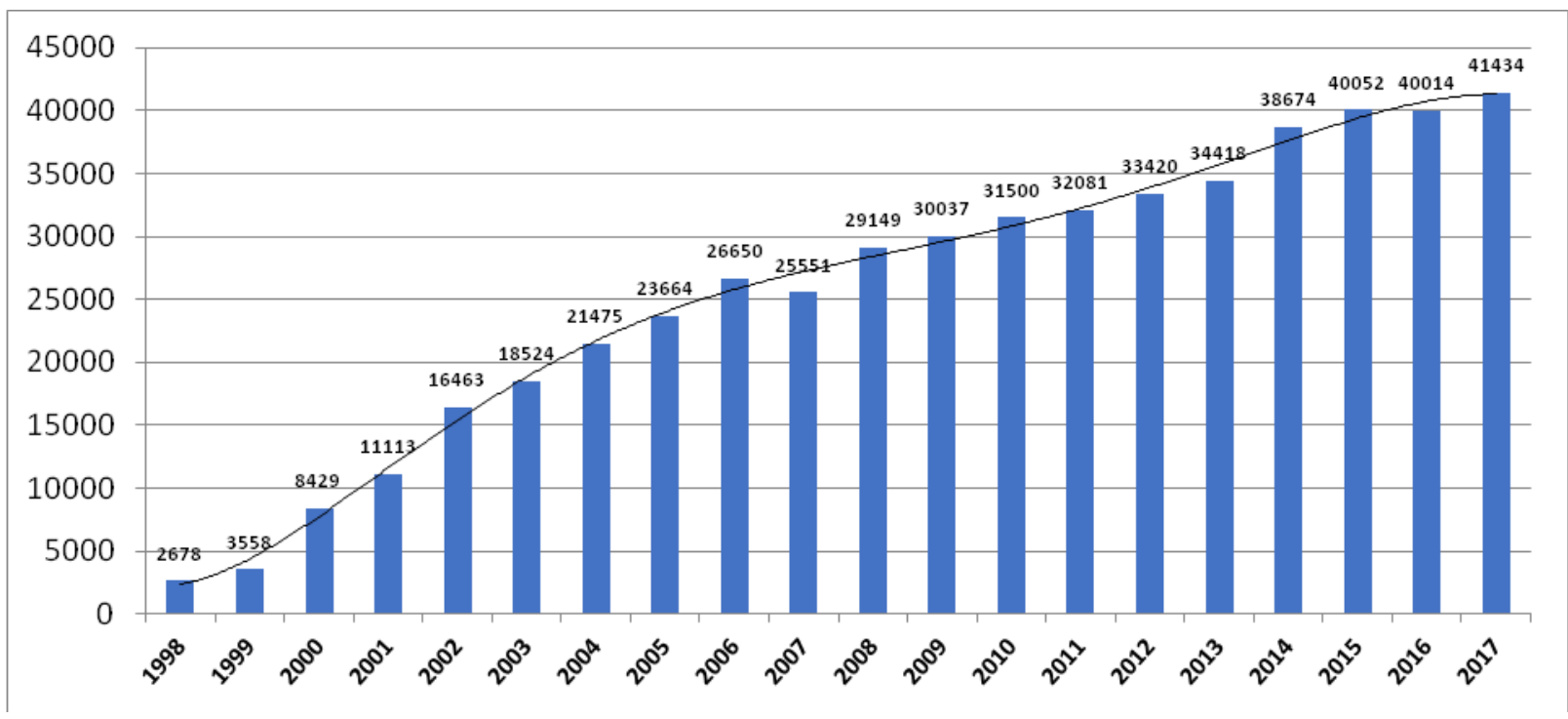

Fonte: Elaborado pelo autor a partir dos dados administrativos disponibilizados pela SAPS/MS.

Nota 1: Para fins de comparação da série histórica de 1998 a 2017 foram utilizados os dados de eSF implantadas da competência de setembro de cada ano, disponíveis em: <http://dab.saude.gov.br/portaldab/historico_pagamento_sf.php>. Acesso em: mar. 2018.

Nota 2: Até a data da consulta, ao disponibilizar os dados sobre o histórico de cobertura, o MS diferenciava a quantidade de equipes cadastradas no CNES e equipes implantadas. Equipes implantadas referiam-se a aquelas que faziam jus ao repasse de incentivo financeiro mensal (PAB variável) mediante envio dos dados da produção e conformidade com as diretrizes da PNAB.

Uma das explicações desse fenômeno está relacionada à dificuldade de atração e à fixação do médico para atuação na ESF. A outra possível explicação refere-se à adoção da ESF como modelo prioritário para a $\mathrm{AB}$, direcionada, principalmente, às áreas de maior vulnerabilidade, ficando as áreas descobertas de ESF e sob responsabilidade de outros tipos de eAB, ou mesmo outros modelos. Também não se descarta uma possível relativização do direito universal à saúde que, diante da escassez de recursos, o que pode ter impulsionado a decisões, política e administrativa, de considerar apenas a população usuária ou "dependente" do SUS e/ou mais vulnerável para fins de priorização das políticas de saúde.

Ainda é possível observar no Gráfico 1 que, apesar dos esforços e das novidades trazidas pela PNAB de 2011, com destaque para a flexibilização da carga horária do médico para a composição de equipe e o incremento no financiamento, apenas houve aumento mais 
significativo no número de eSF a partir de 2013. Naquele ano foi lançado o Programa Mais Médicos, com o objetivo suprir o déficit de médicos no Brasil e proporcionar provimento em áreas de difícil acesso e/ou de maior vulnerabilidade, o que nos leva a considerar a questão do provimento de médicos como fundamental para o avanço da cobertura da ESF (PINTO et al., 2017).

Além de estudos sobre os limites para o aumento da cobertura da ESF, a fim de que a mesma possa se firmar como porta de entrada preferencial do acesso aos serviços de saúde do SUS, para o aperfeiçoamento da PNAB é necessário identificar os problemas e os desafios para o fortalecimento da $\mathrm{AB}$. Nesse aspecto, tem destaque a produção de ARANTES et al. (2016), que realizaram um trabalho de revisão da literatura, analisando as contribuições e os desafios da ESF no desenvolvimento da APS no Brasil a partir das dimensões: tecnoassistencial, político-institucional e organizativa.

$\mathrm{Na}$ dimensão tecnoassistencial foram examinadas as relações estabelecidas entre os trabalhadores da saúde e o desenvolvimento de suas práticas para o bem-estar dos usuários dos serviços. Foi identificado que a ESF contribuiu para maior produtividade e acesso às ações em relação ao chamado modelo tradicional de organização da APS; e maior adesão e continuidade do cuidado em condições crônicas. Ao mesmo tempo, foram identificados como desafios: o risco em reproduzir a racionalidade biomédica; e a dificuldade no atendimento a grupos ou condições específicas emergentes, como obesidade, saúde do adolescente, atendimento de saúde mental e usuários de drogas ilícitas.

Na dimensão político-institucional foram analisados os mecanismos de condução da política, observando-se o investimento em ações e serviços que visam o aprimoramento da APS. Dentre as contribuições, foram identificadas: a ampliação do acesso com equidade; e a institucionalização da avaliação associada ao financiamento. Por outro lado, os desafios foram: a adequação da força de trabalho e a regularização dos vínculos; o subfinanciamento; e a fragilidade na articulação de ações intersetoriais.

$\mathrm{Na}$ dimensão organizativa foram analisadas a forma de organização dos serviços de saúde e a interação entre os níveis de atenção no processo de cuidado, com a finalidade de promover a integralidade. Os avanços foram: o acesso em áreas de vazios assistenciais ou de difícil acesso; e o maior contato com ações programáticas. Os desafios, por sua vez, foram: o reconhecimento da APS como porta de entrada do sistema de saúde; a articulação com os demais níveis do sistema; o planejamento das ações; e a participação social. 
No bojo da avaliação da expansão da ESF, pesquisa realizada em grandes centros urbanos que apresentavam mais de $60 \%$ de cobertura de eSF e mais de 5 anos de implantação teve como eixo de análise a integração da rede assistencial e intersetorialidade. Giovanella et al. (2009) publicaram o trabalho no qual são destacados as potencialidades e os obstáculos que condicionam a consolidação da ESF. A análise foi agrupada nas categorias integração da rede, intersetorialidade e gestão do trabalho. Dentre os obstáculos destacados, traduzidos aqui como desafios, pontua-se em cada uma das categorias:

Integração da Rede: no estudo os serviços de APS com ESF tornaram-se a porta de entrada preferencial do sistema de saúde e o acesso à atenção especializada. No entanto, é necessário reafirmar a APS como porta de entrada do sistema, sendo necessário melhorar o acesso e articular propostas como as Unidades de Pronto Atendimento (UPA) para que não se constituam como serviços concorrentes. A APS precisa realizar o ordenamento e a regulação do acesso a exames e especialidades para que a articulação das redes de atenção seja efetiva. São facilitadores desse processo: a informatização do sistema, o sistema de regulação deve ser guiado pelo estabelecimento de critérios, os fluxos de encaminhamento e o monitoramento do tempo de espera.

Intersetorialidade: as ações intersetoriais que respondem a políticas públicas envolvendo diversas secretarias ou setores são potencialmente mais efetivas do que a atuação restrita a projetos específicos. Isso impacta na atuação da eSF, que trabalha a partir da identificação de necessidades do território e que, por vezes, extrapolam a capacidade clínicaassistencial, sendo necessário contar com a ação de outras secretarias. O território é a base local para a intervenção das eSF e a articulação entre os serviços sociais e o ACS é um facilitador para a identificação das demandas, dos riscos e da promoção de mobilização comunitária.

Ainda sobre o ACS, destaca-se a necessidade de maior articulação entre o trabalho dos ACS e dos Agentes de Combate às Endemias (ACE) no território. Recomenda-se o monitoramento das visitas realizadas, podendo ser estabelecidas rotinas diferenciadas de visita, de acordo com a avaliação de risco e a presença de agravos crônicos, além de ajustes necessários para abarcar a classe média, tendo a APS como porta de entrada para o atendimento no SUS.

Gestão do Trabalho: persiste o desafio na formação e capacitação dos trabalhadores da saúde para atuarem conforme o modelo preconizado. Além disso, existe o desafio da adesão desses trabalhadores, equacionando o provimento, a relação de vínculos trabalhistas, a 
valorização e a fixação desses profissionais, notadamente em áreas de maior vulnerabilidade social.

Analisando as diretrizes operacionais para o Fortalecimento da Atenção Básica do Pacto pela Saúde de 2006, bem como os trabalhos destacados acima, que levantam desafios para a constituição de uma ESF potente, capaz de promover o acesso à saúde de qualidade e reorientar o modelo de atenção, é possível observar congruências com relação aos elementos para o desenvolvimento da APS no Brasil e, portanto, representam demandas ou problemas a serem abordados pela PNAB.

\subsection{O CENÁRIO DA POLÍTICA DE SAÚDE E A APS NA AGENDA DE GOVERNO: O QUE ESTÁ EM DISPUTA?}

Com o aumento da complexidade do processo de cuidado e das demandas de saúde é crescente a necessidade de maior e melhor resposta dos sistemas de saúde, exigindo repensar a configuração da APS na RAS e ampliar os investimentos no apoio diagnóstico, na formação, no provimento e na gestão da força de trabalho, na infraestrutura e na articulação com outros pontos da rede de atenção (GIOVANELLA e LOBATO, 2012; MENDES, 2015).

Os elementos para se produzir uma assistência de qualidade, que seja resolutiva e orientada pela APS, tornaram-se complexos para os municípios e uma tarefa inviável de ser realizada isoladamente. O Conselho Nacional de Secretarias Municipais de Saúde (CONASEMS), entidade que representa os secretários municipais de saúde, alega que os gestores municipais, geralmente, são os com menor capacidade técnica e financeira, mas são os que mais têm arcado com o aumento percentual dos custos do sistema (CARVALHO, 2016).

Com o ciclo de crise política e econômica que por si só provoca a redução dos investimentos e da arrecadação, a manutenção do modelo econômico de cumprimento das metas para o controle da inflação e superávit para o pagamento dos juros da dívida pública, repercute diretamente sobre os estados e, principalmente, os municípios, altamente dependentes dos repasses federais. Por isso, os programas associados à indução financeira do governo federal, em que há custeio por meio de repasses mensais, estabelece uma relação de dependência entre os entes, submetendo os municípios à condição em que o governo federal acumula forte capacidade indutora de suas políticas (BAPTISTA, 2007).

Por isso, houve forte polêmica na introdução do incentivo financeiro por parte do governo federal para o custeio da equipe de atenção básica "tradicional", prevendo a 
flexibilização da quantidade e a carga horária do médico e a não exigência do ACS em sua composição. Juntamente com esse arranjo de equipe, houve a desregulamentação do parâmetro mínimo anterior de ACS por eSF e a desobrigação de $100 \%$ da cobertura da população adstrita com ACS (BRASIL, 2017; MOROSINI et al., 2018).

Outra importante novidade da proposta da PNAB 2017 diz respeito à introdução de padrões essenciais e padrões ampliados. De acordo com o texto da Portaria que estabeleceu as novas diretrizes da PNAB 2017:

Padrões Essenciais - ações e procedimentos básicos relacionados a condições básicas/essenciais de acesso e qualidade na Atenção Básica; e - Padrões Ampliados ações e procedimentos considerados estratégicos para se avançar e alcançar padrões elevados de acesso e qualidade na Atenção Básica, considerando especificidades locais, indicadores e parâmetros estabelecidos nas Regiões de Saúde (BRASIL, 2017).

Essas demandas entraram na agenda da revisão das diretrizes da PNAB e aparentemente estão relacionadas a demandas dos gestores. Contudo, embora essas mudanças estejam relacionadas a problemas cotidianos da gestão da APS nos municípios, segmentos críticos à proposta ponderaram que elas não enfrentam os desafios apontados para a ampliação da cobertura e o desenvolvimento de uma APS abrangente e resolutiva, capaz de se firmar como porta de entrada preferencial no acesso ao SUS e com capacidade para ordenar a rede de atenção, conforme proposto pela própria PNAB 2017.

Esse posicionamento foi explicitado por meio de nota pública de entidades influentes no movimento sanitário brasileiro, constitutivo da Reforma Sanitária que deu origem ao SUS, como o CEBES e a ABRASCO, sendo também o posicionamento de boa parte das entidades profissionais e dos movimentos sociais que fazem parte do $\mathrm{CNS}^{2}$ e são críticos à revisão da PNAB 2017. Segundo eles, incorporar o chamado "modelo tradicional" de organização de equipe como elegível para o recebimento de recursos caracterizaria o esvaziamento da indução no modelo baseado na ESF, assim como o estabelecimento de padrões essenciais e ampliados poderiam ser desvirtuados e facilmente transformados em padrões mínimos de

\footnotetext{
${ }^{2}$ O Conselho Nacional de Saúde é uma instância colegiada, deliberativa e permanente do SUS, integrante da estrutura organizacional do Ministério da Saúde. Criado em 1937, sua missão é fiscalizar, acompanhar e monitorar as políticas públicas de saúde nas suas mais diferentes áreas, levando as demandas da população ao poder público, por isso é chamado de controle social. As atribuições atuais do CNS estão regulamentadas pela Lei $\mathrm{n}^{\circ} 8.142 / 1990$. O conselho é composto 48 conselheiros(as) titulares e seus respectivos primeiros e segundos suplentes, que são representantes dos segmentos de usuários, trabalhadores, gestores do SUS e prestadores de serviços em saúde. Além do Ministério da Saúde, fazem parte do CNS movimentos sociais, instituições governamentais e não-governamentais, entidades de profissionais de saúde, comunidade científica, entidades de prestadores de serviço e entidades empresariais da área da saúde (BRASIL, 2018a)
} 
“cestas básicas", análogos à proposta de "Cobertura Universal de Saúde”, em uma visão seletiva e focalizada de APS, conforme já ponderado por NORONHA (2013).

O movimento que se posicionou contrário à revisão da PNAB 2017 alega que o conjunto de medidas expressa uma visão de APS seletiva, entendida como um nível de atenção composto por um pacote básico de ações e serviços de saúde, dirigido a uma parcela da população e estabelecido como regulador do acesso para outros níveis de atenção de maior densidade tecnológica, tendo como resultado o retrocesso no modelo tecnoassistencial e acesso à saúde. Segundo esses grupos, com essas mudanças haverá restrições na capacidade de cobertura das ações da APS e redução no acesso à saúde (ABRASCO, 2017).

Por outro lado, a proposta é defendida por gestores, representados pelo Ministério da Saúde, CONASS, que agrega os secretários estaduais, e CONASEMS. O CONASS e o CONASEMS também emitiram uma nota pública alegando que desde de 2015 vinham debatendo a necessidade de aprimoramento da PNAB "para adequá-la à situação de saúde que contempla mudanças no perfil etário, epidemiológico, ambiental e nutricional nas realidades das regiões brasileiras", alegando que a Saúde da Família continuará a ser a estratégia prioritária de organização da APS para o Brasil, mas que os $40 \%$ da população brasileira, não cobertos pela ESF, necessitam de ações e serviços na APS que sigam os mesmos princípios e diretrizes a serem implementados com a nova PNAB (CONASEMS e CONASS, 2017).

Na ocasião, o DAB/MS (2017) posicionou-se por meio do seu site, alegando que "a proposta é resultado de pactuações de diversas reuniões, eventos, encontros da $\mathrm{AB}$ e conferências com as diferentes instâncias e atores da Saúde Pública, que ocorreram ao longo dos últimos dois anos".

Ainda de acordo com o Departamento, a proposta buscou reunir as demandas dos profissionais de saúde, gestores, conselhos e entre outros representantes, e as mudanças visaram adequar as diretrizes da PNAB à realidade atual, sem deixar de priorizar a ESF (BRASIL, 2017).

Por todos os elementos apresentados até aqui, a APS permanece presente na agenda de prioridades do governo por meio da revisão das diretrizes e normas que regulamentam a PNAB e está em constante debate quanto às suas diferentes concepções.

Considerando que a configuração da agenda de revisão da PNAB realizada em 2017 apresentou como resultado mudanças significativas nas diretrizes para a organização e o funcionamento das equipes de saúde e que essa proposta foi alvo de intenso debate, questionase: 
a) Quais os fatores foram definidores para a introdução do incentivo financeiro por parte do governo federal para o custeio das chamadas equipes de Atenção Básica, que se diferenciam do arranjo da eSF por flexibilizar a composição e a carga horária dos profissionais e por não exigir ACS?

b) Quais os fatores foram definidores para a flexibilização do parâmetro mínimo do número de ACS por eSF e a cobertura de $100 \%$ da área adstrita, proposta pela revisão da PNAB 2017?

c) A formulação dessas propostas, consideradas centrais nas diretrizes da PNAB 2017, surgiu quando, por intermédio de quem, como e por quê?

d) Quais os desafios apontados para o desenvolvimento da APS estão relacionados a essas mudanças?

A pertinência desse estudo justifica-se pela emergência da disputa e das contradições em torno da revisão da PNAB de 2017, em que é necessário explorar o contexto, as motivações e as justificativas das diferentes posições sobre o tema, a fim de se compreender a condução e os efeitos da Política para o desenvolvimento do SUS.

Além disso, busca analisar os elementos que foram constitutivos da formação da agenda de mudança nas diretrizes da PNAB e como essas proposições e justificativas, determinantes na forma como se dá a organização do modelo tecnoassistencial, relacionam-se com os desafios apontados para o desenvolvimento da APS no Brasil contemporâneo e, consequentemente, impactam na garantia do acesso ao SUS. 


\section{OBJETIVOS}

\subsection{OBJETIVO GERAL}

Analisar como as mudanças realizadas na Política Nacional de Atenção Básica em 2017 entraram na agenda de governo.

\subsection{OBJETIVOS ESPECÍFICOS}

a) Situar o contexto de reformulação da Política Nacional de Atenção Básica;

b) Identificar os atores que participaram ativamente do processo de revisão das diretrizes da PNAB e suas respectivas demandas;

c) Levantar os motivos e os interesses explicitados e não explicitados para a introdução das principais mudanças incorporadas no processo de revisão da PNAB 2017, com destaque para as diretrizes para a composição da equipe de Atenção Básica;

d) Analisar os fatores condicionantes do processo que oportunizaram a revisão das diretrizes para a composição da equipe de Atenção Básica da PNAB 2017. 


\section{REFERENCIAL TEÓRICO-CONCEITUAL}

\subsection{ALGUNS CONCEITOS DO CAMPO DE POLÍTICAS PÚBLICAS COMO PONTO DE PARTIDA}

Este trabalho toma como marco teórico para a condução da pesquisa e análise dos dados alguns referenciais do campo de estudo das políticas públicas. O campo está diretamente relacionado à compreensão da natureza do Estado e seu funcionamento, tendo em vista que diversos autores definem políticas públicas como uma ação exclusiva e inerente a ele (VIANA, 1996; SOUZA, 2006; MARQUES, 2013).

A política pública materializa o resultado da disputa política e o empreendimento de recursos do Estado, para intervir, por meio de suas organizações, nas demandas oriundas de diferentes grupos que compõem a sociedade (VIANA, 1996; FREY, 2000; SOUZA, 2006).

SOUZA (2006, p. 26), em Políticas Públicas: uma revisão da literatura, resume política pública como: "o campo do conhecimento que busca, ao mesmo tempo, colocar o governo em ação e/ou analisar essa ação e, quando necessário, propor mudanças no rumo ou curso dessas ações".

Para RUA (2012, p. 17), as políticas públicas são precedidas de decisões políticas, as quais expressam certa adequação "entre fins pretendidos e meios disponíveis", e correspondem a uma escolha dos atores, baseada em suas preferências. Neste sentido, a política pública seria o conjunto de ações para a implementação da decisão tomada.

Como elementos introdutórios, torna-se relevante a diferenciação do termo política, empregado na tradição dos estudos do campo de políticas públicas como politics e policy. Politics refere-se ao processo de definição a partir da negociação e/ou imposição entre os grupos e os atores políticos. Mediado por relações de poder, é marcado pelo conflito, imposição de preferências, conteúdos e decisões. O debate, a priori público, daria origem a negociações e acordos para a formação de maioria e a implementação de determinado projeto. Policy, por sua vez, refere-se à ação do Estado, materializado pela política pública, resultante do processo de disputa política (politics). Diz respeito ao conteúdo propriamente dito da política pública, configurado em programas de ação do governo (FREY, 2000; RUA, 2012).

Apesar de a análise de políticas públicas provir da tradição da ciência política, preocupada com os processos políticos em organizações e sistemas políticos, a política pública é um campo multidisciplinar composto por contribuições teóricas advindas de outras 
áreas, como economia, administração, psicologia e sociologia, que forneceram subsídio para a construção de modelos de análise aplicáveis a vários setores (SOUZA, 2006).

Essa perspectiva de análise de políticas públicas emerge nos Estados Unidos da América a partir do período pós-guerra e debruça-se sobre o estudo da ação dos governos. Neste aspecto, ARAÚJO e RODRIGUES (2017) dão pistas para considerar a pertinência do contexto de desenvolvimento deste campo de estudo. As autoras destacam que as políticas públicas floresceram em um contexto de estabilidade democrática e dos chamados "trinta anos gloriosos" do capitalismo, caracterizado como um período de contínuo crescimento econômico e alargamento das ações do Estado. De acordo com as autoras, a percepção difundida no meio acadêmico era que o desenvolvimento de conhecimentos científicos e informações sobre a eficiência das políticas públicas contribuiria para a maximização da ação do Estado na promoção do bem-estar social.

Assim, como apontado em diversos trabalhos de outros autores, SOUZA (2006) afirma que Lasswell é um dos importantes precursores da área ao propor a aplicação de métodos científicos (racionais) às formulações e às decisões do governo em relação aos problemas públicos. É atribuído a ele a introdução das expressões policy analysis e policy science, sugerindo a aplicação do pensamento racional e do método científico à produção das ações dos governos e, também, como forma de estabelecer um diálogo entre os atores do processo de políticas públicas (os analistas, os grupos de interesse, a classe política e o governo).

A produção de Lasswell contribuiu para a estruturação do campo de análise das políticas públicas, ao propor as etapas sequenciais do processo das políticas, e lançou as bases do que se consolidaria como o modelo do ciclo de políticas. Ressalta-se que os demais modelos de análise foram desenvolvidos a partir do refinamento ou da crítica sobre as suas proposições (ARAÚJO e RODRIGUES, 2017).

Lasswell (1962 apud VIANA, 1996, p. 6) propôs sete etapas sequenciais para a divisão do processo de construção e desenvolvimento das políticas públicas, a saber: intelligence; recommending; prescribing; invoking; applying; appraising e terminating. Para este trabalho, no qual o objetivo não é abordar o conjunto dos modelos de análise de políticas, parece pertinente a tradução e a síntese produzida por ARAÚJO e RODRIGUES (2017, p. 14) sobre as sete etapas propostas por Lasswell:

Informação (recolha de dados); iniciativa (aprovação de medidas de política); prescrição (formulação de medidas, normas e regras); invocação (justificação e especificação dos benefícios e das sanções); aplicação (concretização das medidas); 
avaliação (sucesso ou insucesso das decisões), e cessação (regras e instituições criadas no âmbito da política aprovada).

A proposição de Laswell tornou-se o ponto de partida para a elaboração dos quadros teóricos e modelos de análise. Segundo FREY (2000), embora diversas versões sobre a descrição das etapas tenham sido produzidas, e com contribuição de diferentes autores para o modelo, é possível observar categorias comuns dentre todas as propostas de explicação das fases do processo do ciclo de políticas públicas.

Tomando como objetivo deste trabalho abordar os elementos de análise presentes no processo de configuração da agenda, consideramos válida a proposição de VIANA (1996, p. 6), que, no estudo de abordagens metodológicas de análise em políticas públicas, ressaltou a sintetização das etapas do ciclo de políticas públicas em "construção da agenda, formulação de políticas, implementação de políticas e avaliação de políticas".

Nessa perspectiva, a construção da agenda ou configuração da agenda (agendasetting) seria o processo pelo qual há uma percepção de uma demanda, que passa a ser identificada como um problema político. O debate sobre a composição da lista de problemas é marcado pela disputa e convencimento entre os atores e resulta na entrada de alguns problemas e outros não na agenda do governo. A formulação de políticas diz respeito à elaboração de estratégias de solução do problema, à escolha das alternativas e medidas de legitimação da decisão, como a mobilização da base de apoio político, e à preparação de argumentos explicativos da ação política. A implementação de políticas caracteriza-se pela mobilização de recursos das instituições para a implementação da decisão política, geralmente viabilizadas por meio de programas e normativas que orientam a ação. A avaliação de políticas trata do acompanhamento e da avaliação dos programas de ação empregados na política pública, visando à aferição do atingimento dos seus objetivos e metas. Desta forma, subsidia modificações nos objetivos, nas metas e nos meios da política (mecanismo de feedback), retomando o início do ciclo das políticas públicas (VIANA, 1996; ARAÚJO e RODRIGUES, 2017).

A contribuição do modelo do ciclo de políticas consiste em um instrumental que contribui para a decomposição em etapas do complexo processo das políticas. As várias fases correspondem a uma sequência de elementos do processo político-administrativo e podem ser investigadas a partir de categorias de análise, como poder, decisão, redes políticas e sociais, e práticas político-administrativas que caracterizam tipicamente cada etapa (FREY, 2000).

No entanto, vale ressaltar que se trata de um modelo heurístico e descritivo, que constrói um quadro de análise idealizado sobre o processo político e de forma prescritiva. $\mathrm{Na}$ 
prática, dificilmente este se dá de forma sequencial e com cada fase bem delimitada. Porém, por outro lado, representa uma importante ferramenta que, como afirma MARQUES (2013), "pode fornecer um primeiro mapeamento da configuração de cada política específica, a ser complexificado após a compreensão dos detalhes que cercam a política sob estudo”.

Desta forma, cada uma das etapas pode ser estudada separadamente, lançando foco em determinada questão para se ganhar maior profundidade na análise ou abordando uma fase em relação à outra, sendo que o processo de decomposição ou desmembramento facilitaria o estudo de especificidades e compreensão do próprio processo das políticas.

Dentre as críticas sobre as limitações do modelo do ciclo de políticas públicas, Jonh KINGDON (2003) destaca que o processo de produção da política não ocorre de forma ordenada e em etapas sequenciais. Em seu trabalho, Agendas, alternatives and public policies, a partir de estudos de casos aplicados para a análise da política pública de saúde e transporte dos EUA, o autor argumenta que a definição da agenda, com a eleição dos problemas prioritários para o governo, não ocorre previamente à elaboração de alternativas e soluções. $\mathrm{Na}$ verdade, ele advoga que o processo de delimitação dos problemas e das soluções seguem fluxos independentes e que as alternativas de soluções são ponderadas e defendidas por um longo período de tempo até que encontrem uma oportunidade de serem empregadas com a configuração de uma agenda favorável.

\subsection{A ABORDAGEM SOBRE A CONFIGURAÇÃO DA AGENDA}

A abordagem sobre o processo de configuração da agenda busca responder como uma demanda torna-se objeto de atenção do governo a ponto de entrar na sua lista de prioridades e passaras fases de formulação de estratégias ou programas, decisão das escolhas de alterativas e implementação das ações definidas. Isso remete ao questionamento sobre quem decide e como decide, e até mesmo sobre o que se denomina como agenda.

A agenda é definida por KINGDON (2003) como uma lista de temas ou problemas que são alvo, em dado momento, de séria atenção, tanto de autoridades governamentais quanto de pessoas fora do governo, mas estreitamente associadas às autoridades. Ainda, segundo o autor, ao se abordar a configuração da agenda, deve ser feita uma distinção entre os processos da agenda e o conjunto de alternativas, pois ambos seriam elementos pré-decisórios no processo de políticas públicas. O processo de seleção do conjunto de alternativas restringiria as possíveis soluções a serem escolhidas e aplicadas a determinados problemas. 
Kingdon sustenta seu argumento baseado no modelo teórico chamado Garbage Can, elaborado por COHEN et al. (1972) no âmbito da Teoria das Organizações. Esses autores trabalham a ideia de que as organizações, notadamente as públicas, apresentam preferências complexas, ou seja, sua ação não é guiada por preferências bem definidas. Ainda, caracterizam-se por: emprego de tecnologia pouco clara; os processos não são entendidos por seus próprios membros; o seu funcionamento se dá por tentativa e erro, a partir de resíduos de experiências de aprendizagem passadas; possuem participação fluída; seus dirigentes mudam com grande frequência; e seus participantes variam em quantidade e inserção, o que resulta em incerteza quanto aos limites da organização.

Essas características das organizações levariam a certos modos de como são resolvidos os problemas e definida a tomada de decisão. Os autores consideram que é gerado um contínuo fluxo relativamente independente de problemas e soluções nas organizações. A forma de escolha consiste em analisar o conteúdo desses fluxos e estabelecer uma relação entre eles, de maneira que se articule uma determinada solução a um determinado problema ou conjunto de problemas, com a análise da capacidade e a disposição para se intervir e, considerando as preferências dos dirigentes, definir a lista de prioridades das organizações.

KINGDON (2003) utiliza esses elementos na formulação do seu modelo de análise, conhecido como Modelo dos Múltiplos Fluxos (Multiple Streams Model), para elucidar o mecanismo pelo qual são determinados os problemas que passam a ser objeto da ação pública, enquanto outros são negligenciados. Os elementos do seu modelo de análise compreendem os três fluxos (problemas, soluções e político), os atores do processo e a convergência dos fluxos, com a abertura da janela de oportunidades.

Segundo CAPELLA (2007), os modelos dos múltiplos fluxos e do equilíbrio interrompido destacam-se no campo das políticas públicas por suas contribuições em elucidar como as agendas governamentais são formadas e alteradas.

O Modelo do Equilíbrio Interrompido (Punctuated Equilibium Model) foi desenvolvido por Fran Baumgartner e Brian Jones. De acordo com SOUZA (2006), esse modelo argumenta que a política pública é caracterizada por longos períodos de estabilidade, o que explicaria o desenvolvimento de políticas do tipo incremental e por períodos de instabilidade, caracterizado pela interrupção da agenda e mudanças rápidas e mais radicais nas políticas. O cenário das macropolíticas e as mudanças na direção do governo seriam os principais elementos de mudança no subsistema, responsáveis pela interrupção de uma política pública. 
Embora esses dois modelos apresentem similaridades em sua base de análise, podendo ambos serem úteis na análise da configuração da agenda em políticas públicas, neste trabalho optou-se pelo Modelo dos Múltiplos Fluxos de Kingdon, por considerar que os múltiplos fluxos oportuniza isolar cada um dos processos presentes na configuração da agenda e, ao mesmo tempo, por ter a vantagem de explorar a associação dos problemas com a escolha de alternativas, como também a associação com os elementos do fluxo político. Já o Modelo do Equilíbrio Interrompido seria mais adequado para se analisar o desenvolvimento de uma política pública ao longo de um extenso período, bem como captar a influência do legado institucional. Pretende lançar luz sobre os elementos envolvidos do processo incremental em períodos de estabilidade e a sua reconfiguração ou mesmo interrupção abrupta, ligadas às questões da dinâmica entre os macro e os subsistemas.

\subsection{A ABORDAGEM DA CONFIGURAÇÃO DA AGENDA E A ESCOLHA DE ALTERNATIVAS SEGUNDO A DINÂMICA DOS MÚLTIPLOS FLUXOS}

Delimitada a agenda, resta elucidar quem decide e como decide o que entra para a agenda. Como explicitado anteriormente, sobre as opções no desenvolvimento desse texto, o caminho para abordar essas questões da configuração da agenda tem por base o Modelo dos Múltiplos Fluxos de Kingdon.

\subsubsection{Fluxo de Problemas}

Nem todas as questões demandadas pela sociedade tornam-se objeto dos formuladores de políticas, apenas quando se tornam objeto de preocupação dos governos, integrando sua lista da agenda de decisões, é que passam a ser alvo de ação concreta por parte do Estado. $\mathrm{O}$ fluxo de problemas analisa como uma determinada questão passa a ser considerada um problema para os governos, sendo que os elementos desse processo são os mecanismos pelos quais uma questão ou situação é percebida pelos atores e de que forma é definida como problema.

KINGDON (2003) apresenta esses elementos como indicadores, eventos-foco e feedback. Os indicadores servem para o acompanhamento de uma determinada situação ao longo do tempo, oferecendo subsídio para avaliar a sua magnitude ou identificação de uma grande mudança no seu padrão, o que favoreceria uma situação tornar-se um problema. Um evento-foco chama a atenção para determinada situação e pode ser desencadeado por uma 
crise, um desastre, uma experiência pessoal ou um símbolo poderoso. $\mathrm{O}$ autor afirma que um evento-foco tem efeito passageiro e apenas agiria como mecanismo para destacar um problema quando existe uma percepção preexistente sobre ele, ou quando esse evento-foco está associado a outros similares. Por último, o feedback seria o reconhecimento sobre determinada situação a partir da avaliação e do monitoramento de programas de ação de políticas já existentes. Esse mecanismo pode ocorrer a partir de uma rotina formal de avaliação das instituições ou por meio informal, como reclamações que conseguem acessar alguma autoridade ou mesmo a ação da mídia e oposição.

\subsubsection{Fluxo de Soluções}

As propostas de soluções e alternativas são produzidas por comunidades de especialistas. KINGDON (2003) afirma que os problemas e as soluções não necessariamente são gerados aos pares, pelo contrário, ao se ter uma ideia e criar determinada solução, as pessoas apresentam a sua alternativa associando-a a problemas identificados. O autor explica o surgimento de alternativas e soluções por meio de um processo de seleção, sendo estas ordenadas pela imposição de critérios de viabilidade técnica e financeira e aceitação das comunidades de especialistas, classe política e/ou população. Dessa forma, as ideias que sobrevivem ao processo de seleção são difundidas nos diversos meios, percorrendo um longo caminho por meio da persuasão e do convencimento, são apresentadas em congressos e publicações e são reproduzidas em debates até chegarem a ser consideradas pelos formuladores de políticas. É nessa última etapa do processo que os empreendedores de políticas têm papel fundamental em promover uma ideia para conectá-la com os formuladores de políticas.

\subsubsection{Fluxo Político}

O fluxo da política segue de forma independente aos demais fluxos, tendo sua dinâmica e regras próprias. Os principais eventos desse processo estão relacionados a como determinado tema repercute na sociedade e às mudanças provocadas na composição das forças políticas, desencadeadas por eleições, alteração na conjuntura e substituição de dirigentes das instituições. O fluxo da política influencia fortemente o alto ou baixo grau de reconhecimento de uma situação na agenda de decisão do governo e seu funcionamento acontece por meio da negociação e barganha com a finalidade de produzir maioria. 
KINGDON (2003) identifica esses elementos como "clima nacional", que se refere à forma como as pessoas, em geral, pensam ou se posicionam sobre determinados temas. A percepção, pelos tomadores de decisão, de que há um clima favorável ou não sobre determinada questão influencia o seu próprio posicionamento. Outro elemento é a análise da arena política, as forças políticas, que se influenciadas pelos grupos de pressão podem definir um contexto favorável para seguir ou mesmo bloquear o prosseguimento de uma questão na agenda. E, por último, refere-se às mudanças no governo, no Congresso Nacional ou mesmo na direção das instituições, que, segundo o autor, é um dos elementos de maior influência sobre alterações na agenda,

Tratando-se de contextos democráticos, uma vitória no processo eleitoral, com construção de maioria, por si só representa a formação de coalizão e negociação para a priorização de uma agenda que foi anunciada no projeto de governo.

Segundo KINGDON (2003), a configuração da agenda ocorre quando há junção desses três fluxos no surgimento de uma janela de oportunidade. Essa junção significa que se configura uma agenda típica de política pública quando um problema se sobressai, está disponível o reconhecimento de uma solução e o contex to político é favorável.

Essas janelas de oportunidade se abrem por um curto período em momentos específicos e determinadas por certas condições. Esses momentos podem ser previstos, como no caso das eleições, ou serem imprevisíveis, desencadeado por um evento-foco. As condições, dadas pelos três fluxos, são determinadas, principalmente, pelo fluxo de problemas e fluxo da política.

O Modelo dos Múltiplos Fluxos apresenta-se como uma ferramenta adequada para a formação de um quadro de análise sobre como é o processo de definição dos problemas na agenda de decisão do governo e como as alternativas são produzidas no processo de configuração da agenda. 
Figura 1 - Modelo dos Múltiplos Fluxos de Kingdon.

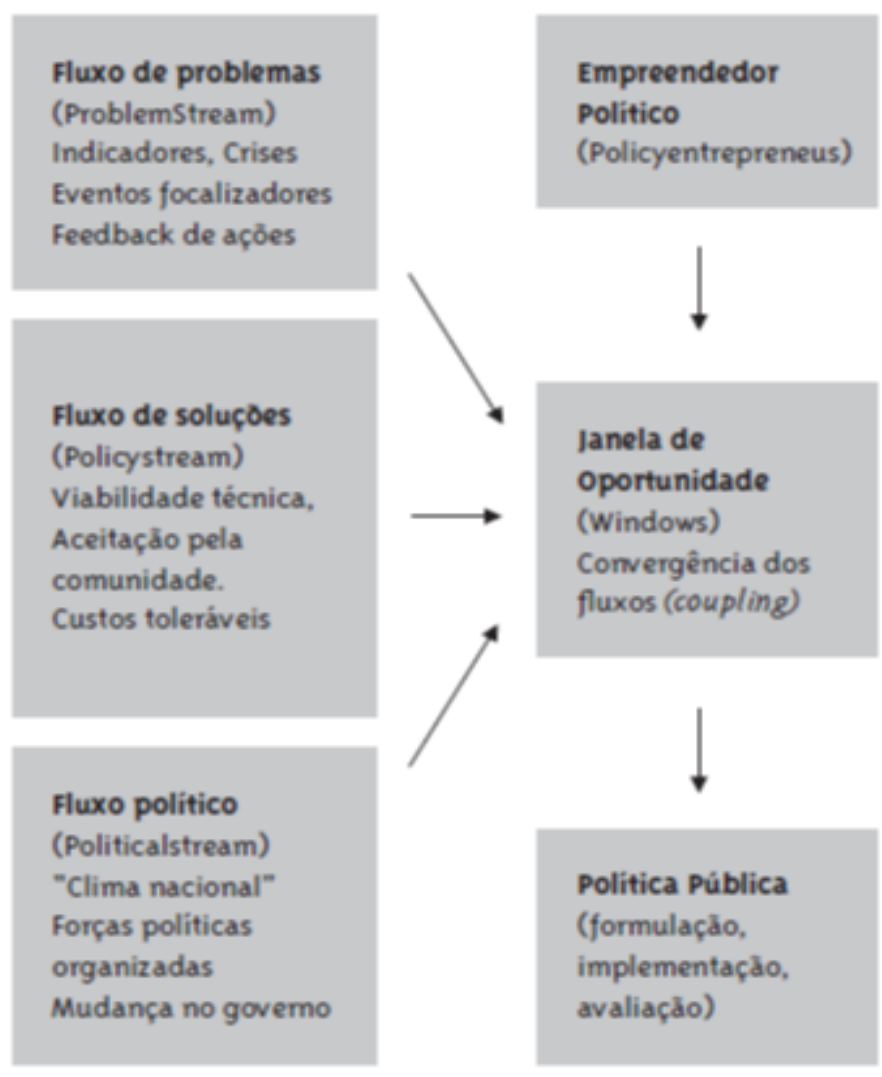

Fonte: Extraído de GOTTEMS et al., 2013, p. 513.

De acordo com GOTTEMS et al. (2013, p. 518), as contribuições do Modelo dos Múltiplos Fluxos para a análise de políticas públicas podem ser divididas em:

1) estudo da macropolítica e sua influência nas políticas setoriais; 2) análise das influências das relações intergovernamentais e dos governos com a sociedade civil na formação da agenda; 3) exame da atuação dos atores e empreendedores na implantação da política; 4) estudo dos processos decisórios dos governos locais e nacionais.

\subsubsection{Atores Políticos e sua Influência na Configuração da Agenda}

Tratando-se de políticas públicas e concebendo a organização estatal em camadas hierárquicas, a figura que representa o maior poder de decidir é o presidente ou a maior autoridade do governo, configurando-se, também, como tomadores de decisão o Congresso Nacional e, no caso de políticas setoriais mais específicas, o ministro ou seus assessores que ocupam cargos de autoridade em sua respectiva área. Esses atores, chamados de governamentais, têm maior poder sobre a definição da agenda pela posição que ocupam, mas pouca influência sobre a formulação de propostas de alternativas ou soluções. Estas últimas 
são desenvolvidas por comunidade de especialistas, atores do processo de formulação de políticas públicas classificados por Kingdon como atores invisíveis. Este grupo inclui pesquisadores, acadêmicos, burocratas de carreira, analistas e consultores que também podem atuar em favor de grupos de interesse (KINGDON, 2003).

Entre os atores não governamentais, compostos por partidos políticos, organizações não governamentais, movimentos sociais, comunidade de especialistas, empresas privadas, entre outros, constituem os chamados grupos de pressão. Esses grupos podem exercer sua influência tanto na definição de problemas a serem priorizados na agenda quanto nas alternativas e soluções e, geralmente, possuem maior atuação no bloqueio da agenda de determinado tema, através de seus dispositivos de poder no jogo político (RUA, 2012).

Neste aspecto, por exemplo, um partido político influencia a definição de uma agenda por meio do seu programa apresentado no processo eleitoral. Desta forma, a orientação da atuação de um partido conservador com relação a um assunto sensível, como a questão do aborto legal, seja no Legislativo ou Executivo, estaria associada às pautas defendidas por sua base de apoio, que, no caso, teria posição contrária à legalização do aborto. Outro exemplo comum, que podemos observar no cotidiano atual da política, seria a atuação de empresas privadas ou grandes grupos de interesse econômico. Estes influenciam na proposição de políticas públicas por meio de lobby no Congresso Nacional e/ou a mobilização de recursos para que as instituições trabalhem a favor de seus interesses, como os setores da indústria farmacêutica, que influenciam a produção de estudos clínicos e estimulam a judicialização para o consumo e a incorporação de seus produtos pelo sistema público de saúde.

No Modelo dos Múltiplos Fluxos, KINGDON (2003) destaca uma figura chamada de empreendedores de políticas (policy entrepreneurs). Eles são indivíduos dispostos a investir tempo e recursos em uma ideia, visando promover políticas que possam de alguma forma lhes favorecer. Esse tipo de empreendedor figura entre os diversos atores do processo de políticas públicas, podendo pertencer à classe política, ser um servidor de carreira, acadêmico, lobista, consultor-analista ou mesmo dirigente de uma instituição do Estado.

Os empreendedores de políticas podem agir evidenciando um problema com intuito de levá-lo ao topo da lista de preocupações do governo ou investir sistematicamente em uma ideia para promover uma solução entre o meio. São atentos à abertura de janelas de oportunidades, tendo papel fundamental na articulação entre os problemas e as soluções.

Outro importante elemento a se considerar no processo de definição do que importa na lista de problemas do governo, diz respeito à limitada fonte de recursos do Estado e à 
capacidade que temos em lidar, ao mesmo tempo, com inúmeras informações. Considerando esses aspectos, seria impossível responder a todas as demandas e solucionar todos os problemas ao mesmo tempo (KINGDON, 2003).

Essa condição nos leva a considerar que a definição do que estará na lista de problemas prioritários do governo e passará ao processo de decisão ou não é resultante da disputa pelos seus recursos entre os atores políticos. Esse processo constitui a arena política e a condição da disputa, permeada por relações de poder, é expressa por meio do conflito, da persuasão, da negociação, do confronto e das coalizões, sendo que esta última objetiva formar maioria e hegemonia de poder.

O Quadro 2, produzido a partir de KINGDON (2003) e CAPELLA (2006), sintetiza o Modelo dos Múltiplos Fluxos, buscando discriminar os elementos de análise de cada categoria.

Quadro 2 - Descrição das categorias e dos elementos do modelo de análise dos múltiplos fluxos.

(Continua)

\begin{tabular}{|c|c|c|}
\hline $\begin{array}{l}\text { Categoria de } \\
\text { Análise }\end{array}$ & Descrição & $\begin{array}{l}\text { Elementos que compõe a } \\
\text { análise }\end{array}$ \\
\hline $\begin{array}{l}\text { Fluxo de } \\
\text { Problemas }\end{array}$ & $\begin{array}{l}\text { Analisa como uma determinada questão passa a ser } \\
\text { considerada um problema para os governos, os } \\
\text { elementos desse processo são os mecanismos pelos } \\
\text { quais uma questão ou situação é percebida pelos } \\
\text { atores e de que forma é definida como problema. } \\
\text { Não há vínculo causal entre problemas e soluções. } \\
\text { Questões não se transformam em problemas } \\
\text { automaticamente, problemas são construções que } \\
\text { envolvem interpretação sobre a dinâmica social. }\end{array}$ & $\begin{array}{l}\text { Problemas são representados } \\
\text { por meio de indicadores, } \\
\text { eventos-foco e feedback. } \\
\text { Podem ser representados por } \\
\text { símbolos que relacionam } \\
\text { questões a problemas. }\end{array}$ \\
\hline $\begin{array}{l}\text { Fluxo de } \\
\text { Soluções }\end{array}$ & $\begin{array}{l}\text { As soluções não são desenvolvidas necessariamente } \\
\text { para resolver um problema. A princípio, são geradas } \\
\text { nas comunidades de especialistas, difundem-se e } \\
\text { espalham-se em um processo que vai difundindo e } \\
\text { aperfeiçoando a ideia. } \\
\text { Soluções tecnicamente viáveis, que representam } \\
\text { valores compartilhados, contam com consentimento } \\
\text { público e a receptividade dos formuladores de } \\
\text { políticas têm maiores chances de entrar para a } \\
\text { agenda. }\end{array}$ & $\begin{array}{l}\text { Aceitação pela comunidade de } \\
\text { especialistas e formuladores } \\
\text { de políticas, que levam em } \\
\text { consideração a sua viabilidade } \\
\text { técnica e custos toleráveis. }\end{array}$ \\
\hline Fluxo Político & $\begin{array}{l}\text { O fluxo da política segue de forma independente } \\
\text { aos demais fluxos, tendo sua dinâmica e regras } \\
\text { próprias. Os principais eventos desse processo } \\
\text { dizem respeito sobre como determinado tema } \\
\text { repercute na sociedade e as mudanças provocadas } \\
\text { na composição das forças políticas desencadeadas } \\
\text { por eleições, alteração na conjuntura (incluindo } \\
\text { outros subsistemas) e substituição de dirigentes das } \\
\text { instituições. }\end{array}$ & $\begin{array}{l}\text { O contexto político } \\
\text { compreende o "clima } \\
\text { nacional", forças políticas } \\
\text { organizadas e mudanças no } \\
\text { governo. }\end{array}$ \\
\hline
\end{tabular}


Quadro 3 - Descrição das categorias e dos elementos do modelo de análise dos múltiplos fluxos.

(Conclusão)

\begin{tabular}{|c|c|c|}
\hline $\begin{array}{l}\text { Categoria de } \\
\text { Análise }\end{array}$ & Descrição & $\begin{array}{c}\text { Elementos que compõe a } \\
\text { análise }\end{array}$ \\
\hline $\begin{array}{l}\text { Janela de } \\
\text { Oportunidades }\end{array}$ & $\begin{array}{l}\text { Abre-se uma janela de oportunidades, bastante } \\
\text { determinada pelo fluxo político, em que o } \\
\text { empreendedor de políticas atua na convergência } \\
\text { entre os fluxos de problemas e soluções para a } \\
\text { configuração de uma agenda. }\end{array}$ & $\begin{array}{l}\text { Identificação de uma janela de } \\
\text { oportunidades e atuação do } \\
\text { empreendedor de políticas na } \\
\text { convergência dos fluxos. }\end{array}$ \\
\hline Atores & $\begin{array}{l}\text { O presidente exerce influência decisiva sobre a } \\
\text { agenda. Alta burocracia e legislativo também } \\
\text { afetam a agenda. } \\
\text { Os grupos de interesse podem exercer sua } \\
\text { influência tanto na definição da agenda como nas } \\
\text { alternativas e soluções, geralmente possuem maior } \\
\text { atuação no bloqueio da agenda de determinado tema } \\
\text { através de seus dispositivos de poder no jogo } \\
\text { político. A mídia retrata questões ligadas a agenda } \\
\text { já estabelecida, pode influencia na propagação de } \\
\text { eventos-foco e percepção sobre um problema. }\end{array}$ & $\begin{array}{l}\text { Relação dos atores } \\
\text { governamentais e atores não } \\
\text { governamentais (grupos de } \\
\text { pressão ou de interesse) que se } \\
\text { posicionam na arena política } \\
\text { de formação da agenda. }\end{array}$ \\
\hline
\end{tabular}

Fonte: Adaptado a partir da produção de KINGDON (2003) e CAPELLA (2006). 


\section{PERCURSO METODOLÓGICO}

\subsection{NATUREZA DA PESQUISA}

O campo da análise de políticas públicas, no que se refere à configuração da agenda, orienta a investigação sobre como, quando, quem e por que uma determinada demanda entra na lista de prioridades do governo, seguindo, a partir disso, para a formulação de estratégias ou programas, a decisão das escolhas de alterativas e a implementação das ações definidas (KINGDON, 2003; SOUZA, 2006).

Nesse sentido, a presente pesquisa caracteriza-se como um estudo de caso analítico, com abordagem qualitativa e enfoque no processo de configuração da agenda de revisão da PNAB 2017. Segundo BARDIN (1977), a pesquisa qualitativa tem a capacidade de associar em sua análise o significado e a intencionalidade inerentes aos atos, às relações e às estruturas sociais.

A abordagem qualitativa fundamenta-se na existência de uma relação dinâmica e inseparável entre o mundo real e a subjetividade, por isso preocupa-se com a compreensão interpretativa da ação social, buscando esclarecer como os indivíduos ou grupos de indivíduos interpretam e conferem sentido às suas experiências e ao mundo em que vivem (MINAYO, 2005).

Já o estudo de caso propõe analisar um fenômeno a partir da exploração intensa de um único caso, um mergulho profundo e exaustivo em um objeto delimitado, que permite explorar a realidade social de um modo que não se pode revelar puramente por meio de análise estatística global (GOLDENBERG, 2011).

Considerou-se a interação do pesquisador com a situação estudada e os sujeitos da pesquisa, buscando-se "compreender os fenômenos segundo a perspectiva dos sujeitos" (GODOY, 1995, p. 58), partindo-se do levantamento dos posicionamentos dos atores e suas narrativas, do estudo de normativas relacionadas à política em análise, bem como das publicações acadêmicas e dos arquivos de mídia relacionados ao processo em disputa.

Para contemplar esses aspectos, a coleta de dados foi dividida em duas partes, utilizando técnicas diferentes, que correspondem à análise documental e a entrevistas com atores chaves. A pesquisa documental consiste em um extenso levantamento e análise de documentos que não receberam tratamento ou análises anteriores. É útil para a compreensão ou elucidação de um fenômeno do qual não existe suficiente literatura produzida e pode colaborar para o desenvolvimento de futuras pesquisas (SÁ-SILVA et al., 2009). 
A análise documental, correspondente à primeira parte da coleta de dados, foi realizada pelo levantamento de documentos relativos ao processo de discussão e desenvolvimento da PNAB 2017. Desta forma, os pontos de partida para esta etapa foram a identificação e a sistematização do posicionamento de entidades e instituições que se manifestaram na iminência da revisão da PNAB em 2017, seguidas do levantamento e da análise de documentos que registraram o processo de revisão.

A segunda parte da coleta de dados consistiu na entrevista com atores que se fizeram presentes na arena de disputa da agenda de revisão da PNAB 2017 e visou complementar a análise documental no que diz respeito ao aprofundamento dos elementos de análise identificados. Além disso, buscou identificar motivos e interesses para a introdução das mudanças incorporadas no processo de revisão da PNAB 2017, com destaque para as diretrizes para a composição da equipe, tentando extrapolar as motivações expostas em documentos públicos e oficiais.

Como já descrito anteriormente, no campo de análise das políticas públicas, é relevante destacar quem decide e como decide, portanto, as diferentes narrativas sobre o processo de definição da agenda, identificadas pelas entrevistas, contribuíram para complementar a análise dos fatores que oportunizaram a configuração da agenda de revisão da PNAB 2017.

Embora a coleta de dados tenha sido realizada nessas duas etapas, é importante destacar que a análise e o tratamento dos dados não foram realizados de forma linear e sequencial. O processo foi marcado por idas e vindas e, a partir de cada novo elemento identificado nos documentos e nas entrevistas, foram realizadas pesquisas complementares e produção de novas sínteses.

A seguir, a descrição do tratamento e a análise dos dados serão apresentadas separadamente por uma questão didática, com o intuito de favorecer a compreensão dos passos metodológicos adotados. 


\subsection{ANÁLISE DOCUMENTAL}

\subsubsection{Documentos e Fonte de Coleta de Dados}

A relação de entidades e instituições que se posicionaram quanto ao processo de revisão da PNAB 2017 foi identificada por meio das notas públicas e dos conteúdos com posicionamento sobre o tema, veiculados em seus meios de comunicação, como sítios eletrônicos oficiais, e reproduzidos pelas mídias sociais.

De forma complementar, também foram levantadas notícias veiculadas nas mídias comercial e independente, como blogs, jornais e revistas de alcance nacional, cuja relação será apresentada nos resultados.

Além da consulta direta a sites institucionais, a captação dessas fontes foi realizada programando-se o termo "Política Nacional de Atenção Básica" no recurso Google Alerts ${ }^{3}$, que se trata de uma ferramenta que detecta conteúdos relevantes que aparecem na internet e têm relação com o tema selecionado. Dessa forma, toda vez que uma nova notícia que continha o termo Política Nacional de Atenção Básica era indexada ao Google, o usuário era notificado por $e$-mail e tinha acesso ao link da notícia.

Também foi utilizado o serviço de newsletter do site Uma Outra Saúde 4 , que seleciona diariamente as principais notícias relacionadas à saúde publicadas tanto pelos jornais e revistas comerciais quanto pelos meios independentes ou institucionais.

Com a identificação inicial do conjunto de atores e seus respectivos posicionamentos, foram então eleitas as principais fontes para a análise documental. Nessa identificação, destacaram-se atores governamentais, como o CONASEMS, CONASS e o próprio Ministério da Saúde, bem como da sociedade civil organizada e das corporações profissionais.

Com essa etapa, os registros e os documentos oriundos das reuniões do Pleno do CNS e das reuniões da Comissão Intergestores Tripartite (CIT) foram definidos como fontes principais para a coleta de dados da análise documental. Esses documentos foram escolhidos porque registraram as discussões relativas à revisão da PNAB 2017 de duas importantes

\footnotetext{
${ }^{3}$ Google Alerts é um serviço que detecta novos conteúdos indexados pelo Google — como páginas da web, notícias, artigos, posts de blog, etc. — notificando o usuário cadastrado por e-mail. Disponível em: <https://support.google.com/websearch/answer/4815696?hl=pt-BR> e <https://resultadosdigitais.com.br/blog/google-alerts/>. Acesso em 07 abr. 2019.

${ }_{4}^{4}$ Outra Saúde é um site que pretende ampliar a produção e a circulação das informações sobre o SUS e o direito à saúde. Com reportagens, entrevistas em vídeo e resenhas, também reproduz matérias publicadas por veículos parceiros e, além disso, oferece uma newsletter diária e gratuita com as principais notícias nacionais e internacionais sobre saúde. Disponível em: <https://outraspalavras.net/outra-saude-quem-somos/>. Acesso em: 07 abr. 2019.
} 
instâncias de gestão e pactuação do SUS, que agregam os atores que foram identificados, inicialmente, na composição da arena política de disputa, bem como permitiram captar os posicionamentos e os consensos entre as principais entidades e instituições que protagonizaram o processo de revisão da PNAB 2017.

São documentos públicos, disponíveis no site do $\mathrm{CNS}^{5}$ e no portal do Ministério da Saúde $^{6}$ ou do CONASS. Além disso, são documentos datados e muito bem sistematizados, com o registro do posicionamento dos atores, suas pautas são pactuadas previamente e contribuem para a construção de uma linha do tempo sobre a discussão do tema, o que favorece a análise do processo em articulação com os elementos presentes nos fluxos políticos, de problemas e soluções, que, por sua vez, constituíram as categorias principais de análise do estudo.

Foi observado que o movimento crítico à revisão alegou que não houve suficiente debate com o conjunto da sociedade e com o controle social. Por outro lado, o Ministério da Saúde e o CONASEMS justificaram ao CNS e em documentos públicos que a revisão da PNAB foi um processo de aprimoramento da Política acumulado ao longo dos anos e que vinham debatendo questões relativas às mudanças desde 2015.

Por isso, com base na alegação dos agentes governamentais e buscando identificar os elementos pré-decisionais da configuração da agenda de revisão, foi realizado o recorte temporal de janeiro de 2015 a dezembro de 2017 para o levantamento e a análise de documentos do CNS e da CIT.

\subsubsection{Análise Documental - Procedimentos Adotados para o Tratamento dos Dados}

Inicialmente, foram elencadas todas as pautas das reuniões do CNS realizadas no período de 2015 a 2017, sendo destacadas as que abordavam elementos dos contextos político e econômico e que apresentavam discussões diretamente ligadas à PNAB. Após esse primeiro filtro, foram analisados os resumos executivos destacados e, por fim, os itens das atas destacadas. Além disso, as resoluções, as recomendações e as moções oriundas dessas discussões do Pleno do CNS e que abordavam o tema em destaque também foram incluídas na análise.

\footnotetext{
${ }^{5}$ Disponível em: <http://conselho.saude.gov.br/atas/atas inicial.htm>

${ }^{6}$ Disponível em: <http://portalms.saude.gov.br/gestao-do-sus/articulacao-interfederativa/comissao-intergestorestripartite/pautas-de-reunioes-e-resumos $>$
} 
No caso da CIT, encontram-se disponíveis no site do Ministério da Saúde e do CONASS apenas as pautas, os resumos executivos e algumas apresentações sobre os temas debatidos. Seguiu-se o mesmo procedimento, destacando-se as pautas relacionadas à discussão dos contextos político e econômico, bem como a assuntos diretamente ligados à condução da PNAB no período de 2015 a 2017.

Esse processo de identificação das pautas e dos documentos de interesse do CNS e da CIT foi registrado e organizado utilizando-se os programas do pacote da Microsoft Office 2016. Com isso, foram classificados os trechos e os documentos de interesse por ordem cronológica, tipo de documento, nome do documento, ator ou instituição e fonte. Abaixo, as Tabelas 1 e 2 apresentam a quantidade de documentos da CIT e do CNS analisados, de 2015 a 2017.

Tabela 1 - Número de reuniões e documentos analisados da Comissão Intergestores Tripartite, 2015 a 2017.

\begin{tabular}{lcccc}
\hline & $\mathbf{2 0 1 5}$ & $\mathbf{2 0 1 6}$ & $\mathbf{2 0 1 7}$ & Total \\
\hline Total de reuniões da CIT & 10 & 8 & 13 & 31 \\
\hline $\begin{array}{l}\text { Total de documentos da CIT analisados, segundo os } \\
\text { critérios estabelecidos para o estudo }\end{array}$ & 10 & 8 & 13 & 31 \\
\hline
\end{tabular}

Fonte: Elaborado pelo autor.

Tabela 2 - Número de reuniões e documentos analisados do Conselho Nacional de Saúde, 2015 a 2017.

\begin{tabular}{lcccc}
\hline & $\mathbf{2 0 1 5}$ & $\mathbf{2 0 1 6}$ & $\mathbf{2 0 1 7}$ & Total \\
\hline Total de reuniões do CNS & 13 & 13 & 14 & 40 \\
\hline $\begin{array}{l}\text { Total de documentos do CNS analisados, segundo os } \\
\text { critérios estabelecidos para o estudo }\end{array}$ & 3 & 4 & $15^{*}$ & 22 \\
\hline
\end{tabular}

Fonte: Elaborado pelo autor.

*Nota: Além das atas, foram considerados na análise 2 documentos de recomendação e 1 moção do CNS.

Para o tratamento dos dados da análise documental, os documentos selecionados foram transferidos, categorizados e analisados com apoio do software ATLAS.ti - Qualitative Data Analysis, versão 7.5.7. Foram agregados criando-se famílias de documentos primários, "Documentos do CNS" e "Documentos da CIT" e, em seguida, à luz das perguntas da pesquisa e considerando os elementos de análise do Modelo dos Múltiplos Fluxos, cada um dos documentos selecionados foi lido novamente. Trechos de interesse foram destacados, recebendo códigos de identificação conforme os elementos de análise predefinidos: problemas, soluções e fluxo político. Além desses códigos, os trechos também receberam 
outros códigos, criados e atribuídos conforme o conteúdo apresentado, na perspectiva da categorização temática.

A análise documental foi realizada entre o período de maio e outubro de 2018, a qual possibilitou identificar os sujeitos que, representando o posicionamento de seus grupos, entidades/instituições, participaram do processo de discussão e revisão da PNAB 2017. Isso permitiu estabelecer a lista de potenciais indivíduos a serem entrevistados na segunda parte da pesquisa.

\subsection{ENTREVISTAS - COLETA E TRATAMENTO DOS DADOS}

As entrevistas foram realizadas com o objetivo de complementar os achados da análise documental, considerando, principalmente, as questões não explicitadas pelo discurso oficial dos atores. Por isso, buscaram considerar as diferentes narrativas sobre o processo de revisão da PNAB 2017, bem como os dissensos e as contradições.

Assim como na análise documental, o roteiro semiestruturado para a condução das entrevistas, bem como a sua análise, foram orientados pelo modelo de análise dos múltiplos fluxos de Kingdon (2003). Aplicando-se as perguntas de pesquisa deste trabalho às categorias e aos elementos de análise dos múltiplos fluxos, as questões foram elaboradas, as quais compuseram a base teórica para o roteiro das entrevistas.

Quadro 4 - Base do roteiro das entrevistas.

(Continua)

\begin{tabular}{|l|l|}
\hline Categoria de análise & \multicolumn{1}{c|}{ Questões norteadoras } \\
\hline Fluxo de Problemas & $\begin{array}{l}\text { 1) Quais os principais problemas ou desafios da Atenção Básica } \\
\text { atualmente? } \\
\text { Considerando que uma das principais mudanças da revisão da PNAB 2017, } \\
\text { diz respeito às diretrizes para composição da equipe de atenção básica, } \\
\text { com introdução do incentivo financeiro para custeio da equipe de atenção } \\
\text { básica e flexibilização dos critérios para número de ACS na eSF e } \\
\text { acompanhamento das famílias. } \\
\text { 2) Qual foi o problema ou conjunto de problemas que motivou a revisão } \\
\text { das diretrizes para a composição de equipe prevista na Política } \\
\text { Nacional de Atenção Básica? }\end{array}$ \\
\hline 3) Quais os indicadores caracterizam ou evidenciam esse problema?
\end{tabular}


Quadro 5 - Base do roteiro das entrevistas.

(Conclusão)

\begin{tabular}{|c|c|}
\hline Categoria de análise & Questões norteadoras \\
\hline Fluxo Político & $\begin{array}{l}\text { 1) Qual era o contexto nacional que favoreceu a convergência dessa } \\
\text { proposta na agenda de governo? } \\
\text { 2) Quais os elementos do contexto político institucional que } \\
\text { propiciaram a entrada dessa proposta na agenda de governo? }\end{array}$ \\
\hline Janela de Oportunidades & $\begin{array}{l}\text { 3) Em que momento houve convergência entre os problemas e a } \\
\text { proposta de solução apresentada na agenda de governo? } \\
\text { 4) Quais os sujeitos foram fundamentais para promover essa } \\
\text { convergência entre os problemas e a proposta de solução, colocando } \\
\text { a proposta de revisão das diretrizes da PNAB na agenda de governo? }\end{array}$ \\
\hline Atores & $\begin{array}{l}\text { 6) Quais foram os grupos de defesa e de oposição que compuseram a } \\
\text { arena de disputa (forças políticas) sobre o processo de revisão das } \\
\text { diretrizes da PNAB 2017? }\end{array}$ \\
\hline
\end{tabular}

Fonte: Elaborado pelo autor.

Nota: questões definidas a partir das perguntas de pesquisa desse projeto, aplicadas as categorias de análise do modelo dos múltiplos fluxos.

Os dados da análise documental colaboraram para que a base do roteiro de entrevista fosse adaptada de forma específica para cada um dos sujeitos a ser entrevistado. Desta forma, cada entrevista foi preparada previamente de forma singular, a fim de contemplar questões complementares, visando explorar as justificativas e os elementos circunstanciais de falas ou posicionamentos de cada ator/instituição.

Após selecionados os primeiros sujeitos a serem entrevistados, iniciou-se a fase de preparação para as entrevistas. Foi estabelecido contato com os atores selecionados e/ou suas entidades de origem, com subsequente envio de carta convite contendo a apresentação do projeto de pesquisa, o Termo de Consentimento Livre Esclarecido (TCLE) (Anexo 1), a autorização para a gravação de entrevista (Anexo 2) e as orientações para o agendamento da entrevista.

Entre novembro de 2018 e março de 2019 foram realizadas 10 entrevistas pelo pesquisador, com uma duração média de 60 minutos. Dessas, 04 foram realizadas por web conferência e todas foram gravadas e transcritas utilizando os programas do pacote Microsoft Office e Express Scribe Transcription Software, conforme o protocolo do projeto.

Com relação ao perfil dos entrevistados, todos possuem longa experiência de atuação no SUS, acumulando em suas trajetórias atuação na pesquisa, na assistência e/ou no gerenciamento de serviços de saúde, bem como na docência e na gestão em diversas esferas de governo. Dentre as instituições e entidades envolvidas, captadas por meio da 
autodesignação do cargo/função das pessoas entrevistadas em relação à sua participação no processo de revisão da PNAB 2017, figuraram o CONASS, o CONASEMS, o Ministério da Saúde, o CNS (segmento de profissionais de saúde e comunidade científica na área da saúde), o CONACS e os pesquisadores da área de Saúde Coletiva.

Para o tratamento dos dados das entrevistas foram adotados os mesmos procedimentos da análise documental, utilizando-se o software ATLAS.ti 7.5.7, e os códigos criados na análise documental, que dão origem às subunidades de análise, foram empregados também na análise das entrevistas. Além dos mesmos códigos utilizados na análise documental, ainda foram criados códigos complementares, conforme o conteúdo apresentado no material das entrevistas e que não havia sido identificado nos documentos da CIT e do CNS.

\subsection{ANÁLISES DOS DADOS}

O software ATLAS.ti 7.5.7 permite a organização e a extração dos dados por meio de relatórios dos códigos que foram atribuídos aos trechos destacados nos documentos. Desta forma, procedeu-se a leitura do relatório de cada um dos códigos atribuídos aos documentos, agora de forma comparada entre as fontes de dados.

A partir da leitura exaustiva do conjunto dos trechos destacados nas fontes de dados, agregados aos códigos atribuídos, as categorias temáticas de análise subjacente aos elementos de análise dos múltiplos fluxos foram definidas. Os códigos finais foram estabelecidos pela análise do conteúdo dos trechos, em comunicação com o modelo de análise dos múltiplos fluxos e o referencial teórico abordado na introdução deste trabalho, o qual tratou de uma revisão de literatura sobre os desafios e as alternativas para o desenvolvimento da APS no Brasil.

Considerando as três principais fontes de dados - os resumos executivos da CIT, os documentos do CNS (atas, recomendações e moções) e as entrevistas, foram eleitos 63 documentos, os quais fizeram parte da análise de dados, conforme a Tabela 3.

Tabela 3 - Quantidade de documentos e códigos que fizeram parte da análise dos dados, por tipo de fonte.

\begin{tabular}{lcc}
\hline $\begin{array}{c}\text { Família de } \\
\text { documentos }\end{array}$ & $\begin{array}{c}\text { Documentos primários } \\
\text { selecionados }\end{array}$ & $\begin{array}{c}\text { Códigos } \\
\text { atribuídos }\end{array}$ \\
\hline CIT & 31 & 19 \\
CNS & 22 & 22 \\
Entrevistas & 10 & 32 \\
\hline Fonte: Elaborado pelo autor. &
\end{tabular}


A leitura das três fontes de dados resultou na identificação de 391 trechos de interesse para a pesquisa, os quais foram agrupados em 32 códigos por associação de conteúdo, possibilitando, portanto, uma perspectiva de análise sob o ponto de vista de 32 temas ou perspectivas de análise.

A Tabela 4 apresenta os códigos atribuídos aos trechos destacados, segundo a fonte de dados. Os códigos representam os assuntos ou temas de discussão, sendo que a tabulação quantifica a presença deles nas discussões e nas pactuações da CIT e do CNS, bem como a frequência que aparecem na narrativa dos atores entrevistados.

Tabela 4 - Temas identificados e frequência, por tipo de documento.

(Continua)

\begin{tabular}{|c|c|c|c|c|c|}
\hline \multirow[t]{2}{*}{ N. } & \multirow[t]{2}{*}{ Temas (códigos) } & \multicolumn{4}{|c|}{$\begin{array}{l}\text { Frequência dos temas por tipo de } \\
\text { documento }\end{array}$} \\
\hline & & CIT & CNS & Entrevistas & Total \\
\hline 1 & Acesso & 2 & - & 3 & 5 \\
\hline 2 & Apoio logístico - Sistema de Informação & 12 & 2 & 3 & 17 \\
\hline 3 & Arboviroses e baixa cobertura vacinal & 22 & - & 2 & 24 \\
\hline 4 & Arranjo e composição de equipe & - & - & 6 & 6 \\
\hline 5 & $\begin{array}{l}\text { Articulação do Grupo de Trabalho de Atenção Básica do } \\
\text { Conselho Nacional de Saúde com os ACS/ACE }\end{array}$ & - & - & 3 & 3 \\
\hline 6 & Atenção Básica articulada com a Rede de Atenção & 1 & 1 & 2 & 4 \\
\hline 7 & Bloqueio da agenda de revisão da PNAB & & 5 & 3 & 8 \\
\hline 8 & Consulta pública & 3 & 2 & 2 & 7 \\
\hline 9 & Contexto de revisão da normativa do SUS & 14 & 4 & 2 & 20 \\
\hline 10 & Crise e polarização da Política & - & - & 7 & 7 \\
\hline 11 & Crise econômica & 4 & 3 & 2 & 9 \\
\hline 12 & Desdobramento da PNAB 2017 & - & - & 3 & 3 \\
\hline 13 & Disputa de modelo & - & 2 & 3 & 5 \\
\hline 14 & Entrada da revisão da PNAB na agenda & 5 & 11 & 9 & 25 \\
\hline 15 & Expansão da cobertura & - & 1 & 6 & 7 \\
\hline 16 & Grupos de disputa & - & - & 8 & 8 \\
\hline 17 & $\begin{array}{l}\text { Grupo de Trabalho de Atenção Básica do Conselho } \\
\text { Nacional de Saúde }\end{array}$ & - & 9 & 3 & 12 \\
\hline 18 & Indução de modelo & - & 1 & 3 & 4 \\
\hline 19 & Infraestrutura - Requalifica Unidade Básica de Saúde & 2 & 1 & 3 & 6 \\
\hline 20 & Integração entre a Vigilância em Saúde e a Atenção à Saúde & - & 1 & 3 & 4 \\
\hline 21 & Mudança de dirigente & 8 & - & 5 & 13 \\
\hline 22 & Nova modalidade de equipe de Atenção Básica & 5 & 1 & 9 & 15 \\
\hline 23 & Padrões essenciais e ampliados & - & 1 & 2 & 3 \\
\hline 24 & Plano de saúde acessível & - & 6 & 1 & 7 \\
\hline 25 & PMAQ & 4 & - & 3 & 7 \\
\hline 26 & Provimento e formação médica & 27 & 4 & 6 & 37 \\
\hline 27 & Regulamentação da profissão e carreira dos ACS/ACE & 5 & 4 & 10 & 19 \\
\hline 28 & Resolubilidade da Atenção Básica & 4 & 1 & 5 & 10 \\
\hline 29 & Revisão da PNAB e formação & 3 & - & 3 & 6 \\
\hline
\end{tabular}


Tabela 5 - Temas identificados e frequência, por tipo de documento.

(Conclusão)

\begin{tabular}{llcccc}
\hline \multirow{2}{*}{ N. Temas (códigos) } & \multicolumn{4}{c}{ Frequência dos temas por tipo de } \\
documento
\end{tabular}

Fonte: Elaborado pelo autor a partir dos relatórios de análise dos dados.

Foram identificados 19 temas nos documentos da CIT, sendo que 5 (acesso; arboviroses e baixa cobertura vacinal; mudança de dirigente; PMAQ; e revisão da PNAB e formação) não figuraram entre os temas destacados nos documentos do CNS.

Dos 22 temas destacados nos documentos do CNS, 8 (bloqueio da agenda de revisão da PNAB; disputa de modelo; expansão da cobertura; grupo de trabalho de Atenção Básica do CNS; indução de modelo; integração entre a Vigilância em Saúde e a Atenção à Saúde; padrões essenciais e ampliados; e plano de saúde acessível) não foram destacados nos documentos da CIT.

Já na análise das entrevistas, foram atribuídos 32 temas, sendo que 5 deles (arranjo e composição de equipe; articulação do grupo de trabalho de Atenção Básica do CNS e os ACS/ACE; crise e polarização da Política; desdobramento da PNAB 2017; e grupos de disputa) foram atribuídos somente no material das entrevistas.

Esse levantamento considerou a identificação de temas a partir dos trechos de interesse destacados nos documentos, conforme os objetivos e os critérios de seleção de documentos desta pesquisa.

Destaca-se que os temas captados nas fontes de dados e identificados pelos códigos aplicados nesse estudo podem ser explorados em profundidade individualmente ou agrupados em categorias de interesse, conforme o objetivo, subsidiando, assim, novos estudos, de acordo com o resultado típico das análises documentais.

Ainda como parte dos recursos apresentados pelo software ATLAS.ti 7.5.7, foi gerada uma rede de relações entre os códigos (network), que compreendeu dados das 3 famílias de documentos primários (Documentos do CNS, Documentos da CIT e Entrevistas).

Esse mapa da rede entre os códigos é uma representação gráfica das relações entre as categorias temáticas de análise destacadas dos documentos, que colaboram com a identificação dos elementos da configuração da agenda de revisão da PNAB 2017 (Figura 4). 
Nem todos os códigos foram eleitos como elementos de análise para os objetivos deste estudo. Os elementos foram definidos a partir da maior frequência de citações (número de quotations) que apareceram nas 3 fontes de documentos primários, nas conexões na rede de relações entre os códigos e na categorização do conteúdo, enquanto resposta às perguntas de pesquisa e aos elementos do Modelo dos Múltiplos Fluxos. Desta forma, são apresentados e discutidos nos resultados apenas os temas pertinentes ao recorte deste estudo.

Salienta-se que todos os trechos destacados nos documentos foram considerados a partir dos códigos atribuídos e em conjunto com as categorias do modelo de análise. Por isso, é possível analisar em separado ou conjuntamente o que aparece sobre a discussão de "arranjo e composição de equipe" em cada uma das 3 famílias de documentos primários, por exemplo.

Foram analisados, exaustivamente, todos os trechos destacados nos documentos, observando-se no conteúdo: os atores, os elementos do contexto, os consensos, as contradições, as motivações e as justificativas, o que permitiu a identificação de convergências, divergências e contradições entre os grupos da arena de disputa.

Conforme o Modelo dos Múltiplos Fluxos, ao final do trabalho foi produzido o quadro analítico sobre a configuração da agenda de revisão da PNAB (Figura 5), construído a partir das categorias de análise e que expõe os elementos constitutivos da agenda de revisão da PNAB 2017, com destaque para a mudança das diretrizes para a composição de eAB.

Ainda, vale a ressalva de que esta pesquisa não visa definir uma verdade sobre o processo de revisão da PNAB 2017. A exaustiva sistemática da coleta de dados teve a pretensão de contribuir, principalmente, com o registro histórico sobre os diferentes elementos presentes no processo de revisão da Política na agenda de governo, bem como a motivação do posicionamento dos diferentes atores. Com isso, a partir da revisão da PNAB 2017, é possível aprofundar as reflexões sobre a APS brasileira (fenômeno).

\subsection{ASPECTOS ÉTICOS}

O projeto de pesquisa deste trabalho foi submetido e aprovado no Comitê de Ética e Pesquisa da Faculdade de Saúde Pública da USP, conforme parecer n. 2.614.511.

Cada sujeito participante das entrevistas recebeu as informações e os esclarecimentos necessários sobre a pesquisa, quais sejam: a) o risco seria mínimo e estaria relacionado ao desconforto em falar sobre algum assunto do qual não se sentisse confortável; b) a possibilidade de, a qualquer momento, negar-se a responder qualquer questão ou, até mesmo, retirar-se da pesquisa, sem nenhum prejuízo para si; c) a viabilidade de indicar o local de sua 
conveniência para a realização da entrevista; e d) a confidencialidade das informações obtidas na entrevista, assegurando o sigilo dos dados relacionados à privacidade do participante na ocasião de divulgação deste estudo, conforme disposto no TCLE.

Ademais, pela natureza da pesquisa, ainda foi esclarecido de que o conteúdo da entrevista seria analisado de forma a complementar a análise do posicionamento da instituição ou do movimento do qual o participante faça parte ou represente. Todavia, essas informações foram tratadas de forma que não seja possível a identificação nominal dos entrevistados, sendo identificados como "Entrevista 1, Entrevista 2, etc.". 


\section{APRESENTAÇÃO E DISCUSSÃO DOS RESULTADOS}

O recorte temporal dado pelo período de 2015 a 2017 da análise documental e a citação nas entrevistas de eventos anteriores a esse período trouxeram inúmeros dados e exigiu uma contextualização histórica do desenvolvimento da PNAB.

Para tanto, as informações levantadas foram organizadas em uma linha do tempo, estruturada à medida que a análise evidenciou eventos marcantes do contexto e da estruturação da Política e que demandou, por vezes, outros levantamentos para a complementação e a compreensão das informações.

Essa linha do tempo tem como marco inicial a criação do PACS e do PSF, em 1991 e 1994, respectivamente, pois foi recorrente a referência desse período na narrativa dos entrevistados para discutir as questões referentes à indução do modelo de atenção, ao arranjo de equipe e às atribuições do ACS. No eixo central da linha do tempo são apresentados os eventos relacionados ao desenvolvimento da Política que chamaram atenção pela influência na configuração da agenda de revisão da PNAB 2017 e os momentos mais recentes de mudança de governo. Nos eixos laterais mais periféricos são apresentados os eventos que podem ser considerados desdobramentos da PNAB e os eventos do contexto que se destacaram pela sua influência na trajetória da Política.

Embora este trabalho não tenha como objeto central a análise do desenvolvimento da Política, para a compreensão dos elementos pré-decisionais da configuração da agenda foi necessário interpretá-los, levando em consideração o contexto de desenvolvimento dos elementos que convergiram para a sua configuração. Desta forma, nas Figuras 2 e 3 é apresentado o resultado desse trabalho, o qual pretende colaborar para a compreensão da trajetória da $\mathrm{P}$ e no qual os elementos contextuais do processo da configuração da agenda de revisão da PNAB 2017 podem ser explorados. 
Figura 2 - Elementos relacionados ao desenvolvimento da Atenção Primária à Saúde no Brasil, 1991 a 2014.

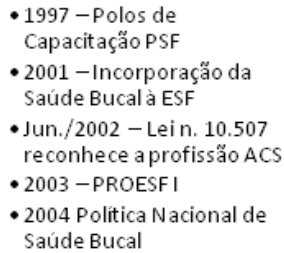

-Jun./2013-Manifestações de Junho

-Jul./2013 - Lançamento do

Mais Médicos

-Mar./2014-Inicio da Lava Jato

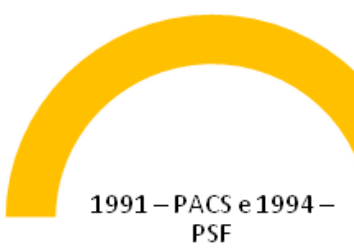

1997 -

Regulamentação em

Portaria do PSF/PACS e

PAB fixo e variável

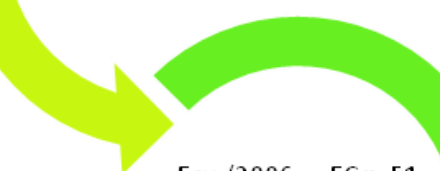

006 - ECn. 51

regularização $\mathrm{e}$

desprecarização dos

vínculos dos ACS/ACE

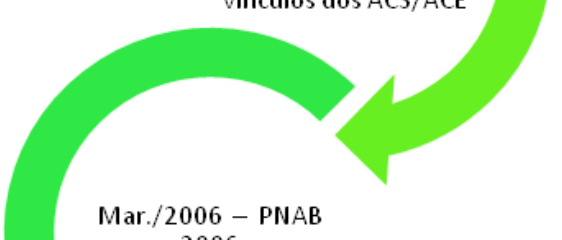

2006

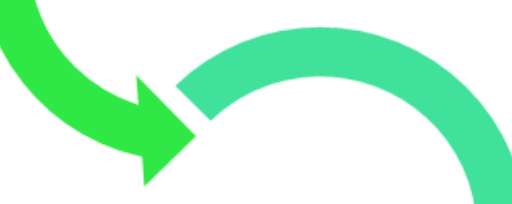

2011 - Governo Dilma

- Ago./2011-Portaria n. 2.027

incorpora arranjos de equipe

permitindo flexibilização da carga

horária do médico

- Set./2011 - PROVAB, Requalifica

UBS, entre outros programas que

mais tarde são incorporados na PNAB

2011

Fonte: Elaborado pelo autor. 
Figura 3 - Elementos do processo de revisão da Política Nacional de Atenção Básica, 2015 a 2017.

- Out./2015-Agravamento da crise econômica e política. Na reforma administrativa o MS é assumido pelo PMDB

- Out./2015 - VI Fórum Nacional de Gestão da AB. Oficina "aprimoramento da PNAB" - Out./2015-PMDB lança documento "Uma ponte para o futuro"

- Dez./2015 - 15a Conferência Nacional de Saúde. Aprova as diretrizes 1.2 e 5.5 relativas a PNAB

-Mar./2016-CIT pactua nova modalidade de equipe de $A B$

-Mar./2016 - PMDB rompe com o governo e Marcelo Castro deixa o MS

- Jul./2016-Discussão sobre as Portariasn. 958 e 959 é pautada no CNS, mas o pleno decide aguardar manifestação do MS

- Ago./2016-Portaria n. 1.482 do MS institui GT de Projeto de Plano de Saúde Acessivel. O MS é questionado sobre o Projeto de Planos de Saúde Acessiveis no CNS.
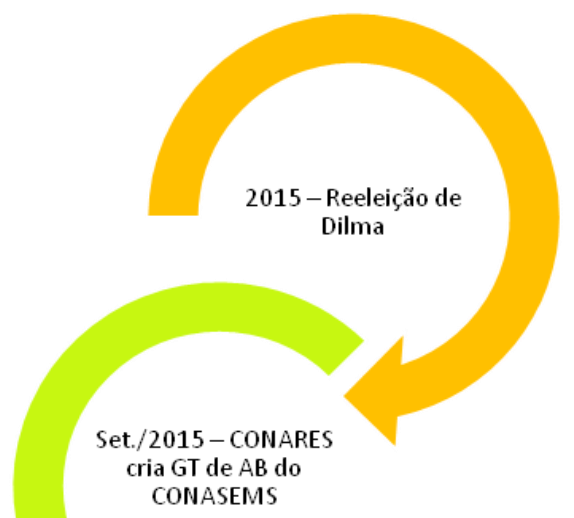

-PSDB não aceita o resultado das eleições e acentua-se a polarização política

- Ajuste Fiscal - Impacto da situação econômico-financeira do Brasil nas Politicas Sociais

- Fev./2015-A AB é destacada dentre as prioridades do MS a partir do PMM - Mar./2015 - V Fórum Nacional de Gestão da AB

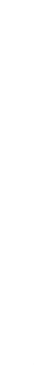

-Abr./2017-CNS define aprofundar capilarizar a discussão sobre a revisão da PNAB

- Mai./2017 - CNS se posiciona para que não haja deliberação sobre a revisão da PNAB sem a devida discussão com o controle semadevi
Social

- Jun./2017-Questionamento do CNS à CIT com relação a proposta de revisão. Propost de consulta à sociedade sobre a revisão da PNAB.

- Jul./2017 - Debate com CONASEMS, CONASS eMS no pleno do CNS sobre a revisão da PNAB

- Jul./2017-Reforma Trabalhista

-Jul./2017-Proposta de Revisão da PNAB e apresentada na CIT e encaminhada para Consulta Pública

- Agosto/2017-Reunião Extraordinária do CNS, realizada no RJ, promove Seminário para Discutir a PNAB
Set. $/ 2015-$ CONARES
cria GT de AB do
CONASEMS

CONASEMS

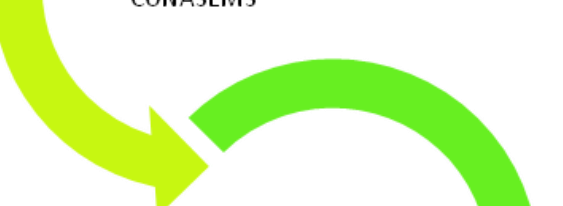

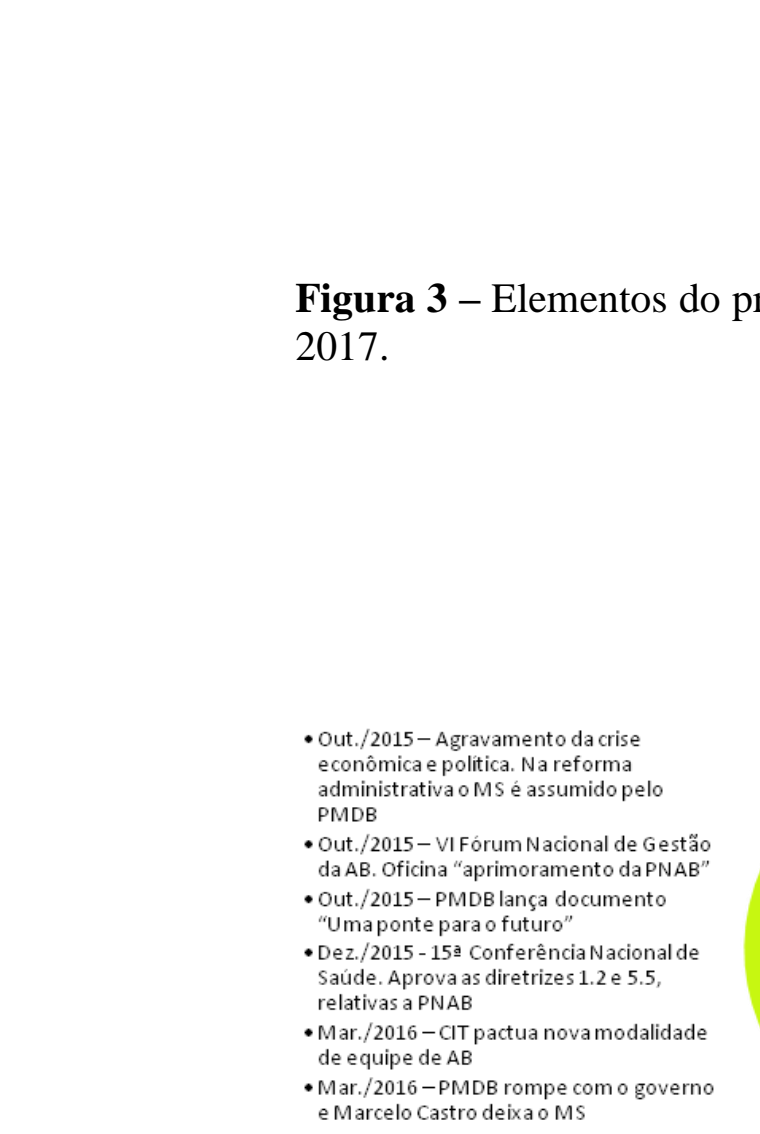
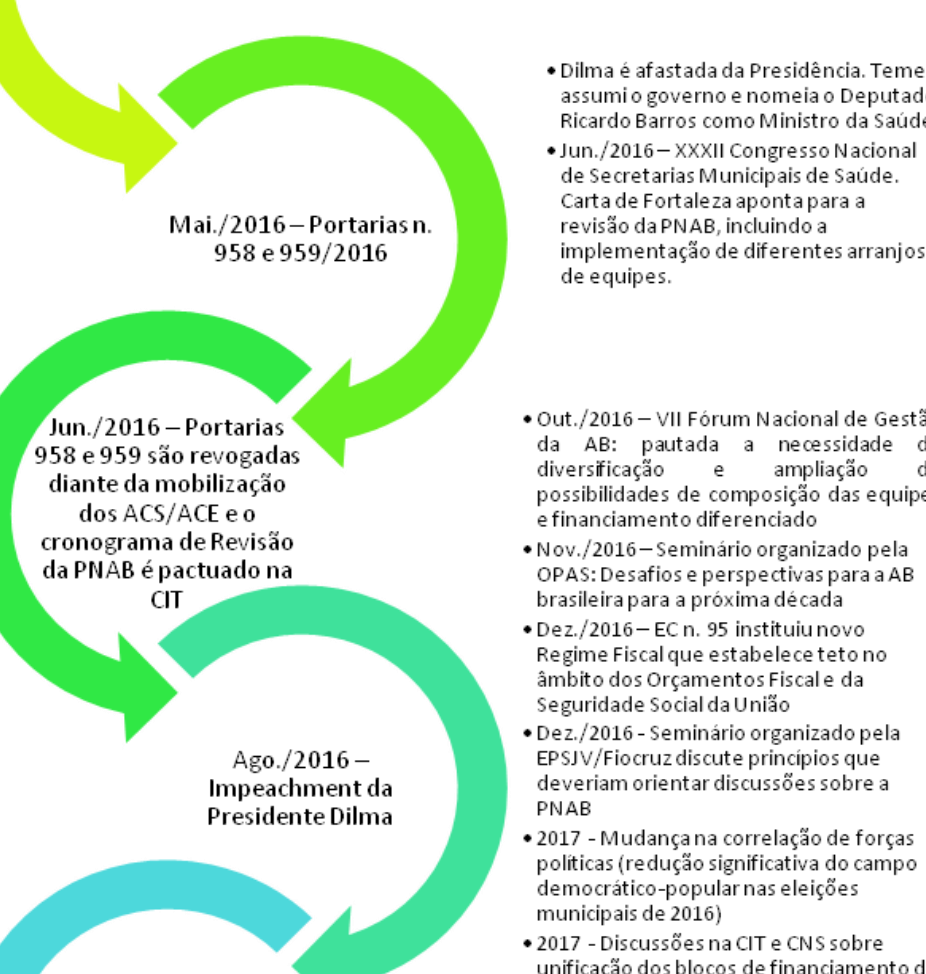

- nes

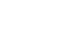

(1) 
Para a interpretação do desenvolvimento da Política e dos elementos que foram constitutivos da proposta de revisão, parece válido considerar o conceito de Path Dependence empregado pelo (Neo)institucionalismo Histórico, que valoriza o papel das instituições na trajetória das políticas. Nessa compreensão, as capacidades do Estado e as políticas existentes ou definidas anteriormente estruturam as decisões posteriores, do mesmo modo que o fluxo de eventos históricos e situações críticas conduzem a mudança na trajetória das políticas (HALL e TAYLOR, 2003).

Como dito acima, foi necessário considerar elementos anteriores ao recorte de 2015 , uma vez que os dados levantados indicam que algumas decisões (ou não decisões) foram desdobramentos de fatos ocorridos em anos anteriores, como a lei que estabeleceu o piso salarial dos ACS e dos ACE, apontada como um dos principais elementos do fluxo de problemas e que data de junho de 2014.

Dessa forma, a rede de relações dos códigos representa uma fotografia da interpretação dos elementos de análise, sendo construída a partir de uma perspectiva que considerou o desencadeamento dos fatos, e indica que o fluxo de problemas relativo à questão do ACS foi se avolumando à medida que o processo de conquistas dos agentes impactou no posicionamento dos gestores. A partir de 2015, importantes mudanças nos sistemas econômico e político produziram mudanças na trajetória da Política.

A Figura 4 apresenta essa rede de códigos que ajudou na identificação dos elementos de análise da configuração da agenda de revisão da PNAB, colaborando, consequentemente, na interpretação da relação entre os temas em análise neste trabalho. 
Figura 4 - Rede de temas da análise da configuração da agenda de revisão da PNAB 2017.

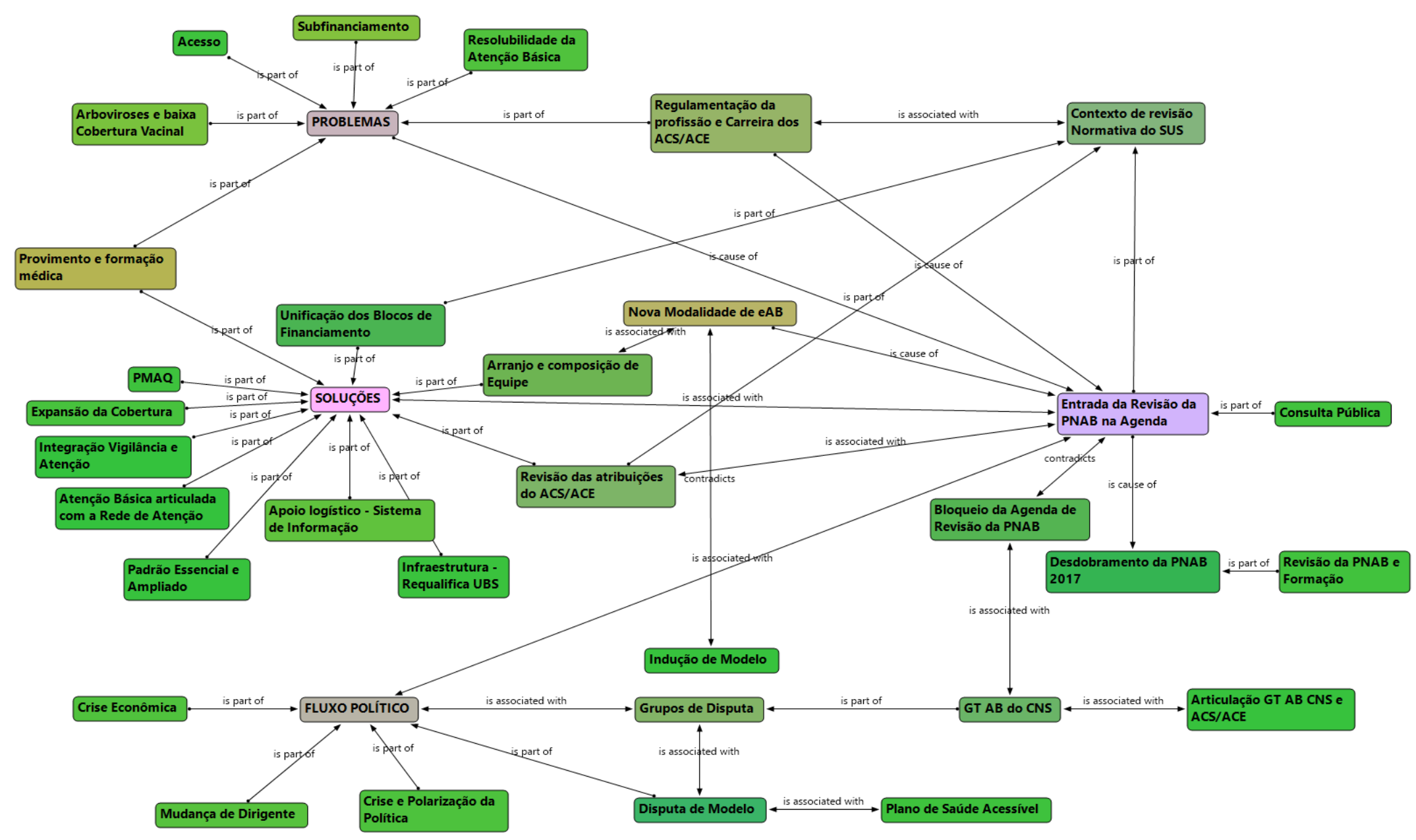

Fonte: Elaborado pelo autor. 
Para se ater aos objetivos deste estudo, nem todos os temas identificados serão descritos individualmente e tratados em profundidade. Serão apresentados e discutidos a partir dos elementos de análise dos múltiplos fluxos, buscando elucidar a configuração da agenda de revisão da PNAB 2017, com destaque na mudança das diretrizes para a composição de equipe.

\title{
5.1 FLUXO POLÍTICO: O CONTEXTO DA AGENDA DE REVISÃO DA PNAB
}

O período analisado é marcado por importantes eventos políticos e econômicos que reverberaram em grandes mudanças na condução das políticas públicas, sendo um capítulo à parte da própria história do País. A esta pesquisa interessa contextualizar que após um período prolongado de avanço econômico e social, favorável para o desenvolvimento de políticas públicas, a partir de 2015, o País entrou em uma forte crise econômica (PAULA e PIRES, 2017).

Não cabe aqui discorrer sobre os motivos da crise econômica, mas o fato é que esse processo foi agravado pela crise política, marcado pelo acirramento e pela polarização política pós eleições de 2014 que, conforme PAULA e PIRES (2017), podem ser observados pela taxa de crescimento do Produto Interno Bruto (PIB):

\begin{abstract}
A economia brasileira, após um período de expansão (2004-2013), em que a taxa de crescimento média foi de 4,0\% a.a., acompanhado por um processo de melhoria na distribuição de renda e na pobreza, contraiu abruptamente a partir de 2014, vindo a sofrer uma forte e prolongada recessão em 2015-2016, com uma taxa de crescimento do PIB média negativa em 3,7\%, acompanhado de uma piora em vários indicadores sociais.
\end{abstract}

No início do segundo mandato do governo Dilma Rousseff, em 2015, Joaquim Levy é indicado para o cargo de Ministro da Fazenda, cuja missão era conter o horizonte de recessão, implementando novas medidas econômicas. A fórmula adotada foi o chamado ajuste fiscal, que buscou equilibrar os gastos do governo diante da queda de arrecadação (SICSÚ, 2015).

Esse processo rapidamente incidiu sobre as políticas sociais, podendo os seus efeitos serem observados nas discussões da CIT e do CNS referentes às prioridades e ao orçamento da saúde no início do governo, conforme trecho a seguir:

\footnotetext{
Ainda sobre o orçamento para 2015 para a Saúde, relatou ser esse um momento de ajuste da economia, maior rigor fiscal, e que esse ajuste se faz necessário para que o crescimento do país possa ser retomado. Todo ajuste tem um grau de exigência, de compromisso, e definição de prioridades (CIT, 2015, Ministro da Saúde, p.2).
}

No CNS, que estava em processo de preparação para a $15^{\text {a }}$ Conferência Nacional de Saúde, as discussões inevitavelmente contemplavam debates sobre os elementos da 
conjuntura e a definição das diretrizes da saúde. Neste sentido, foi apresentada a Carta de Goiânia na reunião do Pleno do CNS, oriunda do $11^{\circ}$ Congresso da ABRASCO, ocorrido entre 28 de julho e 1 de agosto de 2015:

[...] após as eleições de 2014, o governo, diante das pressões do mercado financeiro e da mídia comercial, ao invés dos ajustes necessários para a continuidade do crescimento e da redução das disparidades sociais, promoveu uma reorientação radical da Política Econômica, provocando recessão, desemprego e diminuição de investimentos nas Políticas Sociais. Tal orientação econômica levou ao enfraquecimento da coalizão governista e abriu espaço para facções conservadoras que não se intimidam em destilar sua aversão às instituições democráticas. Na saúde, em que tantas conquistas têm sido alcançadas nos 27 anos de SUS, o período recente tem sido marcado por retrocessos: a derrota do Projeto de Lei de Iniciativa Popular que estabelecia o piso de 10\% das Receitas Correntes Brutas da União para a saúde, a constitucionalização do subfinanciamento com a Emenda Constitucional 86, aliadas ao reforço da mercantilização e da financeirização da prestação de serviços de saúde com a legalização da abertura de capital estrangeiro, além da proposta de emenda à Constituição (PEC 87/2015) que prorroga a Desvinculação de Receitas da União (DRU) até 2023 e amplia de $20 \%$ para $30 \%$ o percentual das receitas de tributos federais que podem ser usadas livremente. Ressalta-se ainda a drenagem de recursos para o pagamento de uma dívida pública jamais auditada (ABRASCO, 2015).

Com o avanço das crises econômica e política, para tentar manter a base governista e sinalizar as medidas de resposta à insatisfação popular, como a redução de gastos do governo, Dilma Rousseff anunciou, em outubro de 2015, a Reforma Administrativa. Destacaram-se entre as medidas da Reforma: a redução de 8 ministérios e 30 secretarias; o corte de 3 mil cargos em comissão; e a redução em $20 \%$ dos gastos de custeio e de contratação de serviços de terceiros, dentre outras medidas.

No discurso em que anunciou a Reforma, em sinalização ao mercado e ao empresariado, a Presidente afirmou que:

\begin{abstract}
Melhorar a gestão pública federal é um desafio constante. Um dos seus objetivos é elevar a competitividade do País, garantindo segurança jurídica dos contratos, estabilidade dos marcos regulatórios, com a simplificação de procedimentos, autorizações, concessões e fiscalização dos serviços regulares. É fazer com que a ação do Estado não seja um empecilho ao investimento, uma barreira ao investimento. Mas que seja um suporte ao investimento e a ação inovadora do setor privado e também dos cidadãos e das cidadãs (ROUSSEFF, 2015).
\end{abstract}

Em busca de apoio político do Congresso Nacional, em outubro de 2015, o Ministério da Saúde passou a ser dirigido pelo Deputado Federal Marcelo Castro, do partido do Movimento Democrático Brasileiro (MDB), o que ocasionou mudanças imediatas na direção do órgão e de suas prioridades, criando contrariedade e insatisfação na base de sustentação popular do governo no setor da saúde (GUIMARÃES, 2015).

Em sua primeira participação na reunião da CIT como Ministro da Saúde, Marcelo Castro, ao tratar do financiamento do SUS, afirmou que: 
No próximo ano (2016), haverá grandes restrições de recursos, uma vez que a regra estabelecida anteriormente pela EC $n^{\circ} 29$ era de que o orçamento do MS seria o orçamento realizado do ano anterior acrescido do PIB nominal. Contudo, houve entendimento no sentido de se mudar essa regra no Congresso Nacional para uma regra supostamente mais vantajosa (EC $\left.n^{\circ} 86 / 2015\right)$, que seria a de estabelecer um percentual de $15 \%$ sobre as receitas correntes líquidas da União, o que, de fato, seria a mais vantajosa, ao longo do tempo, todavia, dada as dificuldades com a queda do PIB neste ano, essa regra se tornou mais danosa para o ano de 2016, porque serão menos recursos que o definido na regra anterior. [...] ou seja, o orçamento do ano que vem será de 7.5 bilhões a menos do que o orçamento deste ano (CIT, 2015, p. 2).

A passagem de Marcelo Castro pela Pasta foi breve, pois, embora o então PMDB fizesse parte do governo e estivesse à frente de 8 ministérios, em dezembro de 2016, articulam com o Partido da Social Democracia Brasileira (PSDB) a admissibilidade do processo de pedido de impeachment da Presidente Dilma Rousseff na Câmara dos Deputados. Marcelo Castro permanece no cargo de Ministro da Saúde até abril de 2016, pedindo demissão após o anúncio do rompimento do PMDB no mês anterior.

É nesse período de transição e instabilidade política que se abriu a janela de oportunidades para a entrada da proposta de mudança nas diretrizes para a composição de eAB na agenda do governo. No final de março de 2016, no auge da crise política do governo Dilma Rousseff e da saída de Marcelo Castro à frente do Ministério da Saúde, a proposta de nova modalidade da eAB foi pactuada na CIT. No período de vacância do cargo de Ministro da Saúde, houve a publicação das Portarias no 958 e 959, de 10 de maio de 2016, que propuseram rever a composição mínima da eSF, prevendo a flexibilização da composição entre o número de ACS e/ou substituição por técnicos de enfermagem.

Pela narrativa dos atores que estavam acompanhando organicamente o processo em 2016, percebe-se que a proposta de revisão da PNAB vinha sendo debatida antes daquele período, mas que diante do cenário de mudanças de dirigentes do Ministério da Saúde, surgiu uma janela de oportunidades na qual foi consolidada a proposta, expressa pela Portaria $\mathrm{n}^{\circ}$ 958, de 10 de maio de 2006.

A gente estava no auge da discussão desse grupo que estava discutindo o todo do modelo. Não me recordo as motivações internas, porque tecnicamente a gente tinha sugerido para fazer essa discussão no todo da revisão da PNAB. Mas aí saiu precipitado, só esse recorte (da proposta da portaria 958). Mas naquele momento tinha alguma situação política que não me lembro se vinha do Congresso, se vinha de movimento, que a gente já tinha essa possibilidade de discutir porque teve essa situação política que fez sair antes da discussão do todo da Política de Atenção Básica. Não era para sair, mas acabou que saiu (Entrevista 4).

Nos depoimentos abaixo, fica evidente o protagonismo do CONASEMS enquanto articulador da proposta e a forte determinação das mudanças no sistema político (notadamente a troca de dirigentes) para a entrada da revisão da PNAB na agenda de governo: 
Em 2016, quando teve a mudança de governo, a discussão (sobre a PNAB) passou imediatamente para a tripartite, sem que a gente terminasse os posicionamentos. Mas enfim, as discussões passaram a ser tripartite, com a participação do CONASS e Ministério da Saúde (Entrevista 6).

Esse processo é bem contextualizado a seguir:

Essa discussão começou nos Fóruns de Gestão da Atenção Básica do Ministério da
Saúde. A demanda mais forte de revisão veio dos Congressos do CONASEMS.
Quem mais cobrava a revisão era o pessoal do CONASEMS. No Ministério da
Saúde a gente teve nesse período 4 Ministros da Saúde e você sabe que a cada
mudança as coisas ficam meio abaladas. Quando teve nova mudança de Ministro a
pressão do CONASEMS e CONASS foi grande para pactuar. No período de
discussão da política tivemos o impeachment da Dilma, saiu o Ministro Arthur,
entrou Marcelo Castro e depois com o Temer teve o Ricardo Barros. Então, teve
uma turbulência política muito grande (Entrevista 7).

Como reação, os movimentos dos ACS e ACE, liderados pela CONACS e pela Federação Nacional dos Agentes de Comunitários de Saúde e Combate às Endemias (FENASCE), mobilizam-se contra as Portarias no 958 e 959, de 10 de maio de 2016.

Nesse mesmo período, em 12 de maio de 2016, o Senado Federal autorizou a abertura do processo de impeachment propriamente dito, o que determinou o afastamento da Presidente Dilma Rousseff até o julgamento do processo. Imediatamente, assumiu o VicePresidente Michel Temer, que já tinha articulado a composição de um novo governo com indicações dos partidos que ocupariam os órgãos da Administração Pública em troca de apoio político.

Com isso, ainda no dia 12 de maio de 2016, Ricardo Barros, Deputado Federal do Partido Progressista e engenheiro, assumiu o Ministério da Saúde e Secretário Executivo da Pasta, assumiu o então Secretário de Vigilância em Saúde, Antônio Carlos Nardi, que havia sido Presidente do CONASEMS por dois mandatos no período anterior.

Frente à ameaça, CONACS e FENASCE organizaram uma grande mobilização em Brasília, Distrito Federal, e, após uma articulação com um conjunto de Deputados, pressionaram o governo recém instaurado a recuar, o que resultou na revogação das Portarias no 958 e 959, em 10 de junho de 2016.

Todavia, o recuo do governo foi apenas aparente e estratégico, pois, conforme pode ser observado na pactuação da CIT de 30 de junho de 2016, ainda no mesmo mês de revogação das Portarias supra, a revisão da PNAB foi encaminhada para discussão de forma mais ampla, a qual passou a ser discutida no Grupo de Trabalho (GT) de Atenção à Saúde da CIT, conforme o registro de encaminhamento do resumo executivo da CIT: 
reunião da CIT de outubro de 2016 (CIT, 2016, p. 17).

Conforme a análise de PINTO (2018) sobre a mudança da PNAB e seu contexto, observa-se que os documentos "Ponte para o Futuro" e "Travessia Social" " anunciaram as mudanças estruturais e de cunho neoliberal, que de fato foram implementadas com o processo de impeachment, que levou ao afastamento definitivo de Dilma Rousseff e sua substituição pelo seu vice, Michel Temer, em 31 de agosto de 2016.

Esse processo foi definido como "golpe de Estado" pela própria Presidente Dilma Rousseff em sua defesa durante a sessão do Congresso Nacional, na qual rebateu a acusação de crime de responsabilidade e atribuiu a motivação do impeachment a um conluio que objetivava a substituição do projeto de governo debatido e eleito em 2014 (ABRANTES, 2016).

Portanto, observa-se que o período caracteriza-se pela implementação de um projeto de governo que não foi definido democraticamente, uma vez que não foi submetido à apreciação popular, sendo decorrente do processo de impeachment. Como consequência, o período é marcado pelo o agravamento da crise e a polarização política, o que se reflete no posicionamento dos atores que compuseram a arena de disputa da revisão da Política.

Com relação ao contexto, ainda é possível observar nos registros da CIT e, sobretudo, do CNS, as discussões sobre o impacto da Emenda Constitucional (EC) $n^{\circ}$ 95, a chamada lei do teto de gastos, da reforma trabalhista e da movimentação para aprovar a reforma da previdência. Na saúde, especificamente, como consequência das reformas do Estado, há também a revisão de importantes normativas do SUS, destacando-se, neste estudo, a unificação dos blocos de financiamento, a discussão dos planos de saúde acessíveis e a própria PNAB.

A janela de oportunidades surgiu em função da conjuntura político-econômica, que contou com uma mudança abrupta do governo mesmo sem eleições. Conforme descrito por KINGDON (2006) em seu modelo de análise dos múltiplos fluxos, mudanças de dirigentes ou de governantes são elementos de maior relevância no fluxo político, apresentando-se como elemento determinante para a configuração de uma agenda.

Neste estudo, como sugerido por KINGDON (2006), as mudanças nos subsistemas político e econômico apresentaram forte influência sobre o grau de reconhecimento de uma

\footnotetext{
${ }^{7}$ Disponível em: https://www.fundacaoulysses.org.br/wp-content/uploads/2016/11/UMA-PONTE-PARA-OFUTURO.pdf

${ }^{8}$ Disponível em: https://complemento.veja.abril.com.br/pdf/TRAVESSIA\%20SOCIAL\%20\%20PMDB LIVRETO PNTE PARA O FUTURO.pdf
} 
situação na agenda de decisão do governo, sendo definidora na priorização de determinados problemas e escolha de alternativas.

\subsubsection{Os Atores e a Arena Política de Disputa}

O levantamento do posicionamento de entidades e instituições acerca da revisão da PNAB propiciou a identificação dos atores que compuseram a arena política. A relação apresentada no Quadro 4 não esgota o universo de manifestações ocorridas na iminência do processo de aprovação da revisão da PNAB 2017, porém concentra as principais e primeiras manifestações em relação à proposta.

O conteúdo dessas manifestações representa uma síntese dos argumentos e das motivações de seus posicionamentos, servindo para indicar a composição da arena política, bem como as pistas de como os atores atuaram e seu posicionamento no processo em disputa. 
Quadro 6 - Relação de entidades e instituições com posicionamento relativo à proposta de revisão da Política Nacional de Atenção Básica 2017.

\begin{tabular}{|c|c|c|c|c|}
\hline Instituição/Entidade & $\begin{array}{c}\text { Tipo de } \\
\text { documento }\end{array}$ & Data & Posicionamento & Fonte \\
\hline $\begin{array}{l}\text { Frente Brasil Popular, Frente de } \\
\text { Esquerda Socialista, Frente } \\
\text { Nacional Contra a Privatização da } \\
\text { Saúde/Fórum de Saúde do Rio de } \\
\text { Janeiro e Frente Povo Sem Medo }\end{array}$ & $\begin{array}{l}\text { Moção de } \\
\text { Repúdio }\end{array}$ & $31 / 10 / 2016$ & Contra a proposta de revisão & $\begin{array}{l}\text { http://emdefesadosus-rj.blogspot.com/2016/10/mocao-de-repudio- } \\
\text { revisao-da-politica.html?m=1 }\end{array}$ \\
\hline $\mathrm{DAB} / \mathrm{MS}$ & $\begin{array}{l}\text { Matéria do site do } \\
\text { DAB/MS }\end{array}$ & $18 / 11 / 2016$ & Defesa da proposta de revisão & http://dab.saude.gov.br/portaldab/noticias.php?conteudo=_\&cod=2276 \\
\hline Rede Unida & Nota Pública & 08/06/2017 & Contra a proposta de revisão & $\begin{array}{l}\text { http://www.redeunida.org.br/en/comunicacao/news/rede-unida- } \\
\text { manifesta-sobre-revisao-da-pnab/ }\end{array}$ \\
\hline $\begin{array}{l}\text { ABRASCO, CEBES e } \\
\text { ENSP/FIOCRUZ }\end{array}$ & Nota Pública & 27/07/2017 & Contra a proposta de revisão & $\begin{array}{l}\text { https://www.abrasco.org.br/site/noticias/posicionamentos- } \\
\text { oficiais/contra-reformulacao-da-pnab-nota-sobre-revisao-da-politica- } \\
\text { nacional-de-atencao-basica/29798/ }\end{array}$ \\
\hline $\mathrm{DAB} / \mathrm{MS}$ & $\begin{array}{l}\text { Matéria do site do } \\
\text { DAB/MS }\end{array}$ & 27/07/2017 & Defesa da proposta de revisão & http://dab.saude.gov.br/portaldab/noticias.php?conteudo=_\&cod=2426 \\
\hline CONASS e CONASEMS & Nota Pública & 03/08/2017 & Defesa da proposta de revisão & $\begin{array}{l}\text { http://www.conass.org.br/nota-conjunta-conasems-e-conass-sobre- } \\
\text { reformulacao-pnab/ }\end{array}$ \\
\hline $\begin{array}{l}\text { Sociedade Brasileia de Medicina } \\
\text { de Família e Comunidade }\end{array}$ & Nota Pública & 07/08/2017 & Ressalvas a proposta de revisão & $\begin{array}{l}\text { https://www.sbmfc.org.br/noticias/nota-sobre-a-revisao-da-politica- } \\
\text { nacional-da-atencao-basica-pnab/ }\end{array}$ \\
\hline Conselho Federal de Odontologia & Nota Pública & $10 / 08 / 2017$ & Contra a proposta de revisão & $\begin{array}{l}\text { http://cfo.org.br/website/posicionamento-do-cfo-sobre-a-revisao-da- } \\
\text { politica-nacional-de-atencao-basica/ }\end{array}$ \\
\hline Conselho Nacional de Saúde & Recomendação & $11 / 08 / 2017$ & $\begin{array}{l}\text { Recomenda que não seja } \\
\text { deliberada sem amplo debate } \\
\text { com o controle social }\end{array}$ & $\begin{array}{l}\text { https://www.abrasco.org.br/site/noticias/posicionamentos- } \\
\text { oficiais/contra-reformulacao-da-pnab-nota-sobre-revisao-da-politica- } \\
\text { nacional-de-atencao-basica/29798/ }\end{array}$ \\
\hline Conselho Federal de Nutrição & Nota Pública & $11 / 08 / 2017$ & Contra a proposta de revisão & $\begin{array}{l}\text { http://www.cfn.org.br/index.php/cfn-apresenta-proposta-para-a- } \\
\text { revisao-da-pnab/ }\end{array}$ \\
\hline Conselho Federal de Enfermagem & Nota Pública & $14 / 08 / 2017$ & Contra a proposta de revisão & $\begin{array}{l}\text { http://www.cofen.gov.br/cofen-se-manifesta-contra-a-reformulacao- } \\
\text { da-pnab_54159.html }\end{array}$ \\
\hline $\begin{array}{l}\text { Associação Brasileira de } \\
\text { Enfermagem }\end{array}$ & $\begin{array}{l}\text { Carta do } 69^{\circ} \\
\text { Congresso }\end{array}$ & 08/09/2017 & Contra a proposta de revisão & $\begin{array}{l}\text { http://www.abennacional.org.br/site/wp- } \\
\text { content/uploads/2019/02/Carta_Maceio_69_CBEn.pdf }\end{array}$ \\
\hline $\begin{array}{l}\text { Confederação Nacional dos } \\
\text { Agentes Comunitários de Saúde }\end{array}$ & Nota & $29 / 09 / 2017$ & $\begin{array}{l}\text { Mobilização pela revogação da } \\
\text { PNAB } 2017\end{array}$ & http://conacs.org.br/atencao-defensores-o-sus-e-do-povo/ \\
\hline
\end{tabular}

Fonte: Elaborado pelo autor. 
A seguir, o Quadro 5, que apresenta a relação de notícias sobre a revisão da PNAB, é útil para observar a dimensão da repercussão que a revisão ganhou nacionalmente e das justificativas do posicionamento dos atores.

Quadro 7 - Relação de notícias na mídia sobre a revisão da Política Nacional de Atenção Básica.

\begin{tabular}{|c|c|c|c|}
\hline $\begin{array}{c}\text { Canal de } \\
\text { Comunicação }\end{array}$ & Título da Matéria & Data & Fonte \\
\hline $\begin{array}{l}\text { Reportagem do } \\
\text { site da } \\
\text { EPSJV/Fiocruz }\end{array}$ & $\begin{array}{l}\text { Agentes na rua, portarias no } \\
\text { chão. Mobilização massiva } \\
\text { dos agentes comunitários em } \\
\text { Brasília leva Ministério da } \\
\text { Saúde a revogar as portarias } \\
958 \text { e } 959\end{array}$ & $21 / 06 / 2016$ & $\begin{array}{l}\text { http://www.epsjv.fiocruz.br/noticias/report } \\
\text { agem/agentes-na-rua-portarias-no-chao }\end{array}$ \\
\hline EPSJV/Fiocruz & $\begin{array}{l}\text { Que atenção básica para que } \\
\text { SUS? } \\
\text { Seminário organizado pela } \\
\text { EPSJV/Fiocruz discute } \\
\text { princípios que deveriam } \\
\text { orientar discussões sobre a } \\
\text { Política Nacional de Atenção } \\
\text { Básica }\end{array}$ & $31 / 10 / 2016$ & $\begin{array}{l}\text { http://www.epsjv.fiocruz.br/noticias/report } \\
\text { agem/guinada-biomedica }\end{array}$ \\
\hline $\begin{array}{l}\text { Telejornal - Bom } \\
\text { dia Brasil }\end{array}$ & $\begin{array}{l}\text { Ameaça de corte de verba do } \\
\text { Saúde da Família gera reação }\end{array}$ & 04/08/2017 & $\begin{array}{l}\text { https://globoplay.globo.com/v/6055097/pr } \\
\text { ograma/ }\end{array}$ \\
\hline Revista Época & $\begin{array}{l}\text { O governo quer mudar a } \\
\text { atenção básica à saúde. Quais } \\
\text { os efeitos? }\end{array}$ & $10 / 08 / 2017$ & $\begin{array}{l}\text { http://epoca.globo.com/saude/check- } \\
\text { up/noticia/2017/08/o-governo-quer- } \\
\text { mudar-atencao-basica-saude-quais-os- } \\
\text { efeitos.html }\end{array}$ \\
\hline $\begin{array}{l}\text { O Estado de São } \\
\text { Paulo }\end{array}$ & $\begin{array}{l}\text { Governo Federal quer mudar } \\
\text { modelo de atendimento básico } \\
\text { de saúde no País }\end{array}$ & $11 / 08 / 2017$ & $\begin{array}{l}\text { http://saude.estadao.com.br/noticias/geral, } \\
\text { governo-federal-quer-mudar-modelo-de- } \\
\text { atendimento-basico-de-saude-no- } \\
\text { pais,70001932322 }\end{array}$ \\
\hline $\begin{array}{l}\text { Reportagem do } \\
\text { site da Rede } \\
\text { APS }\end{array}$ & $\begin{array}{l}\text { Debate da reformulação da } \\
\text { PNAB extrapola as entidades } \\
\text { e reforça a importância da } \\
\text { APS para o País }\end{array}$ & $14 / 08 / 2017$ & $\begin{array}{l}\text { http://rededepesquisaaps.org.br/2017/08/1 } \\
\text { 4/debate-da-reformulacao-da-pnab- } \\
\text { extrapola-as-entidades-e-reforca-a- } \\
\text { importancia-da-aps-para-o-pais/ }\end{array}$ \\
\hline $\begin{array}{l}\text { Reportagem } \\
\text { Agência Brasil - } \\
\text { EBC }\end{array}$ & $\begin{array}{l}\text { Comissão do SUS aprova } \\
\text { revisão da Política Nacional } \\
\text { de Atenção Básica }\end{array}$ & $31 / 08 / 2017$ & $\begin{array}{l}\text { http://agenciabrasil.ebc.com.br/geral/notici } \\
\text { a/2017-08/comissao-do-sus-aprova- } \\
\text { revisao-da-politica-nacional-de-atencao- } \\
\text { basica }\end{array}$ \\
\hline $\begin{array}{l}\text { Folha de São } \\
\text { Paulo }\end{array}$ & $\begin{array}{l}\text { Governo aprova portaria que } \\
\text { afrouxa normas de } \\
\text { atendimento básico no SUS }\end{array}$ & $31 / 08 / 2017$ & $\begin{array}{l}\text { https://www1.folha.uol.com.br/cotidiano/2 } \\
\text { 017/08/1914654-governo-aprova-portaria- } \\
\text { que-afrouxa-normas-de-atendimento- } \\
\text { basico-no-sus.shtml }\end{array}$ \\
\hline $\begin{array}{l}\text { Reportagem do } \\
\text { site da Rede } \\
\text { APS }\end{array}$ & $\begin{array}{l}\text { Sob protestos, texto da nova } \\
\text { Política Nacional de Atenção } \\
\text { Básica é aprovado }\end{array}$ & 04/09/2017 & $\begin{array}{l}\text { http://rededepesquisaaps.org.br/2017/09/0 } \\
\text { 4/sob-protestos-texto-da-nova-politica- } \\
\text { nacional-de-atencao-basica-e-aprovado/ }\end{array}$ \\
\hline $\begin{array}{l}\text { Reportagem site } \\
\text { da } \\
\text { EPSJV/Fiocruz }\end{array}$ & $\begin{array}{l}\text { A crise por trás da nova } \\
\text { PNAB. Como as controversas } \\
\text { mudanças na atenção básica se } \\
\text { ligam ao contexto econômico } \\
\text { e político do País }\end{array}$ & 06/09/2017 & $\begin{array}{l}\text { http://www.epsjv.fiocruz.br/noticias/report } \\
\text { agem/a-crise-por-tras-da-nova-pnab }\end{array}$ \\
\hline
\end{tabular}

Fonte: Elaborado pelo autor. 
Do ponto de vista do registro histórico, é possível observar que o processo em disputa ganha projeção nacional, sendo que a Escola Politécnica de Saúde Joaquim Venâncio da Fundação Oswaldo Cruz (EPJV/FIOCRUZ) protagonizou não só a vanguarda do posicionamento crítico em relação à revisão da PNAB 2017, como também foi meio de comunicação para noticiar sobre o andamento da agenda. Por outro lado, a repercussão nacional sobre a revisão da PNAB 2017 e a organização de uma ampla coalizão para o bloqueio da agenda apenas ocorreram quando o CNS se tornou palco dessa arena de disputa.

Considerando os títulos e o conteúdo das reportagens, a narrativa de crítica à revisão da PNAB ganhou mais evidência, sendo traduzida como uma ameaça ao SUS, e revelou os principais atores e seus posicionamentos na arena de disputa.

Portanto, as notas públicas de posicionamento das entidades, as notícias veiculadas na mídia comercial e os sites institucionais complementaram a identificação da composição da arena política de disputa em torno da agenda de revisão da PNAB 2017, bem como possibilitaram o acompanhamento de como o tema foi apresentado à sociedade, dando noção do "clima nacional” com relação à proposta de revisão.

A partir do registro das reuniões da CIT e do CNS do período analisado, constata-se que a APS, direta ou indiretamente, esteve constantemente presente na agenda dos gestores. Por outro lado, os temas relacionados à PNAB, propriamente dita, aparecem nas reuniões do Pleno do CNS somente a partir de dezembro de 2016, e, ainda assim, apenas como um desdobramento da discussão de um item de pauta que não tratava da revisão da PNAB, mas que serviu como uma oportunidade para propor a constituição de um GT para discutir a Política no CNS.

Destaca-se que na $289^{a}$ Reunião Ordinária do CNS, realizada em janeiro de 2017, é deliberado sobre a indicação de composição de um GT de Atenção Básica do CNS, com o objetivo de discutir a revisão da PNAB, conforme trecho da Ata a seguir:

De acordo com aprovação do Plenário por unanimidade, será constituído GT do CNS para debater a atenção básica e apresentar diretrizes para o processo de revisão da atenção básica (CNS, 2017, p. 27).

No entanto, foi um longo processo desde outubro de 2016, quando houve o posicionamento dos movimentos sociais do Rio de Janeiro ${ }^{9}$ contra a revisão da PNAB e a matéria da EPJV/FIOCRUZ ${ }^{10}$, que publicizou o processo em andamento, passando por

\footnotetext{
${ }^{9}$ Vide Quadro 4 - Relação de entidades e instituições com posicionamento relativo a proposta de revisão da PNAB 2017.

${ }^{10}$ Vide Quadro 5 - Relação de notícias na mídia sobre a revisão da PNAB.
} 
intervenções que foram relevantes para a revisão da PNAB, até a Política de fato entrar na pauta das reuniões do Pleno do CNS.

Fomos chamando atenção dessa discussão no CNS, mas ela não se tonou pauta de imediato. Somente após um fórum de discussão que aconteceu na Escola Politécnica da FIOCRUZ é que a discussão vira pauta e passa a ser discutida em 2017 (Entrevista 8).

A discussão sobre a revisão da PNAB entra efetivamente na agenda do Pleno do CNS apenas na $291^{\text {a }}$ Reunião Ordinária, em março de 2017, quando é apresentada como ponto de pauta sob o item Contribuições do CNS sobre a revisão da Política Nacional de Atenção Básica (CNS, 2017).

Embora esse período, compreendido entre outubro de 2016 e março de 2017, aparente um hiato na resposta das forças contrárias à revisão da PNAB, há que se considerar que o processo democrático e participativo do controle social segue ritos com tempos bastantes distintos dos colegiados de gestão e de uma negociação exclusiva entre os gestores, especialmente se considerarmos as condições para a construção da narrativa contrária à proposta de revisão da PNAB:

A gente dizia: vocês vão revisar, estão mudando, a gente quer discutir, a gente quer trazer essa questão do financiamento, quer trazer a questão dos recursos humanos, quer trazer o debate da equipe... (Eles diziam): Não, não, vocês estão fantasiando. Não tem nada acontecendo. Aí de repente vem a nova PNAB. Aí teve um prazo curto de consulta pública [...] (Entrevista 1).

De toda forma, foi necessário muito tempo para a formação de uma coalizão capaz de pautar o tema e fazer oposição à proposta de revisão da PNAB. Vale lembrar que a EPJV/FIOCRUZ, em meados de 2016, já alertava sobre essa agenda e, em julho de 2016, quando a Portaria $n^{\circ}$ 958, de 10 de maio de 2016, é pautada na reunião do CNS, há apenas uma curta menção sobre o tema, marcando uma não decisão sobre a proposta que incidia, principalmente, sobre os ACS, conforme pode ser observado na deliberação registrada na Ata da $283^{a}$ Reunião Ordinária do CNS de 2016: “O Plenário decidiu aguardar a manifestação do Ministério da Saúde sobre as Portarias GM/MS 958 e 959/2016, para posicionar-se a respeito".

De acordo com a entrevista 8, quando o assunto era ACS existia uma tensão por ser uma categoria que, historicamente, não participava do CNS e que realiza sua interlocução diretamente com o Legislativo. Além disso, a categoria é representada pelo segmento dos trabalhadores, o qual também caracteriza-se pela tensão e pelo conflito corporativista existentes, o que dificultava a ressonância do tema que até então afetava mais claramente os agentes. 
[...] entidades com compromisso com a Reforma Sanitária como CEBES, ABRASCO e Rede Unida foram trazendo a pauta com muita insistência, depois eles foram entendendo a importância da agenda, mas com muita desconfiança de todo mundo. Quem mais tinha clareza da pauta não era usuário e nem trabalhador, era o gestor. Foi uma agenda difícil de entrar na pauta do CNS, porque tinha dificuldade de interlocutor para apresentar a agenda, tinha dificuldade de entendimento do que estava sendo discutido e a tensão que existia no seguimento dos trabalhadores. Isso só muda a partir de 2017, quando isso passa a ser encarada de outra forma (Entrevista 8).

Cabe lembrar que nesse período houve o processo de impeachment da Presidente Dilma Rousseff, levando à reorganização das forças políticas, bem como a uma intensa agenda dos movimentos sociais em virtude da pauta de reformas que surgiram com a mudança de governo.

Além disso, o controle social prevê a participação dos diversos segmentos, incluindo os gestores, carregando consigo uma complexidade operacional que demanda grande esforço em articular a proposição e a avaliação das políticas de saúde, como também as demandas e as necessidades de cada segmento.

O CNS não tinha nenhum tipo de espaço que problematizasse ou que encaminhasse políticas de atenção. Não havia espaço de formulação e de acumulação que desse conta da agenda de hospital, emergência e, portanto, da política de atenção básica. Então, quando chegava essas pautas da política de atenção, havia muita dificuldade de serem discutidas (Entrevista 8).

Embora o processo de participação do controle social seja mais lento e complexo, o CNS teve um papel fundamental na arena de disputa sobre a agenda de revisão da PNAB 2017, propiciando a ampliação do debate, extrapolando as reuniões do Pleno do Conselho e mobilizando diversos atores em torno do tema da revisão da Política.

\subsubsection{A Atuação dos Atores e as Forças Políticas Organizadas}

A partir desse panorama, foi possível identificar a formação dos grupos de coalizão, construídos a partir dos interesses dos atores. Acerca da dinâmica da arena política e dos atores, RUA (2012) afirma:

Em função das preferências, das expectativas de resultados (vantagens e desvantagens) de cada alternativa para a solução de um problema, e da estrutura de oportunidades, os atores fazem alianças entre si e entram em disputa. Assim se formam as arenas políticas (RUA, 2012, p. 75).

Identificar os atores que compuseram a arena política é fundamental para a análise do que se decidiu e como se decidiu e, no caso desse estudo, apresenta grande relevância devido à posição e à ação dos atores, a serem interpretadas a partir da subcategoria "forças políticas organizadas", pertencente ao fluxo político do Modelo dos Múltiplos Fluxos. 
Devido ao processo de intensa polarização que aparece nos resultados, enquanto elemento de contexto, há basicamente dois grupos de coalizão: o favorável ao processo de revisão da PNAB, caracterizado como um grupo de defesa da proposta, e contrário ao processo de revisão da Política, atuando como um grupo de bloqueio da agenda.

Evidentemente, apesar desses dois grandes blocos, conformados a partir do posicionamento em relação à proposta de revisão da PNAB, existiam distintos interesses e graus de engajamento. Embora nenhum dos atores discordasse da necessidade de revisão de diferentes pontos da PNAB, reconhecendo que a Política poderia ser aperfeiçoada, o contexto de acentuação do acirramento político e da restrição financeira chamou atenção para o risco de perdas com relação aos avanços alcançados no desenvolvimento da Política até aquele período e produziu, portanto, um antagonismo à agenda de revisão.

Além disso, a proposta de solução apresentada contemplava, basicamente, a demanda e os interesses dos gestores, não atraindo apoio político de outros atores. Estes últimos interpretaram que estavam diante de uma agenda restritiva, não se dispondo em contribuir com a proposta, passando a assumir uma estratégia de bloqueio da agenda de revisão da PNAB 2017. A própria repercussão nacional nas mídias pode ser considerada como resultado da estratégia de enfrentamento produzida pelos atores contrários à agenda de revisão.

\footnotetext{
Se você for observar o contexto geral de revisão da PNAB, nesses elementos há uma grande contestação por parte dos movimentos sociais, entidades representativas de trabalhadores e Conselho Nacional de Saúde, mas você vê que não há secretários municipais de saúde, mesmo fora do CONASEMS, se opondo à revisão da PNAB de 2017, pelo menos eu não vi nenhum caso, assim, de secretário, seja em qual região fosse, levantar a mão e dizer: "não, essa PNAB aí é um equívoco, é um retrocesso, etc.", como os movimentos sociais, conselho e entidades de classe trabalhadora faziam (Entrevista 3).
}

Essa reação à proposta de revisão da PNAB 2017 pode ser lida como influência da conjuntura brasileira, a qual expressava o acirramento e a polarização política. Na narrativa dos gestores é remetida uma interferência externa sobre os posicionamentos ao processo de revisão da PNAB 2017. Em uma interpretação bastante simplificada, os posicionamentos contrários às propostas de revisão da PNAB seriam decorrentes de posicionamentos políticos partidários e em razão de ocorrer, por coincidência, no bojo de um governo que estava sendo questionado quanto a sua legitimidade.

Algumas falas ilustram a visão de que o posicionamento contrário à revisão da $\mathrm{PNAB}$ tinha a perspectiva de oposição ao governo recém-empossado:

Porque também ela vinha no final da discussão da questão do problema político que o país enfrentou. Porque quando a gente olha para 2006, ela não foi discutida com ninguém e ninguém falou nada, também em 2011 ela não foi discutida com ninguém e ninguém falou nada. $\mathrm{Na}$ de 2017, que nós começamos e abrimos o debate, ouvimos, teve tudo aquilo... e aí começou: “então é o desmonte”. Porque qualquer 
coisa era associada a política partidária. Diziam: "é por causa do golpe e vão desmontar" (Entrevista 5).

O próximo trecho ilustra bem o peso da conjuntura política sobre o posicionamento dos atores na arena política:

Existia uma arena bastante determinada pela conjuntura e condução política dos
dirigentes das instituições, a gente tentava produzir o diálogo, chamando a
responsabilidade de atores históricos na defesa do SUS. Nos bastidores havia
diálogo, mas a coisa era tão determinada pelas grandes decisões que alguns
representantes até se retiravam do espaço das reuniões do Conselho para não se
posicionar. A gente tinha um foco de bater no Ministério da Saúde porque para
gente esse era o ente que estava golpeando o país. Os outros, por mais que a gente
tinha crítica, eram atores históricos do SUS (Entrevista 8).

Conforme os dados analisados, a proposição da revisão e sua defesa estão circunscritas aos gestores, o que nos leva a crer que o seu conteúdo minimente dialoga com as demandas concretas dos desafios colocados para a gestão da APS, especialmente na esfera municipal. A questão é o porquê o foco ter sido a flexibilização das diretrizes para composição da equipe dentre as diversas alternativas colocadas na revisão da PNAB 2017.

Nesse sentido, vale a pena observar o fluxo de problemas e a escolha de alternativas, apresentados detalhadamente mais adiante, e considerar as críticas feitas à proposta de revisão. Ao que parece a proposta de alternativa consistiu em escolhas e medidas entendidas como possíveis pelos gestores, além de reativa, diante do contexto de restrição financeira, das dificuldades no provimento de médicos e da gestão e regulamentação do trabalho da categoria dos ACS e ACE.

Na minha opinião, pelo ajuste fiscal, com um governo que era menos comprometido com a reforma sanitária e com uma perspectiva de consolidação da Estratégia de Saúde da Família, ele privilegiou a negociação política com acordos que são fundamentais, que são os gestores municipais, em nome de fazer tocar o resto das políticas do Ministério da Saúde. (Entrevista 9)

De fato, dado o contexto, esses eram os problemas anunciados pelos gestores municipais e a agenda demandada pelos dirigentes da sua entidade representativa, que se mostrou, por sua vez, conveniente ao governo federal. Por outro lado, aos movimentos sociais e ao controle social caberia a intransigente defesa dos direitos, estabelecendo para isso estratégias que avaliaram ser eficientes.

Junto a isso havia a discussão da PEC 241, que se confirmou com a EC 95 . Diante
desse contexto de políticas restritivas, onde se corria o risco de perder recurso das
políticas sociais, algumas medidas que já vinham sendo discutidas nos espaços
colegiado dos gestores da saúde, passam a ter grande possibilidade de serem
implementadas. Naquele momento, o cenário político apresentava que o que se
pretendia mudar estava certo e era necessário defender a PNAB, e ser contra a sua
revisão porque estávamos em um momento restritivo, de perdas de direitos
(Entrevista 8).

Dessa forma, os atores que empreenderam esforços no sentido da aprovação da revisão 
da PNAB 2017 funcionaram como grupos de pressão. O CONASEMS foi o ator que empreendeu maiores esforços na configuração da agenda de revisão, construindo a coalizão de pressão para a sua priorização pelo governo e defesa da proposta pelo CONASS e o Ministério da Saúde. O CONASS teve papel de apoio à agenda apresentada pelo CONASEMS, não tendo interesse mais direto com a revisão, restringindo-se em demarcar a priorização da ESF frente novos arranjos de equipe.

Já o Ministério da Saúde, que vinha protagonizando proposições de arranjos de eAB em uma perspectiva de ampliação e melhoria do acesso, incorporando-as à PNAB a partir de cenários específicos, como o caso da equipe ribeirinha, do Consultório na Rua, do PMAQ e do Mais Médicos, acolhe a demanda do CONASEMS. O MS passa a negociar a proposta, uma vez que representava uma alternativa para o alcance da sua meta orçamentária, que tinha a perspectiva de agravamento com a tramitação da lei que aumentaria o piso dos agentes e as restrições financeiras dadas pela EC 95.

Por outro lado, mesmo nesses grupos, é possível observar camadas de posicionamentos conforme os interesses, a inserção de cada instituição e os respectivos atores. O CONASEMS e o CONASS são entidades representativas e, portanto, seus posicionamentos precisam ressoar o conjunto de secretários municipais e estaduais, respectivamente. Há ainda as assessorias técnicas e os dirigentes das diferentes instituições.

Pode-se dizer que as decisões, as quais são definidoras na conformação da política, são tomadas pelos dirigentes. Todavia, são operadas pelos técnicos, que, em alguma medida, influenciam na apresentação dos problemas e na escolha de alternativas. Essas nuances da atuação dos atores podem ser observadas em suas narrativas, como no caso do pessoal técnico.

\begin{abstract}
Acho que ele veio com papel técnico, de trazer um pouco da realidade que vivencia com apoio no território. Pensar o que eu estou vendo, o que está acontecendo, esse movimento. Trazer um pouco isso para gestão, para o olhar de análise. A maioria dos envolvidos tem uma defesa da causa, de que a gente consiga implementar as ações do SUS, fortalecer atenção básica de fato. Então tem coisas que acabam sendo caras para gente, não dá para perder. Acho que isso acaba fortalecendo, mesmo que a maioria das discussões não terminava num consenso, mesmo entre os técnicos e coordenadores, acho que cada um foi tentando trazer elementos para fortalecer a discussão. A gente tem um ganho maior com a redução de danos com essa revisão (Entrevista 2).
\end{abstract}

Por isso, torna-se relevante questionar sobre o interesse de cada ator da arena de disputa e o que motivou a revisão da PNAB 2017. Ao mesmo tempo que fica claro que a disputa é circunscrita às instituições e ao posicionamento dos seus respectivos dirigentes:

[...] foi muito bom a gente discutir. Foi muito bom dar voz e ouvido em diversos fóruns e congressos. A gente discutiu com todos os COSEMS, teve muita disputa e "poluição", porque teve gente que achou que virou uma disputa político partidária, 
mas foi uma disputa de instituições (Entrevista 4).

Já o conjunto de movimentos que se opuseram à revisão da PNAB 2017, liderado pelo CEBES, pela EPJV/FIOCRUZ e pela ABRASCO, aglutinaram forças em torno do CNS, que se constituiu como um importante palco da arena de disputa. Graças às intervenções do CEBES, da ABRASCO, da EPJV/FIOCRUZ e da Rede Unida, a discussão sobre a revisão da PNAB entrou na pauta do CNS, o que deu maior projeção nacional à discussão de revisão da PNAB 2017, prolongando o debate sobre a proposta e a negociação do que entrou ou não na portaria de revisão. Entre a pactuação da proposição de revisão da PNAB na CIT e a publicação da portaria de revisão passou o período de 1 ano.

A proposição da própria consulta pública proposta pelo CNS, que deu maior dimensão à publicização da agenda de revisão da PNAB e contou com mais de 6 mil contribuições, elevou a pressão dos olhares sobre o processo em andamento. Desta forma, esses grupos conseguiram que o CNS se tornasse uma arena central na disputa para o bloqueio da agenda de revisão. A principal estratégia utilizada foi a constante denúncia e alerta sobre os impactos da proposta de revisão, não havendo, portanto, a disposição para discutir as propostas de texto para a revisão da PNAB 2017.

Em 2017 teve toda uma polêmica que partiu de um grupo que era contra a revisão da PNAB. Chamavam a atenção que todas essas mudanças na PNAB vinham no contexto de mudança de governo e estavam atreladas a um desmonte do sistema e do direito à saúde (Entrevista 6).

Outro importante movimento para a ampliação da coalizão para o bloqueio da agenda foi a articulação com o movimento dos ACS. Com isso, a discussão da revisão da PNAB extrapolou a arena do CNS e passou a estar presente no Congresso Nacional por meio de audiências públicas e pressão sobre o governo.

O ACS atuava mais junto ao Congresso. Mas a partir do evento na Fiocruz (seminário “Os desafios para Atenção Básica no SUS”, realizado em 9 de agosto de 2019 pelo CNS) a gente começou a trazer o ACS para o CNS. Eles demoraram para entender a PNAB, estavam preocupados em garantir suas atribuições com a discussão no Congresso, porque entendiam que uma lei era maior que uma portaria, mas o pessoal da Joaquim Venâncio e a gente começou a alertá-los sobre os riscos da PNAB flexibilizar a sua obrigatoriedade na equipe. Aí eles entenderam que não dava somente para fazer a política de boa vizinhança e que só a lei não garantia o seu emprego (Entrevista 8).

Observa-se que, embora a coalizão para o bloqueio da agenda de revisão da PNAB tenha conquistado uma grande amplitude e feito muita pressão sobre o governo, não foi possível alterar a correlação de forças, determinada pelo o alinhamento entre os dirigentes das instituições gestoras, que têm prerrogativa na definição das decisões na CIT.

Todavia, ainda fruto dessa articulação, o movimento dos ACS passou a compor o CNS e continua sendo fundamental nos desdobramentos da revisão da PNAB 2017, a qual ainda 
segue em processo.

Mas a partir da discussão sobre a revisão da PNAB, os ACS passaram a ser conhecidos pelo Controle Social e houve a aproximação dos ACS com o movimento de defesa do SUS. Essa aproximação do Controle Social foi importante, porque para o pedido de revogação da Portaria no Congresso, era fundamental o apoio das entidades dos ACS e sua articulação no Congresso (Entrevista 8).

Destaca-se, ainda, que, como resultado da formação da coalizão que buscou bloquear a proposta de revisão da PNAB, mesmo diante da aprovação da portaria que instituiu as novas diretrizes da PNAB, o CNS deliberou por dar continuidade ao debate sobre a Política, conforme observado na Resolução nº 572 , de 31 de janeiro de 2018:

Criar a Câmara Técnica da Atenção Básica (CTAB/CNS), com o objetivo de discutir a efetivação da Política Nacional de Atenção Básica (PNAB) no Brasil e sua interface com o modelo de atenção à saúde focada na promoção, prevenção e proteção da saúde, no intuito de propor as alterações necessárias na PNAB, bem como as estratégias para que o controle social desenvolva, de forma permanente para garantir a atenção básica como a principal estratégia de inclusão social e de garantia de acesso à assistência à saúde nas condições e direitos previstos na Constituição Federal de 1988 (CNS, 2018).

A criação da Câmara Técnica da Atenção Básica pode trazer ganhos ao controle social à medida que ficou evidente a dificuldade de o tema mobilizar seus membros e entrar na pauta das reuniões do Pleno do CNS. Além disso, com a perspectiva do tema se manter na pauta de prioridades da política de saúde, torna-se fundamental analisar os efeitos da política para subsidiar os debates do controle social.

\subsection{O ADENSAMENTO DE PROBLEMAS E A ESCOLHA DE PROPOSTAS DE ALTERNATIVAS}

Apesar de, segundo KINGDON (2003), os múltiplos fluxos apresentarem uma dinâmica independente, optou-se por apresentá-los em associação, uma vez que apareceram desta forma na coleta de dados. Sugere-se que essa tendência seja devido à natureza das fontes de dados, pois instâncias de deliberação, como a CIT e o CNS, pautam determinados temas associados à escolha de alternativas e à discussão dos encaminhamentos.

Registra-se, ainda, que serão apresentados os temas que se mostraram mais relevantes na análise dos dados, com destaque aos dois últimos subtópicos relacionados às mudanças no modelo de atenção, conforme objetivo do estudo. 


\subsubsection{Arboviroses, Baixa Cobertura Vacinal e Integração entre a Vigilância em Saúde e a Atenção à Saúde}

Os problemas relacionados ao aumento da incidência das arboviroses e da baixa cobertura vacinal são temas que se destacaram no conjunto das discussões. Embora estejam sob responsabilidade técnica da Vigilância em Saúde, são entendidos como problemas associados à APS à medida que as ações de vigilância, prevenção e controle são executadas de fato no território, onde atuam e são de responsabilizadade, principalmente, das equipes de atenção básica.

O início do período analisado coincide com a identificação dos primeiros casos do zika vírus no Brasil, registrados a partir do início do primeiro semestre de 2015, seguido pelo aumento do número de casos de microcefalia no segundo semestre do mesmo ano (ALBUQUERQUE et al., 2018), assim como surtos de dengue e registro de queda da cobertura vacinal a partir de 2016, que levaram ao reaparecimento de casos de sarampo (CONASS, 2017).

Essas questões foram apresentadas pelos gestores nas discussões da CIT, sendo monitoradas constantemente a cada reunião. Destaca-se que, no caso da queda da cobertura vacinal, as causas foram atribuídas a fatores alheios à vigilância, conforme as afirmações da Coordenação Geral do Programa Nacional de Imunização da Secretaria de Vigilância em Saúde do Ministério da Saúde (CGPNI/SVS/MS) nas discussões da CIT: “[...] possivelmente o esquema de vacinação não esteja sendo cumprido por alguns profissionais de saúde e pelas famílias" e "Reforçou a necessidade repensar o modelo de imunização do SUS e discutir a efetividade das salas de vacinas" (CIT, 2017, p. 9-10).

As afirmações da CGPNI, responsável pelo Programa Nacional de Imunização (PNI) causam estranhamento, pois, no momento da explicação do problema à CIT, atribuiu a responsabilidade a elementos externos à sua própria competência. Ao inferir que o problema da baixa cobertura vacinal é devido ao não cumprimento do esquema vacinal na APS, remetendo ao comprometimento das famílias e dos profissionais, ignorou o desabastecimento de insumos e imunobiológicos, justificado em reuniões anteriores da CIT pelo próprio Ministério da Saúde. Não considera também as dificuldades de acesso e a burocratização dos serviços, produzidas pelas excessivas normatizações definidas pelo nível central.

A integração entre a Vigilância em Saúde e a Atenção à Saúde está relacionada diretamente aos elementos contextuais descritos acima. Provocado pela questão dos surtos e das epidemias do período, além dos alertas sobre a queda da cobertura vacinal, o MS afirmou 
serem necessárias ações emergenciais, bem como uma agenda concreta para o enfrentamento da situação. Esse contexto explica a relevância que a incorporação da integração entre a Vigilância em Saúde e a Atenção à Saúde ganhou na discussão e texto de revisão da PNAB.

Essa demanda de integração, tanto a integração da atenção básica, quanto da vigilância, já vem de algum tempo, desde a época das NOBs. Então em alguns momentos é uma agenda que vem mais puxada pela SVS e alguns momentos pela atenção básica. No processo de revisão houve a discussão de integração de fato, de onde nós enxergamos mais essa integração. Teve uma conotação maior com a questão da Zika principalmente. A gente iniciou pelo Zika e Dengue, arboviroses. Era uma agenda comum, tinha uma questão epidemiológica importante para o país, e que alavancou de fato, conseguiu trazer de forma mais efetiva para dentro da política (Entrevista 2).

Outra questão que emerge do tema da integração entre a Vigilância em Saúde e a Atenção à Saúde diz respeito à integração das ações entre os ACS e os ACE, que viria aparecer nas discussões da revisão da PNAB. Esses profissionais estão sob a coordenação da APS e da Vigilância em Saúde, respectivamente. Como será tratada mais adiante, a definição das suas atribuições, o vínculo e a remuneração são assuntos sensíveis para os gestores, uma vez que não estão sob sua governabilidade, pois a discussão da regulamentação da profissão foi articulada pela categoria no Congresso Nacional.

Havia também no horizonte a proposta de unificação das atribuições dos ACS e dos ACE, como também a unificação da própria categoria em um único agente de saúde, proposta pelo CONASEMS, mas que não avançou.

\subsubsection{Apoio Logístico e Infraestrutura}

Este tema aparece relacionado a um leque bastante amplo de perspectivas de análise, pois condiciona a questão da expansão da cobertura e da indução de modelo, do PMAQ e dos padrões essencial e ampliado, do arranjo e da composição de equipe e do provimento e da qualificação dos profissionais. Nos registros analisados, o tema aparece mais diretamente citado como um importante desafio da APS e nas iniciativas do MS relacionadas ao apoio clínico-pedagógico em associação à regulação, como o mecanismo de articulação da APS com a rede de atenção.

No que se refere ao apoio logístico para a articulação da APS com a rede de atenção, os sistemas de informação aparecem massivamente nas discussões dos gestores na CIT, sendo o processo de informatização das Unidades Básicas de Saúde (UBS) e a implantação do Prontuário Eletrônico do Cidadão (PEC/e-SUS) apresentados como alternativas para favorecer a coordenação do cuidado e a articulação da APS com a rede. 
É possível, mas é muito difícil você fazer coordenação do cuidado e comunicação informacional entre os profissionais da atenção básica e especialistas, etc., da rede como um todo. Precisa ter o prontuário e o registro eletrônico de saúde, para o compartilhamento de informações entre os serviços. O médico da atenção básica pode ver o que está acontecendo com o usuário que ele encaminha na unidade, ter maior comunicação com os outros profissionais, acho que isso é muito central (Entrevista 3).

Ainda sobre a infraestrutura, os documentos analisados permitem observar que o Programa de Requalificação das Unidades Básicas de Saúde (Requalifica UBS), instituído em 2011, cujo objetivo é apoiar e financiar a melhoria das condições de infraestrutura por meio de reforma, ampliação e construção de UBS nos municípios, é apresentado como resposta bem-sucedida frente ao problema de inadequação da infraestrutura das unidades de saúde. Todavia, a discussão presente entre os gestores indica uma dificuldade dos municípios na execução do recurso e na conclusão da obra no tempo previsto, o que aponta para a necessidade de avaliar o número de municípios contemplados pelo Programa e o percentual de execução no tempo estimado, bem como os mecanismos administrativos destinados para a transferência dos recursos e a execução das obras conforme o planejado.

Observa-se, ainda, que no início de 2015 houve a incorporação do Requalifica UBS ao Programa Mais Médicos, como um de seus eixos, conforme os registros das reuniões da CIT e do CNS. Cabe ressaltar que a própria APS, a partir do Programa Mais Médicos, o qual é apresentado como prioridade do governo, foi incorporada à agenda.

\subsubsection{Expansão da Cobertura, Provimento e Formação Médica}

A partir das entrevistas, nota-se um consenso entre os diferentes atores de que uma cobertura adequada é fundamental para uma resposta efetiva da APS. Por outro lado, a revisão da PNAB trouxe à tona o dissenso sobre como induzir esse processo e a real capacidade dos municípios em cumprir com essa agenda da forma como vinha sendo estabelecida.

[...] não tem outro jeito senão ampliação do número de equipe de saúde da família, de atenção básica se quiser. Então, precisaríamos fazer um maior investimento na atenção básica, um aumento maior dos orçamentos, destinar a atenção básica para a gente aumentar tanto as coberturas populacionais, aumentar o número de equipes, quanto diminuir o número de pessoas vinculadas a cada equipe, o que ainda é muito alto, isso compromete a qualidade da atenção básica (Entrevista 3).

Dois elementos aparecem como preponderantes do ponto de vista da força de trabalho necessária para a composição da equipe e, portanto, para a expansão da cobertura de Atenção Básica. O primeiro corresponde à questão da falta e/ou à dificuldade de atração de médicos com formação adequada para atuar na APS e o segundo, à questão da regulamentação em torno da categoria dos ACS. 
[...] falha na formação médica, pois os profissionais não conseguem conduzir clinicamente pacientes com pequenas alterações, encaminhando para o especialista, resultando em um dos principais problemas do sistema de saúde que são as filas (CIT, 2015).

Essas duas questões, determinantes na expansão da cobertura de Atenção Básica, estão presentes no debate sobre a indução do modelo de atenção orientado pela ESF. E, desde a revisão da PNAB de 2011, o provimento e a formação médica foram elencados como demanda dos gestores.

O tema da Atenção Básica em 2010 era flexibilização da Estratégia de Saúde da família. Era um discurso de que "atenção básica e saúde da família não funciona, era bonita no papel, mas não tem médicos, os médicos não têm perfil, não tem que só pensar em médico, mas falar da Estratégia de Saúde da família sem médico é falar que ela tem uma resolubilidade menor. O tema era esse porque, por exemplo, a presidenta (Dilma) quando rodou o Brasil, os prefeitos e os governadores só falavam para ela que não tinha como ter médico e ela tinha que rever a política de atenção básica, que exigir quarenta horas e exigir um perfil de profissional que faz visita domiciliar, trabalha em equipe, não era possível (Entrevista 9).

As condições dadas pelo provimento, regulação e gestão do trabalho dos profissionais influenciaram nas escolhas dos gestores sobre o arranjo e a composição de equipe, colocando em segundo plano a discussão e a escolha de indução do modelo tecnoassistencial na APS, e têm forte influência sobre as motivações para a revisão da PNAB de 2017.

Mas, fora isso, os mais evidentes, que sempre produziram crise política é a falta de médicos, preço dos médicos e financiamento global da atenção básica. Esses sempre foram os que deram tensões. Então, desse ponto de vista, eu acho que ali em 2014, estava em um momento muito bom porque até 2014 o financiamento aumentou bastante, produzindo alívio para os gestores municipais e em 2013 teve o lançamento do Mais Médicos. Foi a resposta mais contundente para o problema da falta de médicos e com perfil na atenção básica (Entrevista 9).

Enquanto elementos conjunturais, o subfinanciamento crônico e a agenda restritiva imposta pelas crises econômica e política são definidores na escolha das preferências dos atores.

Eu acho que um dos principais gargalos é o financiamento. Uma atenção básica de qualidade é cara. Se a gente quer uma atenção básica que resolva 80 a $85 \%$ dos problemas, vai ter que investir e acho que a gente tem que começar. Acho que já deu uma melhorada na questão de estrutura, a questão profissional, mas aí nós já temos um problema agora com relação ao Mais Médicos (no final de 2018 já se previa a extinção do programa com o novo governo). Essa fixação, o problema nosso não é com grande centro, o problema é que tem local que não vai. A gente já não tem a nossa cultura de formação pensando nisso, nós não temos uma política de estado (Entrevista 5).

$\mathrm{Na}$ hipótese de o provimento e a formação médica consistirem em um problema estrutural para a expansão e a resolubilidade da APS, o Programa Mais Médicos, instituído em 2013, em resposta à demanda dos prefeitos, aparece como ponto de pauta ou informe em todas as reuniões da CIT analisadas. No início de 2015, a partir do Programa Mais Médicos, 
que elenca os eixos de formação, estrutura e provimento como pontos fundamentais para o fortalecimento da PNAB, a APS é eleita como prioridade do segundo mandato do governo Dilma Rousseff.

Observa-se na CIT, até o primeiro semestre de 2016, além das pautas e dos informes relacionados ao eixo de provimento emergencial de médicos, uma intensa discussão e encaminhamento de propostas relacionadas também ao eixo de formação do Programa Mais Médicos, responsável por profundas mudanças nas diretrizes de formação da medicina e na ampliação da oferta de vagas do curso de medicina (OLIVEIRA et al., 2019).

A partir do segundo semestre de 2016, que coincide com o afastamento definitivo da Presidente Dilma Rousseff, determinado pelo impeachment em agosto de 2016, além de uma revisão da normativa relacionada ao Programa, passam a vigorar na CIT apenas informes relacionados aos editais de substituição e reposição de médicos, sendo o Programa Mais Médicos descolado das questões de infraestrutura e formação que afetam o desenvolvimento da PNAB. Por outro lado, a partir do segundo semestre de 2016, a questão passa a ser pauta nas reuniões do CNS.

[...] o Pleno decidiu: solicitar à Secretaria de Gestão do Trabalho e da Educação na Saúde (SGTES) o envio de informações detalhadas sobre o Programa, para serem distribuídas aos conselheiros; definir o tema como pauta permanente da CIRHRT/CNS, para debate e monitoramento; e pautar informes permanentes sobre o Programa Mais Médicos nas reuniões do Conselho (CNS, 2016).

\subsubsection{Acesso, PMAQ e Padrões Essenciais e Ampliados}

Enquanto elemento de análise, o acesso está relacionado a questões estruturais, como a cobertura de Atenção Básica, o número de pessoas vinculadas à equipe de saúde e a necessidade de definição do escopo de ações sob responsabilidade das equipes. Por outro lado, está relacionado a questões do processo de trabalho, sendo reflexo da discussão do modelo de atenção e das diretrizes para a organização das atividades da equipe, como o tipo de agendamento de consulta.

Tem que melhorar o acesso, sem restrição de dia de atendimento para segmento específico. No país você tem pelo menos duas perspectivas. Tem o grupo que acredita que o trabalho deve ser organizado conforme a demanda espontânea, baseado no atendimento de consulta, que corre o risco de perder de vista os atributos da Atenção Primária e tem o grupo que organiza o trabalho em uma agenda restritiva, a partir dos segmentos e programas como dia do pré-natal, dia da criança, etc. (Entrevista 7).

Na mesma medida, o PMAQ figura como estratégia (alternativa) da gestão, como o próprio nome do Programa anuncia, para a melhoria do acesso e da qualidade, constando principalmente nas discussões da CIT enquanto tema de negociação da proposta para o $3^{\circ}$ 
ciclo do Programa e das etapas da avaliação. O Programa também é apresentado pela gestão federal como uma alternativa para estabelecer o parâmetro do rol de ações e atividades das eAB, sendo um dispositivo para a definição da discussão dos padrões essenciais e ampliados, e incorporado à revisão da PNAB 2017.

Eu acho que se a gente não conseguir aumentar de maneira expressiva a capacidade da atenção, não resolver de fato as necessidades da população, a gente vai ficar nesse negócio de falta de reconhecimento e legitimidade, que aí as pessoas vão para o pronto socorro, para a UPA. Elas saem dali com os seus problemas resolvidos, e a atenção básica ainda está com a maior parte das equipes ofertando muito pouco... os dados do PMAQ mostram isso, a maioria das equipes ainda tem uma oferta muito restritiva (Entrevista 3 ).

Na portaria da PNAB 2017, a questão dos padrões essenciais e ampliados é apresentada por um texto conceitual sintético, atrelando a definição de seu escopo às necessidades e aos critérios locorregionais, negociados entre os atores, incluindo o controle social. O texto sobre esse dispositivo é propositalmente vago e aponta para a criação de uma lista de ações e serviços associada ao financiamento, a ser definida em regulamentação específica.

$\mathrm{Na}$ discussão de qualificação das unidades começamos a pensar em carteira de serviços, tentando trabalhar com necessidades da população e o que que as unidades precisam fazer. Foi discutido carteira de serviços nesse sentido, fomos discutir com a Sociedade Brasileira de Medicina de Família e Comunidade e também tivemos consultoria (Entrevista 6).

Embora a introdução da discussão da relação de ações e serviços de APS tenha sido um ponto bastante polêmico, a inclusão dos ditos padrões essenciais e ampliados não se apresentou exatamente como motivação para a agenda de revisão da PNAB 2017.

O PMAQ não é uma carteira de serviço, mas ele declarava ali um conjunto de coisas, se entendia que toda a equipe de atenção básica, da família, tinha que fazer. Então a gente vinha acumulando nessa discussão, a gente acreditava na importância de se ter uma carteira de serviço naquela perspectiva de empoderamento de gestores e trabalhadores, e usuários, eu acredito nisso e várias pessoas, técnicos, acreditavam na época que era importante cada usuário, cidadão brasileiro, saber, por exemplo, o que esperar em uma unidade básica de saúde e reivindicar isso com o seu prefeito, seu secretário, etc., os trabalhadores reivindicarem melhor qualificação para poder dar conta daquela carteira de serviço. Então, a carteira de serviço é uma agenda, para nós, muito positiva, uma agenda que fortaleceria a atenção básica (Entrevista 3).

Também não se identificou uma coalizão que tenha se dedicado para a sua entrada na revisão. Ou seja, embora tenha havido uma contribuição específica do DAB/MS, a partir das experiências acumuladas com o PMAQ, e do CONASEMS, que também já vinha discutindo a carteira de serviços a partir da experiência de alguns municípios e forte influência de consultores ligados ao movimento da medicina de família, para a estruturação da APS, não se tinha uma proposta consolidada sobre essa questão. Portanto, não foram identificados elementos contundentes para afirmar que a incorporação da ideia de padrões essenciais e 
ampliados à PNAB representava uma agenda do governo sobre a definição de uma APS seletiva.

Nesse sentido, é esclarecedor o registro da $61^{a}$ Reunião Extraordinária do CNS, que contou com o Seminário sobre a Política de Atenção Básica, em que uma das palestrantes destacou:

\begin{abstract}
A respeito de Cobertura Universal de Saúde versus SUS - cobertura universal em saúde versus sistemas universais, explicou que há uma disputa entre expandir cobertura com seguros focalizados (públicos ou privados) e cuidados básicos cristalizando iniquidades e garantir acesso universal com equidade conforme necessidades, independente da renda, em sistemas públicos universais de saúde como o SUS. Nas propostas de Cobertura Universal de Saúde, cesta básica - carteira de serviços é instrumento utilizado para definir oferta seletiva de procedimentos acoplada à implementação de seguros focalizados, como atualmente difundidos por agências internacionais para a chamada cobertura universal (CNS, 2017).
\end{abstract}

Por outro lado, a mesma palestrante ponderou:

A implantação de uma relação nacional de ações e serviços essenciais e estratégicos
da $\mathrm{AB}$, afirmou, poderia contribuir para a garantia de padrões essenciais mínimos
mais qualificados e uniformes em todas as unidades básicas de saúde do país e
mesmo de padrões estratégicos mais avançados de acesso e qualidade. Esta é uma
disputa sempre presente e a direcionalidade depende da constelação de forças
políticas em cada momento histórico (CNS, 2017).

Os apontamentos sobre a questão dos padrões essenciais e ampliados que foram associados a uma agenda de APS seletiva contextualizam-se em meio à discussão da cobertura universal versus sistema universal. Eles foram apresentados como ponderações ou críticas pelos grupos contrários à revisão da PNAB 2017 e estão associados a um contexto mais amplo, o que aponta para a possibilidade de ter havido um posicionamento estratégico frente ao contexto de polarização política, restrição financeira e perda de direitos. Naquele mesmo momento, o Ministro Ricardo Barros apresentava a proposta dos planos de saúde acessíveis, a qual será abordada adiante, destacando-se como uma agenda que contradiz o direito universal à saúde e a integralidade do cuidado.

\title{
5.2.5 A Disputa de Modelo de Atenção Expressa na Proposta de Plano de Saúde Acessível e a Discussão de Arranjo de Equipe
}

Quando o PSF foi instituído, em 1994, pelo Ministério da Saúde, para a reorientação dos serviços de atenção à saúde, há também a instituição do PAB Variável, incentivo financeiro para a implantação e o custeio das equipes. Conforme o estudo de MACHADO et al. (2011, p. 524), a presença da ESF na agenda de prioridades dos governos, "também foi 
evidenciada por um aumento expressivo de gastos com o programa e pela sua influência na definição de propostas nos vários campos de atuação em saúde".

No debate do CNS sobre a PNAB 2017, destacou-se o papel central da indução financeira para o avanço do modelo de atenção alicerceado na ESF.

Frisou que é necessário reconhecer os avanços da $\mathrm{AB}$ e seus efeitos positivos no acesso a serviços de saúde e na saúde da população. Acrescentou que o sucesso da expansão da atenção básica no SUS no país nos últimos anos decorre da continuidade da indução financeira da Estratégia Saúde da Família sustentada ao longo do tempo (CNS, 2017).

Entre outros fatores, a expansão da cobertura de ESF foi atribuída à priorização do modelo e ao seu financiamento específico. Por isso, na PNAB 2017, a introdução do financiamento do arranjo da chamada $\mathrm{eAB}$ foi interpretada como um abandono da priorização da ESF e sintoma da disputa do próprio modelo de atenção.

Essa ideia de disputa de modelo de atenção, na leitura dos segmentos críticos da PNAB 2017, surge como reflexo da mudança na correlação de forças na base social que sustenta a ideia de um sistema universal, estruturado a partir de uma APS abrangente e integral.

O principal desafio é a disputa de modelo. Ainda é a disputa de modelo, ainda é a contratação social a respeito de como é que se produz essa relação econômica da saúde no País. Ainda é hegemônica a lógica da relação de consumo. Esse é um dos principais desafios e gargalos de fazer a atenção básica avançar, porque ela é talvez a espinha dorsal do enfrentamento dessa lógica, ela é a espinha dorsal da mudança de modelo. Então, a força que tem ainda essa característica quando você for pegar os números da atividade econômica, você vai perceber que quase $60 \%$ da atividade econômica é presidida pelo capital privado (Entrevista 1).

O trecho a seguir situa o centro da disputa de modelo de atenção no qual a discussão de priorização e de indução da ESF está inserida:

A mudança do modelo de atenção, enquanto modelo de atenção para superar o modelo neoliberal, privatista, centrado na doença, uni profissional, centrado no médico, esse é o maior desafio. Agora, esse é um desafio complexo, é um desafio de mudança cultural, é um desafio que tem que intervir no mercado de trabalho, tem toda a complexidade, se a gente for analisar a produção da saúde coletiva (Entrevista 9).

Na percepção da direção da entidade dos gestores municipais da saúde, a flexibilidade no arranjo de equipe não expressava um desejo de mudança de modelo de atenção:

Uma coisa muito forte foi essa, do modelo, pois não queremos acabar com o modelo de atenção que o Brasil adotou, reconhecemos que a Estratégia Saúde da Família é o nosso carro chefe. Mas até para conseguir dar conta e qualificar, porque só a indução do Ministério não dá conta, precisa conhecer outros modelos e até dependendo da conformação do território a Saúde da Família não dá conta, porque me obriga, por exemplo, a ter ACS onde ele não vai (onde a necessidade é outra). Onde, como em grandes centros urbanos, outros profissionais, como aquela discussão do técnico de enfermagem compor, mesclar agente, essa discussão da composição de equipe. Haviam outras proposições de mais possibilidades de composição e modelagens de equipe, mas o que a gente conseguiu foi essa da eAB e eSF diante da briga política 
do ACS. Mas tinha a proposta, de quem vai decidir isso, tem que ser a equipe, o território com o gestor na ponta (Entrevista 4).

Pelos documentos e narrativas analisados, a discussão sobre o arranjo e a composição de equipe sempre esteve presente ao longo do processo de desenvolvimento da APS no Brasil e está contida na fala de diferentes atores como um tipo de equipe ou modelagens de equipe, por vezes considerando como uma discussão de modelo de APS.

Na revisão da PNAB 2017, essa discussão emerge a partir da demanda dos gestores municipais, associando o regramento para a composição de equipe a uma excessiva normatização que não se adequava às demandas regionais.

O que os gestores traziam nas reuniões era os sentimentos deles, as suas dificuldades de fazer acontecer a Atenção Básica com tanta diversidade e com uma PNAB que colocava uma regra única para todo o país. E também tinham as situações de grandes centros, que apresentava uma realidade diferente (Entrevista 6).

Foi bastante presente na narrativa dos gestores a crítica sobre a centralidade excessiva do MS na condução e na normatização da política de saúde, que, por meio da indução financeira, descentralizou ações, sem necessariamente descentralizar poder aos estados e municípios.

[...] quando o governo central é muito prescritivo ele compromete essa capacidade de inventividade que eu estou chamando, por quê? Porque ele fica forçando todo mundo, o tempo inteiro, por causa do dinheiro, por causa do PMAQ, por causa de não sei o que, todo mundo a ficar fazendo do mesmo jeito tudo e eu acho isso também ruim (Entrevista 3).

Como proposta de alternativas a essas questões, observa-se na revisão da Política, pontos que geraram polêmica, como a unificação dos blocos de financiamento e a flexibilização dos parâmetros estabelecidos pela própria PNAB 2017.

$\mathrm{Na}$ discussão são observados relatos de experiências que vinham sendo realizadas como forma de adaptação da ESF às realidades e às características locorregionais. Uma delas, bastante citada, diz respeito à Região Norte do País, caracterizada pela dispersão populacional em extensas áreas geográficas, acessadas pela trajetória dos rios e dinâmica das águas. Em outro polo figuram os grandes centros urbanos, com características diversas de vulnerabilidade e desigualdade social.

[...] até 2011 a PNAB não previa a história da unidade básica de saúde fluvial, alguns gestores na região norte fizeram uma certa adaptação do modelo saúde da família, que depois virou a UBS Fluvial e as equipes ribeirinhas, a PNAB não previa isso (Entrevista 3).

Realmente, ao longo do desenvolvimento da PNAB, principalmente a partir de 2011, portarias e regulamentações complementares foram legitimando o incremento de arranjos e tipos de eAB, bem como o reconhecimento da própria eAB na ESF. 
E do ponto de vista da eAB, meio que fazendo um paralelo da equipe, eu já tinha portaria que permitia às parametrizadas (para fins de participação no PMAQ). Era considerada como estratégia de saúde da família, o arranjo de dois médicos de 30 horas (Entrevista 5).

O reconhecimento da $\mathrm{eAB}$, para fins de avaliação no PMAQ, foi utilizado enquanto parâmetro para a discussão do que seria identificado como equipe financiável pelo MS:

Assim como no PMAQ a gente tinha as equipes parametrizadas, que são junções de cargas horárias de profissionais - médico, enfermeiro, dentista - que compõem como se fosse uma equipe de $\mathrm{AB}$, mas a gente chama de parametrizada porque o único funcionamento dela é pelo PMAQ. Conforme o seu despenho, é definido o valor que ela recebe. E elas se equiparam muito com as equipes de saúde da família (Entrevista 2).

Essas adaptações incluíam a discussão de perfis profissionais para a composição da equipe que, a partir da PNAB 2011, passam a incorporar diferentes tipos de eAB, como a ESF Ribeirinha e o Consultório na Rua.

[...] o Consultório na Rua no final de 2011 entrou para ser uma equipe de atenção básica e não tinha Agente. Foi o segundo caso. Discutindo isso, em 2013, começou uma demanda e a gente começou a amadurecer uma ideia de que tinha que ter uma equipe, e era uma equipe que o perfil dela era de uma região menos vulnerável, lugares que não precisavam tanto daquele papel que o Agente faria. Então não precisavam que o Agente estivesse todo mês na casa daquela pessoa, precisavam do Agente focado em uma população mais vulnerável, que era uma população menor no território e que mais importante era ter um técnico de enfermagem que atuasse nos domicílios porque tinha muito idoso, muita doença crônica e muita demanda de cuidado domiciliar (Entrevista 9).

Portanto, o gradativo reconhecimento de diferentes arranjos e tipos de equipe, dada a necessidade de adaptação às diferenças e especificidades locais, representa um elemento importante da trajetória da PNAB, sendo utilizado como argumento na proposição de reconhecimento e financiamento das $\mathrm{AB}$ enquanto proposta de alternativa.

De acordo com a interpretação de uma das entrevistas, há uma diferença entre a demanda de arranjos de equipe prevista na PNAB 2011 e a PNAB 2017. No primeiro caso, buscava-se uma diversificação com a perspectiva de melhoria do acesso; enquanto que, no segundo, tencionava-se uma flexibilização para um menor grau de exigências diante de um cenário de restrição financeira.

Era o contexto de o dinheiro está pequeno, o dinheiro está curto, vem um longo inverno pela frente, que a crise já tinha batido na porta e eu preciso ter mais flexibilidade para eu poder decidir onde é que eu vou gastar. Tanto é que o debate da portaria vem antes, mas na sequência vem a desregulamentação do financiamento. Essa história de acabar com os blocos (Entrevista 9).

Embora a proposta de reconhecimento da $\mathrm{eAB}$ para fins de financiamento esteja interligada à questão da não obrigatoriedade do ACS na equipe, atendendo a uma demanda dos gestores municipais, a sua essência respondia também à demanda de flexibilização da 
carga horária do médico para a composição de equipe e o reconhecimento para fins de financiamento daquilo que já existia em alguns lugares, como nas cidades das Regiões Sul e Sudeste $^{11}$ (PINTO, 2018).

Essa proposta de alternativa foi apresentada pelo CONASEMS e entra para a agenda do governo no início de 2016. O registro do resumo executivo da CIT, de 31 de março de 2016, apresenta a seguinte pactuação: “Criação de uma nova modalidade para a equipe de saúde da atenção básica".

Os atores, sobretudo os gestores, tinham consciência da agenda de revisão da PNAB a partir da demanda de mudanças nas diretrizes para a composição de equipe. O provimento de médicos e o questionamento sobre a atuação e regulamentação dos ACS estavam entre os principais vetores desse processo.

[...] vários secretários já questionavam essa coisa da atuação política do agente comunitário de saúde, a perda histórica das suas funções quando a gente pensa naquilo que motivou a criação dos agentes lá na década de 90 , enfim, várias contestações. A crise das arboviroses de 2015 foi um momento ${ }^{12}$, se em 2014 foi o disparador, 2015 foi um momento decisivo, tanto é que de janeiro até maio de 2016 esse debate não saia da agenda. Por que que eu falo maio de 2016? Porque foi quando foram publicadas as portarias 958 e 959 , isso está tudo interligado com a PNAB 2017. No meu entendimento de como é que essas coisas foram desembocar na PNAB de 2017, tá? As portarias de 958 e 959, que que elas definiam? Que havia possibilidade de equipes de saúde da família existirem sem agentes comunitários de saúde, era isso que estava no texto (Entrevista 3).

Nesse outro trecho de entrevista, o questionamento e as justificativas para a flexibilização das diretrizes para a composição de equipe não estão no arranjo da equipe em si, mas no impacto financeiro que a flexibilização traz ao município.

\begin{abstract}
A nossa proposta no sentido da revisão e do reconhecimento desses modelos é pelo seguinte: Eu tenho uma limitação imposta pela lei de responsabilidade fiscal, eu tenho uma limitação histórica de financiamento, onde o que era o financiamento do Ministério há um tempo, hoje já representa bem menos e o investimento do município foi o que mais cresceu, então, tivemos uma inversão disso aí. E eu tenho que priorizar, não adianta eu continuar com o modelo que não me atende, que não atende a necessidade da população sem financiamento, porque a minha limitação é a mesma (Entrevista 5).
\end{abstract}

A Lei de Responsabilidade Fiscal, aprovada como Lei Complementar em maio de 2000, já impunha limitações aos gestores para o desenvolvimento do sistema de saúde, uma vez que estabelece que a despesa total com pessoal, em cada período de apuração e para cada ente da Federação, não pode exceder os percentuais da receita corrente líquida, que para os

\footnotetext{
${ }^{11}$ Considerando subtipos de equipe eAB cadastradas no CNES em setembro de 2017, as Regiões Sul e Sudeste agregam $21 \%$ e $67 \%$ dessas equipes, respectivamente. Disponível em:

$\langle$ http://cnes2.datasus.gov.br/Lista Tot Equipes.asp $>$

${ }^{12}$ Refere-se às dificuldades no processo de integração do ACE na ESF e das ações entre os ACS e os ACE para o combate das epidemias de dengue, chikungunya e zika.
} 
municípios é de no máximo 60\% no total e destes, 54\% para o Executivo (BRASIL, 2000). Essa já era uma questão importante e que atravessava a perspectiva de expansão de equipes, considerando as limitações impostas pela exigência do tipo de vínculo dos ACS e o cenário de restrição econômica.

Além da questão do ACS, outro ponto criticado na proposta da eAB é o da flexibilização da carga horária dos profissionais para a composição da equipe que, em detrimento da coordenação e da longitudinalidade do cuidado, estaria atendendo o interesse corporativista da categoria médica e do mercado privado.

Nesse sentido, é esclarecedor o posicionamento da Federação Nacional dos Médicos (FENAM), que representava no CNS o posicionamento das entidades médicas tradicionais frente ao debate sobre os modelos de atenção e as prioridades para a área:

Falou que, perpassando governo, ideologia e partido, a gestão estava sendo
incompetente e ignorante. Falou que médicos têm denunciado há muito tempo o
foco na Atenção Básica, pois "a Federação Nacional de Médicos não esquece a sua
responsabilidade social". Disse ser preciso ter mais hospitais e atendimento
secundário. Disse que a proposta de piso para carreira médica foi vetada durante os
governos Itamar Franco e Fernando Henrique Cardoso, por pressão de prefeituras, e
estados (CNS, 2015).

Outro elemento importante da associação da proposta de eAB à discussão sobre a disputa de modelo está relacionado ao fato de a proposta ter sido protagonizada pela gestão de Ricardo Barros à frente do MS, durante o governo de Michel Temer. No início de sua gestão, o então Ministro fez as preocupantes declarações: “O orçamento é finito, não há recursos ilimitados ${ }^{13}$ ", em alusão à proposta de rever o direito à saúde integral previsto pelo SUS e garantido na Constituição. Na sequência, ao propor plano de saúde popular como alternativa ao SUS, declarou: "Sou Ministro da Saúde, não sou só Ministro do SUS"14.

Nesse sentido, a proposta da eAB foi lida em associação a esse cenário de proposta do "Plano de Saúde Acessível", já que esse tipo de arranjo beneficiaria o desenvolvimento desse nicho de mercado, haja vista que a flexibilização da carga horária do profissional médico favoreceria a compatibilização da sua inserção na APS com o trabalho no SUS e nos consultórios dos planos acessíveis.

Isso foi tema de intensa discussão no CNS no final de 2016 e início de 2017, que questionou inúmeras vezes o MS quanto à criação de um GT para a elaboração de uma

\footnotetext{
${ }^{13}$ COLLUCCI, C. Tamanho do SUS precisa ser revisto, diz novo ministro da saúde. Folha de São Paulo, 17 maio 2016. Disponível em: <https://www1.folha.uol.com.br/cotidiano/2016/05/1771901-tamanho-do-susprecisa-ser-revisto-diz-novo-ministro-da-saude.shtml > . Acesso em: 23.10.2018

${ }^{14}$ CANCIAN, N. Ministro da Saúde defende plano de saúde popular para aliviar o SUS. Folha de São Paulo, 06 jul. 2016. Disponível em: <https://www1.folha.uol.com.br/cotidiano/2016/07/1789101-ministro-da-saudedefende-plano-de-saude-mais-popular-para-aliviar-o-sus.shtml> . Acesso em: 23.10.2018
} 
proposta de plano de saúde acessível. Isso se verifica no trecho de encaminhamento do Pleno do CNS:

Plenário decidiu, por maioria, pautar debate na próxima reunião do CNS sobre a Proposta de "Plano de Saúde Acessível". Também foi definido que o Conselho solicitará ao MS cópia do ofício enviado à Agencia Nacional de Saúde Suplementar, com síntese dos debates do GT que tratou do tema, para conhecimento do teor do documento (CNS, 2017).

Assim, esses movimentos que compunham o CNS, posicionaram-se pelo bloqueio da agenda de revisão, alegando que também faziam parte da agenda de revisão do SUS e que o governo era um adversário político:

Então, isso foi para dizer que o Ministério da Saúde tinha seu interesse com a revisão da PNAB. É óbvio que quem estava tentando contribuir com a formulação estava numa lógica de reduzir o dano com a política, mas no próprio DAB tem uma agenda clara, uma formulação que mantém a verticalidade. Só que quem comandava a agenda não era o DAB, era o governo (Entrevista 8).

Em contraposição, essa associação foi negada pelos gestores.

[...] não tinha essa articulação do tipo planos populares com revisão da PNAB, não tinha essa articulação, por isso que é bom ir lá atrás, porque essas reivindicações já vêm de quatro, cinco anos, quando não tinha discussão nenhuma de planos populares, pode ser que essas coisas se encaixaram para o governo, mas a pauta de reivindicações, de mudanças não estava relacionada a essa agenda de desconstrução do SUS (Entrevista 3).

O texto da PNAB 2017, em princípios e diretrizes, revela um esforço para esboçar a concepção de uma APS orientadora da política e princípio do sistema público de saúde. O modo de apresentação do texto de princípios e diretrizes, pouco comum em textos normativos, como as portarias, expressa a ideia de orientação para a operacionalização da Política. Isso pode ser analisado do ponto de vista de uma tentativa de reafirmação do SUS e da influência dos atributos da APS propostos por STARFIELD (2002) na formulação da política pública brasileira da área.

[...] um cuidado maior para que não se tivesse a inserção de ações que mudariam a lógica da atenção básica. Na de 2011 já se falava na questão de equipe de atenção básica, como veio na de 2017. Na época não houve consenso, aí não entrou. Entrou nessa. Por um lado, pensando no processo do trabalho, acho que é um avanço, porque tem lugares que não necessariamente precisa ter porque já existe essas equipes. Só que ela não segue nenhuma diretriz, ela vai fazendo do seu modo. Então tendo uma diretriz, e tendo que são os mesmos atributos da atenção básica, é a mesma lógica do processo de trabalho da saúde da família, eu acho que ela poderia estar vindo como um fortalecimento inclusive dos outros pontos da atenção básica, que não só a saúde da família (Entrevista 2).

A contradição entre o texto da PNAB 2017 e os seus dispositivos expressa negociações e interesses distintos, sobretudo do Ministério da Saúde e do CONASEMS, ao mesmo tempo que excluiu importantes entidades de representação dos usuários e dos trabalhadores da definição sobre a Política. 
[...] nenhum secretário municipal ou estadual disse que a Saúde da Família não prestava, até porque tem estudos que mostram que de fato a ESF é muito mais potente. Mas os secretários colocavam que por mais que quisessem, não tinham condições de ter $100 \%$ de Saúde da Família. E justificavam a dificuldade pela falta do profissional médico, porque o recurso era insuficiente, porque a lei de responsabilidade fiscal não permitia contratar, que o salário para atrair médico era maior do que o do prefeito e isso não é possível pela lei. Então tinham várias justificativas que os municípios colocavam, os COSEMS e CONASEMS, que tinha que ter algum tipo de repasse financeiro para essas equipes que não Saúde da Família. Tinha até proposta que o incentivo financeiro da eAB fosse o mesmo do que da ESF (Entrevista 7).

As críticas relacionadas ao financiamento da eAB recaíram sobre a indicação de uma sinalização de abandono do modelo de atenção baseado na ESF e consequente empobrecimento da APS. Entretanto, de fato, a PNAB 2017 e os seus dispositivos posteriores foram reiterando a ESF como modelo prioritário e a eAB restrita à função de acomodação do interesse de alguns grupos. Na interpretação dos dados apresentados, esse foi o resultado do processo de disputa produzido pela tentativa de bloqueio da agenda e pela iniciativa de mediação do pessoal técnico, dos burocratas de carreira e das assessorias, que tiveram um papel importante na formulação e na negociação dos dispositivos da Política (LOTTA, 2012; ALMEIDA et al., 2018).

Como evidência da afirmação de que a ESF se manteve como modelo prioritário, podemos destacar o posterior processo de regulamentação do incentivo financeiro para a eAB pactuado na CIT, definido pela Portaria $\mathrm{n}^{\mathrm{o}} 1.808$, de 28 de junho de 2018. A Normativa restringiu o valor do incentivo em 30\% do valor da eSF modalidade II e estabeleceu, no parágrafo $5^{\circ}$, a suspensão do incentivo no caso de descumprimento das diretrizes estabelecidas na PNAB, substituição de eSF por eAB ou redução da cobertura de eSF (BRASIL, 2018b). Esses são dispositivos que podem ser considerados como uma iniciativa de reafirmação da ESF como modelo prioritário e corroboram a ideia de que a disputa política e a negociação pela sua centralidade na APS foram bem-sucedidas.

Os dados de cobertura de Atenção Básica, apresentados na Tabela 5, mostram que após a aprovação da PNAB 2017 não houve uma redução significativa do número de eSF, seguindo a tendência de expansão da cobertura observada na série histórica. A redução no número absoluto de equipes, observado entre 2018 e 2019, provavelmente está mais associada à interrupção da cooperação com o governo cubano, o que ocasionou a saída dos médicos cooperados do Programa Mais Médicos no final de 2018. 
Tabela 6 - Dados de cobertura de Atenção Básica no Brasil, 2007 a 2019.

\begin{tabular}{ccccc}
\hline Competência & População & $\mathbf{N}^{\mathbf{o}}$ ESF & $\begin{array}{c}\text { Estim. Pop. } \\
\text { Cob. ESF }\end{array}$ & Cobertura ESF \\
\hline Julho/2007 & 186.770 .562 & 24.173 & 77.883 .513 & $41.70 \%$ \\
Maio/2008 & 183.917 .370 & 29.006 & 91.596 .590 & $49.80 \%$ \\
Maio/2009 & 189.612 .814 & 30.278 & 96.163 .538 & $50.71 \%$ \\
Maio/2010 & 191.506 .729 & 31.451 & 99.332 .859 & $51.86 \%$ \\
Maio/2011 & 190.755 .799 & 32.499 & 102.303 .167 & $53.63 \%$ \\
Maio/2012 & 192.376 .496 & 33.417 & 105.314 .241 & $54.74 \%$ \\
Maio/2013 & 193.979 .108 & 34.555 & 108.985 .567 & $56.18 \%$ \\
Maio/2014 & 201.062 .789 & 37.252 & 117.233 .517 & $58.30 \%$ \\
Maio/2015 & 202.799 .518 & 39.648 & 123.828 .292 & $61.05 \%$ \\
Maio/2016 & 204.482 .459 & 40.773 & 127.104 .784 & $62.15 \%$ \\
Maio/2017 & 206.114 .067 & 41.402 & 129.092 .467 & $62.63 \%$ \\
Maio/2018 & 207.660 .929 & 43.076 & 133.509 .030 & $64.29 \%$ \\
Maio/2019 & 208.494 .900 & 42.719 & 132.305 .093 & $63.45 \%$ \\
\hline
\end{tabular}

Fonte: Dados extraídos do site e-Gestor Atenção Básica. Coordenação Geral de Informação da Atenção Primária - CGIAP/DESF/SAPS/MS. Disponível em: $<$ https://egestorab.saude.gov.br/paginas/acessoPublico/relatorios/relHistoricoCoberturaA B.xhtml>. Acesso em: 7 ago. 2019.

Nota: conforme nota técnica da SAPS/MS, os dados de origem utilizados para cálculo da Cobertura de Atenção Básica são oriundos do CNES e do Instituto Brasileiro de Geografia e Estatística (IBGE).

Conforme o Gráfico 2, também não se observou um aumento geral da cobertura de Atenção Básica em decorrência de novas eAB em detrimento da ESF.

Gráfico 2 - Cobertura de Atenção Básica estimada no Brasil, 2007 a 2019.

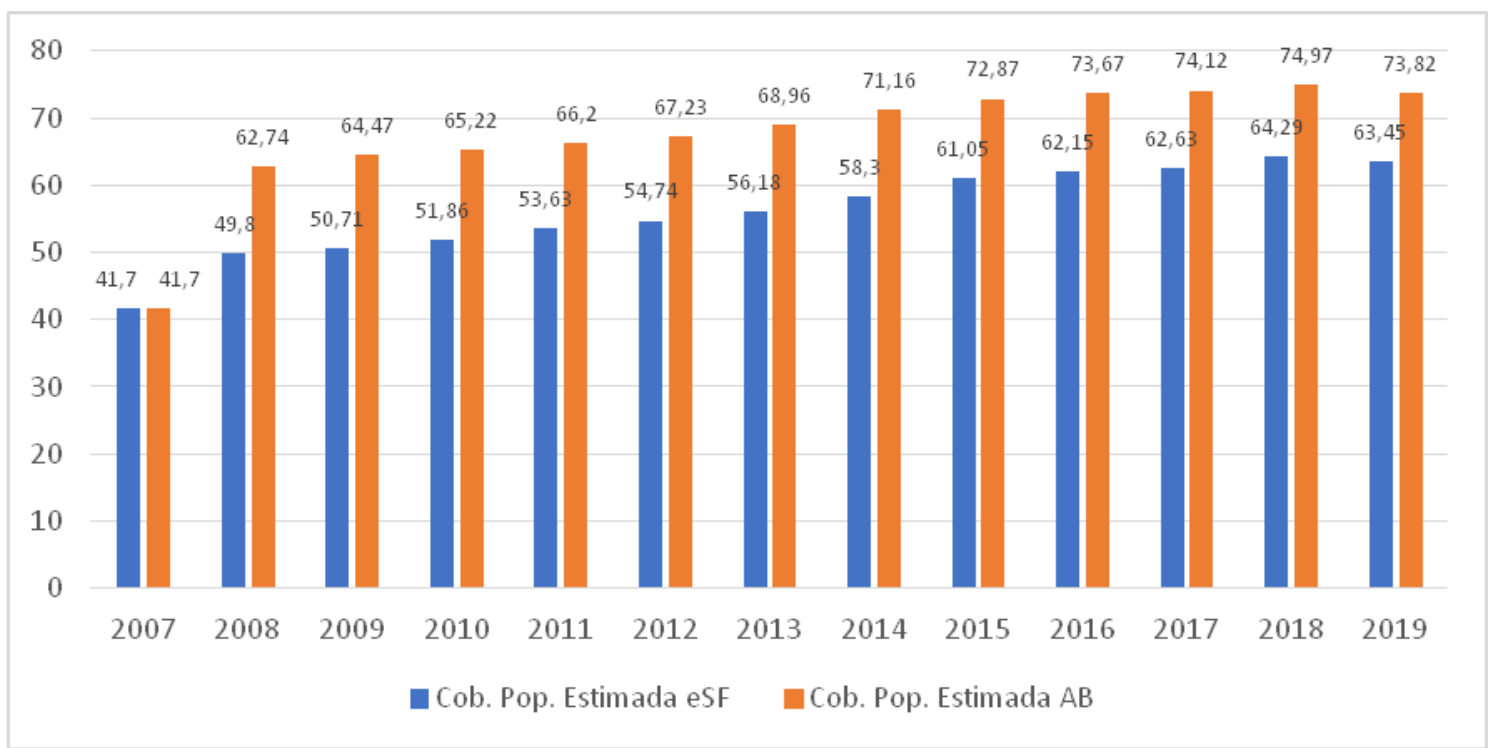

Fonte: Elaborado pelo autor a partir dos dados extraídos do site e-Gestor Atenção Básica. Coordenação Geral de Informação da Atenção Primária - CGIAP/DESF/SAPS/MS. Disponível em: <https://egestorab.saude.gov.br/paginas/acessoPublico/relatorios/relHistoricoCoberturaAB.xhtml>.

Acesso em: 7 ago. 2019.

Nota: para fins de comparação foram utilizados os dados da competência de maio de cada ano e para o ano de 2007, apenas está disponível no sistema dados a partir da competência do mês de julho. 
Por outro lado, como as regras para o cadastro da eAB no sistema do Cadastro Nacional de Estabelecimentos de Saúde (CNES) foram estabelecidas somente no início de 2019, por meio da Portaria $n^{\circ} 18$, de 7 de janeiro de 2019 e que, até o momento do fechamento desse estudo, não havia publicação de portaria de repasse financeiro para esse tipo de equipe, não foi possível avaliar a tendência do impacto dessas medidas sobre o aumento de $\mathrm{eAB}$ em detrimento da queda do número de ESF.

Na revisão da PNAB 2017, a discussão sobre o tipo e a composição de equipe foi composta também pela questão da transição do perfil epidemiológico, especialmente em grandes centros urbanos, onde se sobrepõem múltiplos determinantes de vulnerabilização das populações e nos quais são necessários grandes investimentos para o aumento significativo da cobertura da ESF.

[...] nós estamos na transição de perfil demográfico epidemiológico, onde a necessidade mudou e aquele Agente que foi concebido lá trás, não necessariamente eu tenho necessidade, mas eu tenho necessidade de um outro profissional. Pode ser que determinada região tem necessidade de mais Agente, isso é questão da autonomia, de poder organizar de acordo com a minha necessidade. Eu tenho a região que é um bairro de classe média alta, condomínio. Eles não deixam o Agente entrar, uma questão cultural e social, ele não vai entrar. Então, para que eu tenho que ter? (Entrevista 5).

No bojo da reformulação, veio à tona a discussão sobre o perfil e a competência profissional dos ACS, uma vez que seu escopo de práticas está mais distante da demanda por adensamento tecnológico de caráter biomédico na APS.

Tem locais em que a necessidade de saúde que existe hoje é outra, em grandes centros, se atendem pacientes do interior porque está pactuado, ou muitos sequelados da nova realidade epidemiológica, tem muito politraumatizado de acidente de moto, idosos acamados. Que o ACS não estava, não era o melhor, ele ia visita e se via que o que precisa é cuidado domiciliar. Minimamente de um auxiliar ou técnico de enfermagem, porque o cara está acamado, tem uma situação de vulnerabilidade social e não tem ninguém para ajudar ele (Entrevista 4).

Os elementos de transição epidemiológica e a necessidade da melhoria de resolubilidade da APS, como a pressão por adensamento tecnológico de caráter biomédico, integram o fluxo de problemas e conectaram-se com as propostas de integração entre a Vigilância em Saúde e a Atenção à Saúde, da revisão das atribuições dos ACS e dos ACE e do incremento no número de técnicos de enfermagem para substituir o ACS na equipe. Esta última não se tornou viável diante da mobilização contrária dos ACS e a restrição financeira imposta pelo governo.

Considerando que os ACS têm maior estabilidade nos vínculos devido à regulamentação da categoria e aos dispositivos dados pela Portaria $n^{\circ} 1.808$, de 28 de junho de 2018, que buscavam inibir a substituição da eSF por eAB, a introdução do financiamento 
da $\mathrm{e} A B$ teria mais efeito para o financiamento daquilo que já existia enquanto arranjo de equipe nos municípios e que não era financiado pelo MS.

Outro efeito dado pelas regras da Portaria supra incidia sobre a escolha dos gestores na implantação de novas equipes. Como o recurso para a eAB estava limitado a $30 \%$ do incentivo destinado à ESF, justificava-se a escolha pela eAB apenas no caso de opção por arranjo com flexibilização da carga horária dos profissionais, dialogando, principalmente, com a dificuldade de provimento de médico para o cumprimento das 40 horas semanais.

Não sendo essas as motivações para a escolha do gestor municipal, na lógica do cálculo financeiro do valor do incentivo repassado pelo MS, a tendência do gestor poderia ser a de realizar um redimensionamento das equipes, com uma redistribuição de ACS para implantar novas eSF, o que não feriria a regra, já que houve a flexibilização da cobertura de $100 \%$ do território por ACS. A exemplo, o Distrito Federal, para implantar novas equipes conforme o planejamento, teria uma demanda por novos 3 mil ACS, todavia, diante das limitações impostas pelos instrumentos jurídicos e tipo de vínculo exigido para a contratação de ACS, ampliou o número de eSF realizando uma redistribuição dos agentes (FONSECA, 2019).

Ressalta-se que com a nova mudança da direção do MS em 2019, o DAB passou ao status de Secretaria de Atenção Primária à Saúde, sendo agregado a outros departamentos e criando, ainda, o Departamento de Saúde da Família. Seus principais dirigentes têm formação e influência no movimento de medicina de família e reforçam o discurso de priorização da ESF e o papel central da APS na política de saúde (REIS et al., 2019).

Recentemente foi publicada a Portaria $\mathrm{n}^{\circ} 2.539$, de 26 de setembro de 2019, que altera as Portarias de Consolidação n ${ }^{\circ}$ 2, de 28 de setembro de 2017, e n ${ }^{\circ}$ 6, de 28 de setembro de 2017, para instituir a equipe de Atenção Primária (eAP) em substituição a eAB. Além da mudança de nomenclatura, a grande novidade trazida pela Portaria supra refere-se à composição e à carga horária mínima da equipe, passando a considerar apenas o médico e o enfermeiro com carga horária individual de 20 ou 30 horas, e também flexibilizando nos mesmos termos a carga horária do dentista, no caso de composição com equipe de saúde bucal.

Com relação ao financiamento das eAP, estabelecido na mesma Portaria, o valor passa a ser correspondente ao percentual do valor de uma eSF, conforme a carga horária dos profissionais da equipe mínima. Ou seja, uma eAP com 20 horas de carga horária do médico, receberá $50 \%$ do valor de incentivo de uma eSF, que, de forma geral, no momento da publicação dessa Portaria, fazia jus a R \$ 7.350,00. 
Diferente da proposta de financiamento da eAB, a Portaria em epígrafe não se preocupa em garantir 40 horas de serviços da equipe mínima, sendo o balizador a quantidade de usuários sob sua responsabilidade, o que levanta dúvidas em relação a como serão o funcionamento e o acesso a esses serviços com equipe mínima de 20 ou 30 horas.

A persistência do financiamento de um arranjo de equipe de APS com a flexibilização da carga horária, embora agora com o mínimo de 20 horas, e sem a obrigatoriedade do ACS evidencia a importância dessas duas questões sobre a disputa e a condução da Política.

No texto da PNAB 2017, a questão da flexibilização do número de ACS para eSF, que abrange a desregulamentação da obrigatoriedade do ACS em 100\% do território adstrito, é dada pela recomendação de $100 \%$ de cobertura por ACS apenas para regiões de grande dispersão geográfica, área de risco e vulnerabilidade social.

Uma possível consequência desse processo pode levar a uma reconfiguração da presença do ACS na APS e do seu trabalho na equipe, já que pela atual normatização é obrigatório apenas 1 ACS por eSF e com a eAP, substituta da eAB, não é necessário ACS para fins de repasse do incentivo. Como os seus vínculos são estáveis na maioria do País, e, conforme o Gráfico 4, não se observa uma redução significativa no número de ACS entre 2017 até maio de 2019, torna-se relevante estudos para o acompanhamento do número total de ACS no Brasil, da relação média de ACS por eSF e do seu papel na equipe nos próximos anos.

Gráfico 3 - Quantidade de Agentes Comunitários de Saúde, Brasil, 2007 a 2019.

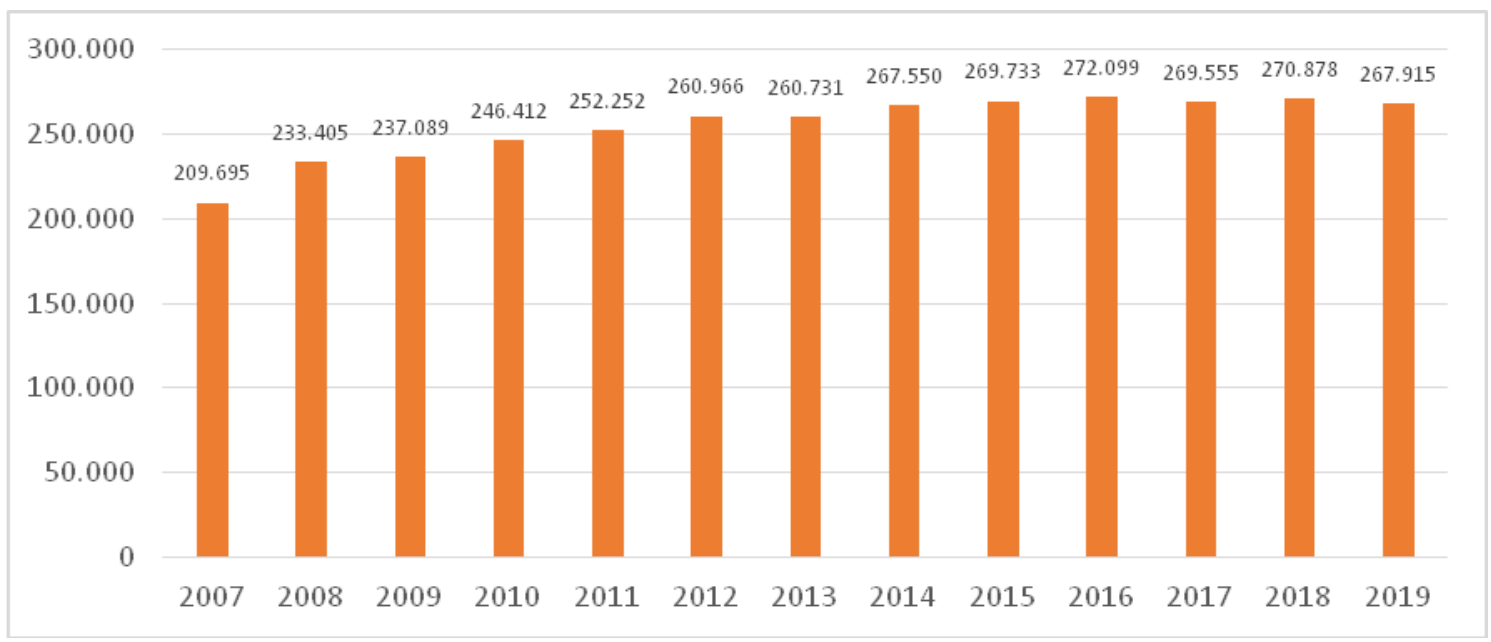

Fonte: Elaborado pelo autor a partir dos dados extraídos pelo e-Gestor Atenção Básica. Coordenação Geral de Informação da Atenção Primária - CGIAP/DESF/SAPS/MS. Disponível em: <https://egestorab.saude.gov.br/paginas/acessoPublico/relatorios/relHistoricoCoberturaACS.xhtml>. Acesso em: 7 ago. 2019.

Nota: para fins de comparação são utilizados dados do mês de setembro de cada ano e para o ano de 2019 foi utilizado dados de maio, disponíveis no momento da consulta. 


\subsubsection{Mudanças no Modelo de Atenção e o Trabalho do ACS}

O movimento dos ACS e dos ACE tem na EC n ${ }^{\circ}$ 51, de 14 de fevereiro de 2006, uma grande vitória. A partir desta Emenda, o artigo 198 da Constituição Federal passa a prever que para estes profissionais o vínculo empregatício se dê por meio de processo seletivo público, prevendo também a posterior regulamentação de suas atividades por lei específica, o que foi atendido por meio da aprovação da Lei $\mathrm{n}^{\circ} 11.350$, de 5 de outubro de 2006.

Garantido o vínculo, o foco da ação política dos agentes deteve-se no piso e na carreira para a categoria, conquistados com a EC $\mathrm{n}^{\circ} 63$, de 4 de fevereiro de 2010, a qual acrescentou a previsão do piso salarial nacional e as diretrizes para o plano de carreira ao parágrafo $5^{\circ}$ do artigo 198 da Constituição Federal. A Lei no 12.994, de 12 de junho de 2014, que fixa o piso nacional dos agentes em $\mathrm{R} \$ 1.014,00$ e estabelece as diretrizes para o plano de carreira dos ACS e dos ACE.

Esse longo processo está intimamente ligado às motivações da revisão da PNAB 2017.Diante da regulamentação que impôs a forma de vínculo e o piso salarial, a manobra encontrada pelo Executivo foi a desregulamentação da obrigatoriedade do ACS na equipe.

[...] o início dessa discussão da revisão da PNAB de 2017 é meados de 2014, porque foi ali que foi promulgada a lei pela presidente Dilma, que definia um conjunto de questões relacionadas aos agentes comunitários de saúde (Entrevista 3).

No momento da regulamentação do piso salarial dos ACS e dos ACE, o CONASEMS já havia se posicionado contrário.

Apesar da pactuação da proposta de parâmetros informou que, os gestores municipais consideram um equívoco o estabelecimento de pisos salariais nacionais, em um país como o Brasil, que tem a natureza federativa (CONASEMS, 2015).

O valor de $95 \%$ do piso, fixado como valor assistencial complementar da União e regulamentado posteriormente pelo Decreto Presidencial $n^{\circ} 8.474$, de 22 de junho de 2015, impõe a contrapartida municipal para o cumprimento do teto salarial, uma vez que o repasse do incentivo feito pelo MS praticamente se iguala ao teto estabelecido em lei, cabendo ao gestor municipal arcar com as despesas de encargos trabalhistas e o custeio das ações do Programa como um todo.

Em relação às pactuações, citadas pelo Ministro, afirmou que existe um sentimento de "contrariedade ou inconformismo" de vários Secretários Municipais de Saúde pelo país diante da situação imposta pelo Decreto $n^{\circ} 8.474$, de 22 de junho de 2015. Afirmou que esta legislação é imprópria ao Sistema Interfederativo (CIT, 2015).

Destaca-se que os agentes são a única categoria que tem sua profissão fixada na Constituição e que suas conquistas, obviamente, são resultado de lutas por melhores condições de vida e trabalho, portanto, legítimas, representando um avanço social do ponto de 
vista dos direitos. Por outro lado, como um movimento de natureza corporativa, cuja base são as reivindicações relacionadas às relações de trabalho, às questões salariais e ao desenvolvimento da carreira, a sua atuação os posiciona em situação constante de conflito com outros segmentos e não necessariamente alinhado à política de saúde para o desenvolvimento do SUS.

Ainda como importante elemento de contexto, observa-se que o marco legal e as grandes conquistas da categoria ocorreram no período entre 2003 e 2015, caracterizado por avanços no campo democrático popular e no desenvolvimento econômico. A partir de 2014, a crise econômica passa a impactar fortemente o País, levando ao ajuste fiscal proposto por Joaquim Levy, Ministro da Fazenda do segundo governo de Dilma Rousseff.

Esse cenário de restrição econômica foi decisivo para o acirramento quanto aos avanços obtidos pela luta dos ACS e dos ACE no período anterior e o posicionamento dos gestores diante do conflito de interesses:

O Ministério diante da lei tirou recurso da $\mathrm{AB}$, de remédio, daqui e dali para dar conta de pagar o ACS. E o Ministério só botar recurso em programa, numa ação carimbada por salário dos ACS é impor mais pagamento por parte do município, porque o pagamento do resto depois fica para o município. Cada vez que aumentava lá, aumentava mais aqui também a contrapartida do município. E não tinha recurso novo, então, sequestrou recurso de outras ações e isso incomodou, independente da proposta de modelagem (Entrevista 4).

A coalizão produzida pelo CONASEMS, CONASS e MS para a questão dos ACS tinha como pano de fundo o horizonte da agenda de restrição econômica e a tramitação no Congresso Nacional de novos projetos de lei que incidiam sobre as reivindicações da categoria, principalmente o reajuste do piso salarial, que vieram a se consumar em 2018, com a Lei $\mathrm{n}^{\mathrm{o}} 13.708$, de 14 de agosto de 2018. Esta Normativa aumentou o piso salarial nacional para R \$ 1.550,00 mensais. Pelo texto, o escalonamento do salário será em três anos, a partir do dia $1^{\circ}$ de janeiro de 2019 , sendo que o novo valor é de $\mathrm{R} \$ 1.250,00$. Os próximos reajustes já estão previstos na Lei, para 2020, o valor é de $\mathrm{R} \$ 1.400,00$, e para 2021, R\$1.550,00. E a partir de 2022 os reajustes serão anuais.

Durante a $1^{\text {a }}$ Reunião Extraordinária da CIT de 2017, foi discutida a Proposta de Emenda à Constituição (PEC) que tramitava no Congresso Nacional referente à remuneração dos ACS. No Resumo Executivo da Reunião, é destacada a seguinte declaração do Ministro da Saúde, Ricardo Barros:

Relatou que o movimento desses profissionais junto ao Congresso gera insubordinação dos municípios sobre esta categoria e que tem desestruturado o sistema de saúde. Afirmou que não é contra os ACS e está empenhado em definir atribuições mais efetivas e qualificação para melhoria e dar resolutividade nas suas ações. Este assunto deverá ser observado de forma mais atenta. É necessária a 
participação dos gestores no debate e é fundamental uma discussão sobre onde deverão ser investidos os recursos da saúde, pois são valores significativos, aproximadamente 1,5 bilhão de reais, que estão sendo solicitados para investir nesta categoria. É uma questão de optar onde deverá haver mais recursos, no âmbito da saúde (CIT, 2017).

Nessa mesma Reunião, o CONASEMS se posicionou da seguinte forma:

O setor de saúde não tem condições de manter a remuneração reivindicada por esses profissionais. Os gastos dos municípios com Atenção Básica já são muito elevados. Citou a Lei de Responsabilidade Fiscal que estabelece parâmetros a serem seguidos relativos ao gasto público de cada ente federativo e um equívoco o estabelecimento de pisos salariais nacionais, em um país como o Brasil, que tem a natureza federativa (CIT, 2017).

Logo após a publicação da portaria regulamentando a revisão da PNAB, em outubro de 2017, houve uma discussão sobre o tema no CNS, em que o então diretor do DAB/MS, João Salame, afirmou:

[...] que cerca de $30 \%$ do orçamento do DAB é destinado ao pagamento dos ACS e se houver aumento do piso, chegará a $40 \%$. Todavia, disse que não é contra o aumento do piso, mas entende que é preciso debater como se dará o financiamento. Destacou que questões relativas ao funcionamento do Sistema precisam ser debatidas para além de posições políticas ideológicas e frisou que o DAB irá trabalhar para contribuir na construção dessa política (CIT, 2017).

Considerando asas entrevistas 7 e 10, fica evidente que a reformulação da PNAB 2017 foi uma das respostas aos avanços dos direitos conquistados pela categoria dos ACS e ao cenário de restrição econômica, bem como resultado da mediação entre os atores para não descaracterizar o acúmulo construído com a ESF.

[...] quando eles perceberam que a gente tinha força política dentro do Congresso Nacional, e que qualquer situação a gente iria se recorrer do Congresso, como foi o caso da lei Ruth Brilhante, eles se apressaram em fazer essa reforma na PNAB, na Política Nacional. E aí eles criam a equipe mínima (Entrevista 10).

Mediação construída entre gestores:

Não vejo Saúde da Família sem ACS, porque é ele quem visita e faz esse elo com a comunidade, por outro lado, do jeito que as coisas ficaram, o ACS não responde o comando da equipe ou da gestão municipal. Ele está sob o comando do vereador, do deputado, de não sei quem... então, a gente se colocou no lugar do gestor municipal e defendemos que o menos é mais. Com um país desse tamanho, o mínimo que você puder escrever que não descaracterize a ESF como um todo... porque lá na PNAB não está escrito que tem que ser 1, está dizendo que o mínimo tem que ser 1. Então, eu diria que foi uma estratégia para poder manter o ACS e ao mesmo tempo não ficar refém deles (Entrevista 7, grifo nosso).

Além dos efeitos da regulamentação da carreira e do piso salarial que motivaram a flexibilização do número de ACS na eSF ou mesmo a sua não obrigatoriedade no arranjo da eAB, os argumentos sobre a perda do seu papel e a relevância figuraram como justificativas no discurso dos gestores para a flexibilização da sua presença na equipe. 
Por outro lado, essas mesmas questões relacionadas ao seu papel e à relevância são apontadas como argumentos por quem defende a presença do ACS como essencial na APS. Um desses elementos refere-se à abordagem familiar e comunitária a ser desenvolvida pela APS.

Em vários documentos oficiais, como também na literatura acadêmica disponível sobre o tema, o ACS é definido como o elo entre a equipe e a comunidade. Podemos estender esse elo com a comunidade, atribuído ao trabalho do ACS, como a mediação entre os distintos saberes e poderes da população, dos profissionais e/ou do serviço de saúde (NUNES et al., 2002; BORNSTEIN e STOTZ, 2008; GOMES et al., 2010; QUEIRÓS e LIMA, 2012).

Essa expectativa estaria associada à origem da figura do agente de saúde, advindo de experiências como as pastorais da saúde dos anos 70, ligadas à Igreja Católica e às comunidades eclesiásticas de base, como também do visitador sanitário da antiga Fundação SESP e PIASS. Na verdade, essa competência era muito mais decorrente da sua forma de recrutamento, que buscava selecionar lideranças da própria comunidade, que conheciam os aspectos da dinâmica local e de seus moradores. Em geral, tinham instrução mínima e passavam por um treinamento para absorver o escopo de ações programáticas dos serviços na lógica de promoção, prevenção e identificação dos casos a serem atendidos (BORNSTEIN e STOTZ, 2008; DURÃO et al., 2011).

Dessa forma, a aposta no agente de saúde, oriundo da comunidade, foi que ele contribuiria para o tensionamento sobre a forma de trabalho da equipe, provocando o rompimento de uma visão restrita de saúde e alargando o centro da atenção do indivíduo para a família e comunidade, considerando abordando os determinantes sociais e tendo como enfoque as ações de promoção e prevenção (QUEIRÓS e LIMA, 2012).

Essa construção ancorava-se no bojo do processo da Reforma Sanitária brasileira e estava alinhada à constituição do SUS. Como observa-se no tema (eixo) da Reformulação do Sistema de Saúde, da VIII Conferência Nacional de Saúde, em que o relatório final recomendava:

[...] incorporação dos agentes populares de saúde como pessoal remunerado, sob a coordenação do nível local do Sistema Único de Saúde, para trabalhar em educação para a saúde e cuidados primários" (BRASIL, 1986, p. 12).

Esse movimento, por sua vez, traduzia o desejo de mudança do modelo de atenção, o qual envolve inúmeras outras iniciativas estruturais, como apontava o próprio relatório da Conferência, mas que diante da correlação de forças, dado o contexto histórico, impuseram limites ao desenvolvimento do próprio SUS, que resumiu a abordagem comunitária a uma 
visão ideológica, restrita a pauta da presença dos ACS na equipe de saúde (DURÃO et al., 2011).

É importante salientar que com as políticas de cunho neoliberal da década de 90 buscou-se avançar dentro do que era possível na concretização do SUS. Nesse sentido, é esclarecedora a interpretação de DURÃO et al. (2011) sobre a constituição do Estado e as políticas de saúde do Brasil:

Em meados da década de 1970, para dar conta da crise que afetava o setor de saúde, ganha peso no país um novo modelo de gestão das políticas de saúde: o modelo comunitário, para o qual o local passa a ser a principal instância de implementação. A participação da comunidade era considerada como uma forma de os setores mais pobres aproveitarem seus próprios recursos para a superação da pobreza (DURÃO et al., 2011, p. 131).

A literatura mais recente sobre o assunto aponta para um distanciamento desse papel comunitário à medida que há um progressivo processo de institucionalização da figura do agente. Contraditoriamente, à medida que se profissionaliza, o saber técnico em saúde vai dando contorno a algumas de suas atribuições e competências, com uma forte influência das ações de vigilância e de programas temáticos instituídos pelo Ministério da Saúde, aproximando-se do núcleo tradicionalmente biomédico da equipe e distanciando-se do saber popular e comunitário (PEREIRA e OLIVEIRA, 2013; BARROS, 2016; ALONSO et al., 2018).

Nessa perspectiva, parece uma simplificação restringir o debate sobre a territorialização e o enfoque comunitário da APS à presença ou não do ACS na equipe, haja vista que existem diferentes estratégias e tecnologias em constante desenvolvimento que abordam a identificação das necessidades de saúde locais, os determinantes sociais, as formas de participação e o engajamento comunitário, a mobilização e articulação social.

Obviamente, não se trata de defender a extinção do ACS enquanto membro da equipe e interlocutor privilegiado das demandas sociais. Pelo contrário, em determinados contextos, o ACS continua sendo um sujeito fundamental no desenvolvimento do trabalho da equipe e para a contribuição na orientação comunitária da APS. Todavia, chama atenção que a sua obrigatoriedade na equipe não parece ser a decisão central na política de saúde que traduz a manutenção do foco na mudança do modelo de atenção e na abordagem comunitária.

A decisão sobre a flexibilização dos arranjos de equipe, com uma não priorização da abordagem comunitária com o ACS, traduz muito mais os interesses econômicos em disputa e o reposicionamento sobre o papel do Estado. Certamente isso tem influência sobre a definição do modelo tecnoassistencial orientado pela APS e representa um sintoma dos elementos conjunturais da macropolítica, estes sim, pelo que já foi apresentado até aqui, com fortes 
indícios de uma tendência de priorização do modelo centrado no médico, privatista e com prática profissional subalterna ao aparato tecnológico determinado pelo interesse econômico do mercado da saúde.

Diante do exposto, observou-se que a configuração da agenda de revisão da PNAB 2017 é reflexo do fluxo de problemas e escolha de alternativas, cujas principais motivações advêm das questões relacionadas à regulamentação da profissão e ao piso salarial dos agentes, bem como à dificuldade de provimento de médicos. Essas são questões que vinham se avolumando enquanto problemas para a gestão e a mudança no fluxo político, como a restrição econômica e a troca de dirigentes, foram determinantes para a configuração da agenda.

Na Figura 5 são apresentados os múltiplos fluxos da configuração da agenda de revisão da PNAB 2017. Trata-se de uma representação do modelo de análise empregado neste estudo. 
Figura 5 - Múltiplos fluxos da configuração da Agenda de revisão da Política Nacional de Atenção Básica de 2017.

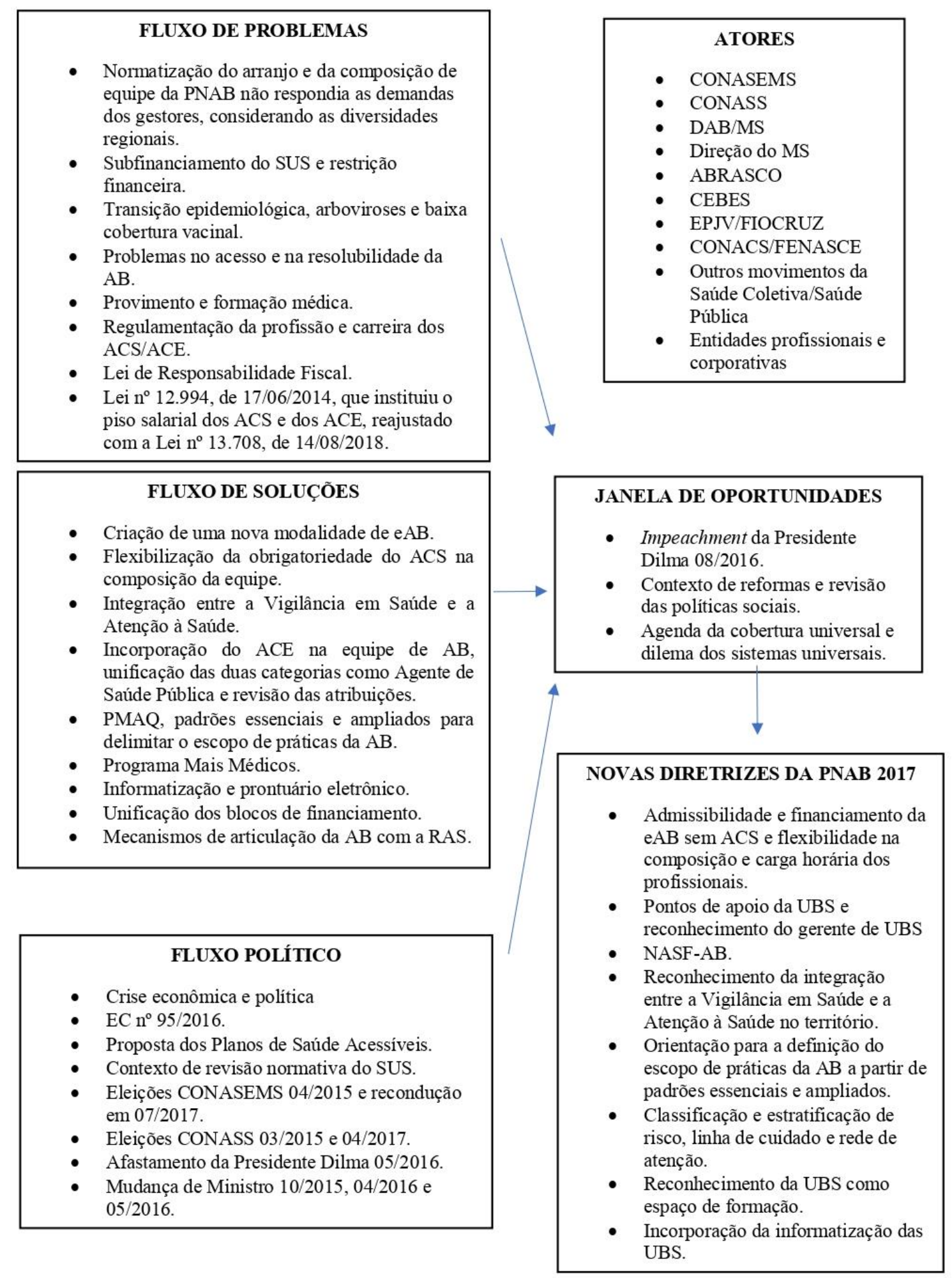

Fonte: Elaborado pelo autor com base no modelo de análise dos múltiplos fluxos. 


\section{CONSIDERAÇÕES FINAIS}

É possível apontar a troca de dirigentes do Ministério da Saúde, que sucedeu o processo de impeachment da Presidente Dilma Rousseff, em agosto de 2016, como elemento determinante para a convergência dos múltiplos fluxos, assim como para a abertura da janela de oportunidades para a configuração da agenda de revisão da PNAB 2017. Esse processo foi decorrente de rupturas no pacto social e forte instabilidade política, fatores que tiveram grande influência na dinâmica do Estado de Direito no Brasil a partir desse período.

No curso de um projeto de governo substitutivo ao que foi eleito democraticamente pela população impôs-se uma intensificação do ajuste fiscal na economia, como também a reformulação no arcabouço legal e social que sustenta a garantia da universalidade e da integralidade dos direitos sociais. Essa perspectiva é evidenciada pela determinação do "teto dos gastos" do governo federal, imposta pela EC n 95, de 15 de dezembro de 2016, e pelas reformas e leis aprovadas ou que seguiram em tramitação no Congresso Nacional.

Sugere-se que este cenário repercutiu em maiores limitações no financiamento, não só do sistema universal e público de saúde, bem como no conjunto de políticas sociais. O contingenciamento e a restrição do financiamento têm como efeito direto a retração dessas políticas. Todos esses são elementos do fluxo político, determinantes na configuração da agenda de revisão da PNAB 2017.

Quanto ao fluxo de problemas, a questão da regulamentação da profissão dos agentes comunitários de saúde, que resultou na fixação do piso salarial da categoria, e as dificuldades na gestão do trabalho foram os temas de destaque na agenda dos gestores. O CONASEMS foi o principal empreendedor no sentido de visibilizar a flexibilização das diretrizes para a composição de equipe como uma alternativa de solução.

As principais motivações para agenda de revisão da PNAB 2017 foram determinadas pelo gargalo do financiamento enfrentado pelos gestores e pela flexibilização do parâmetro no número de ACS por equipe, como a criação da eAB, com flexibilidade da carga horária dos médicos. Essas duas questões, demandadas pelo CONASEMS, encontraram ressonância na condução do governo que vinha implementando uma agenda restritiva.

Apesar de grupos contrários à revisão atribuírem ao governo uma orientação de agenda de abandono da priorização da ESF e desmonte do SUS, parece mais preciso afirmar que a agenda político-econômica do governo, que sofreu mudanças bruscas com o processo de impeachment, impôs a acentuação das condições restritivas para o desenvolvimento da 
PNAB e que esse processo foi definidor das decisões e motivações para o conteúdo da revisão.

A análise dos dados coletados não permitiu confirmar a narrativa de que a proposta de revisão da PNAB 2017 representa de imediato um projeto de APS seletiva. Essa seria dada menos pelo texto da PNAB e muito mais pela determinação dos elementos dos subsistemas político e econômico sobre o papel do Estado. O que o texto materializa, em formato de portaria, é a normatização e o regramento para o desenvolvimento da Política nas condições do contexto de 2016-2017. A este respeito, cabe recomendar que outras análises sejam produzidas, considerando a avaliação do conteúdo e os efeitos da PNAB em seu processo de implementação, buscando reconhecer aspectos mais específicos e potencialmente relacionados ao projeto de APS seletiva.

Com relação aos múltiplos fluxos, o modelo de análise mostrou-se particularmente útil para isolar e explicitar os elementos constitutivos da configuração da agenda de revisão da PNAB 2017. Dado o contexto histórico de importantes mudanças nos sistemas político e econômico, o fluxo político comprovou ser definidor na configuração da agenda de governo.

Os achados do fluxo de problemas e soluções encontram ressonância nos desafios e nas propostas de alternativas apontadas pela literatura destacada na introdução deste trabalho, sugerindo que as instâncias colegiadas dos gestores e do controle social vêm abordando temas relevantes para o desenvolvimento da APS no Brasil, sendo necessários estudos complementares relacionados à avaliação da relevância das ações e dos programas no resultado obtido pela implementação da Política.

Por outro lado, as categorias de análise propostas por Kingdon não foram suficientes por si só para subsidiar a análise sobre todos os dados identificados na coleta. Desta forma, de antemão, o fluxo político foi adaptado, optando-se por ampliá-lo em uma leitura mais abrangente do contexto, justamente para captar elementos dos sistemas econômico e político em uma perspectiva histórica, além de buscar a atuação dos atores na configuração da agenda. Nesse sentido, as narrativas captadas pelas entrevistas foram fundamentais para subsidiar a complementariedade da análise, notadamente para expor as contradições e os posicionamentos divergentes.

Para isso, foi dada especial atenção ao conceito de arena política, não muito abordado por Kingdon em seu modelo de análise. Esse conceito favoreceu a identificação dos atores políticos, suas motivações e a formação das coalizões, que fazia parte dos objetivos específicos do estudo, o que oportunizou extrapolar a tendência de uma análise polarizada e homogênea sobre a atuação dos atores. 
No que concerne ao desenho do estudo, exploratório, e que adotou a análise documental como uma das técnicas de coleta, é importante registrar que foi gerada uma grande quantidade de dados, exigindo proporcional esforço de sistematização para a identificação de temas relativos aos avanços e desafios para o desenvolvimento da APS no Brasil, inclusive demandando a utilização dos recursos do software ATLAS.ti para a adequada sistematização. Todavia, por tratar-se de uma pesquisa de mestrado, em que o tempo é mais limitado, não foi possível aprofundar a análise e a discussão sobre todos os elementos identificados, sob o risco de fugir do objetivo proposto.

Assim, considera-se que o exíguo esforço de sistematização aqui empregado representa uma contribuição da trajetória deste trabalho e visa subsidiar outras pesquisas, visto que os elementos identificados podem ser considerados como temas relevantes que figuraram no debate da arena tripartite dos gestores e na estância máxima do controle social da saúde no período de 2015 a 2017. Sugere-se que a sistematização produzida dos temas, embora não aprofundada neste trabalho, oportuniza novos estudos e outras abordagens sobre os avanços e desafios para o desenvolvimento da APS no Brasil.

Destaca-se que, apesar de ter sido consumada a revisão da PNAB 2017, parte do esforço para o bloqueio da agenda obteve sucesso, haja vista não ter prosperado a eAB e, até o momento, a ESF seguir como modelo prioritário na APS.

Recomenda-se um estudo sobre a questão de como se processará a presença do ACS na equipe, em relação tanto aos parâmetros e à flexibilização quanto ao seu papel e escopo de práticas. Não há regulamentação ou precisão sobre o que se chama de área de risco e vulnerabilidade social para a cobertura de $100 \%$ de ACS, sendo necessário acompanhar a proporção de ACS por eSF ao longo do tempo pós PNAB 2017.

Por fim, os arranjos e as diretrizes para a composição de equipe e o escopo de práticas atrelado ao financiamento são questões em aberto, residindo aí a discussão sobre o modelo tecnoassistencial, o que pode ser uma forte tendência para o debate sobre a APS nos próximos anos.

Dentre as muitas questões levantadas neste trabalho, tão difíceis de serem definidas quanto o percurso para se chegar às suas possíveis respostas, fica a reflexão de que os problemas estruturais do SUS são sentidos cotidianamente e de diferentes formas pelos atores envolvidos em sua construção. E que é fundamental lançar luz sobre a definição e a produção das políticas públicas, sobretudo no contexto de restrição econômica e perda de direitos. 


\section{REFERÊNCIAS}

ABRANTES, T. Veja a íntegra do discurso de Dilma Rousseff no Senado. Revista Exame. 2016. Disponível em: <https://exame.abril.com.br/brasil/veja-a-integra-do-discurso-de-dilmarousseff-no-senado/>. Acesso em: 27 abr. 2019.

ASSOCIAÇÃO BRASILEIRA DE SAÚDE COLETIVA (ABRASCO). Carta de Goiânia. In: $11^{\circ}$ CONGRESSO DA ABRASCO, 2015, Goiânia. Disponível em:

<https://www.abrasco.org.br/site/outras-noticias/institucional/carta-de-goiania-associacaobrasileira-de-saude-coletiva/12853/>. Acesso em: 03 out. 2018.

ASSOCIAÇÃO BRASILEIRA DE SAÚDE COLETIVA (ABRASCO). Contra a

reformulação da PNAB: nota sobre a revisão da Política Nacional de Atenção Básica. 2017. Disponível em: <https://www.abrasco.org.br/site/noticias/posicionamentos-oficiais/contrareformulacao-da-pnab-nota-sobre-revisao-da-politica-nacional-de-atencao-basica/29798/>. Acesso em: 06 out. 2017.

ALBUQUERQUE, M. F. P. M. et al. Epidemia de microcefalia e vírus Zika: a construção do conhecimento em epidemiologia. Cadernos de Saúde Pública, Rio de Janeiro, v. 34, n. 10, 2018. Disponível em: <http://www.scielo.br/scielo.php?script=sci_arttext\&pid=S0102311X2018001003001\&lng=pt\&nrm=iso >. Acesso em: 04 abr. 2019.

ALMEIDA, C. Equidade e reforma setorial na América Latina: um debate necessário. Cadernos de Saúde Pública, Rio de Janeiro, v. 18, supl. p. S23-S36, 2002. Disponível em: $<$ http://www.scielo.br/scielo.php?script=sci_arttext\&pid=S0102311X2002000700004\&lng=en\&nrm=iso >. Acesso em: 20 jun. 2017.

ALMEIDA, E. R. et al. Política Nacional de Atenção Básica no Brasil: uma análise do processo de revisão (2015-2017). Revista Panamericana de Salud Publica. 42: e180, 2018. https://doi.org/10.26633/RPSP.2018.180. Disponível em: $<$ http://iris.paho.org/xmlui/bitstream/handle/123456789/49559/v42e1802018.pdf?sequence=3 \&isAllowed=y $>$. Acesso em: 20 mar. 2019.

ALONSO, C. M. do C.et al. Trabalho dos agentes comunitários de saúde na Estratégia Saúde da Família: metassíntese. Revista de Saúde Pública, São Paulo, v. 52, n. 14, p. 1-13, 2018. Disponível em: <http://www.scielo.br/scielo.php?script=sci_arttext\&pid=S0034-

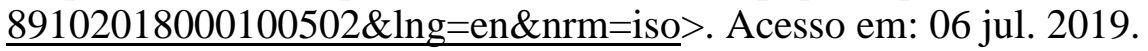

ARANTES, L. J. et al. Contribuições e desafios da Estratégia Saúde da Família na Atenção Primária à Saúde no Brasil: revisão da literatura. Ciência \& Saúde Coletiva, Rio de Janeiro, v. 21, n. 5, p. 1499-510, 2016. Disponível em: $<$ http://www.scielo.br/scielo.php?script=sci_arttext\&pid=S1413-

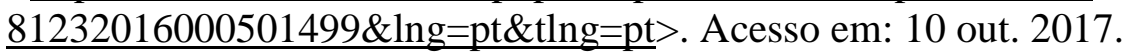

ARAUJO, L.; RODRIGUES, M. L. Modelos de análise das políticas públicas. Sociologia, Problemas e Práticas, Lisboa, n. 83, p. 11-35, 2017. Disponível em: <http://www.scielo.mec.pt/pdf/spp/n83/n83a01.pdf>. Acesso em: 25 ago. 2018.

BAPTISTA, T. W. de F. Análise das portarias ministeriais da saúde e reflexões sobre a condução nacional da política de saúde. Cadernos de Saúde Pública, Rio de Janeiro, v. 23, n. 3, p. 615-26, 2007. Disponível em: 〈http://www.scielo.br/pdf/csp/v23n3/20.pdf $>$. Acesso em: 05 jun. 2017.

BARDIN, L. Análise de conteúdo. Lisboa: Edições 70, 1977. 
BARROS, L. S. O cotidiano de trabalho do ACS: trilhando caminhos entre prescrições e invenções. 2016. Dissertação (Mestrado em Saúde Coletiva). Universidade Federal de São Paulo, São Paulo, 2016.

BODSTEIN, R. Atenção básica na agenda da saúde. Ciênc. Saúde Coletiva, Rio de Janeiro, v.7, n.3, p. 401-412, 2002.

BODSTEIN, R. et al. Estudos de Linha de Base do Projeto de Expansão e Consolidação do Saúde da Família (ELB/Proesf): considerações sobre seu acompanhamento. Ciência \& Saúde Coletiva, Rio de Janeiro, v. 11, n. 3, p. 725-31, 2006.

BORNSTEIN, V. J.; STOTZ, E. N. Concepções que integram a formação e o processo de trabalho dos agentes comunitários de saúde: uma revisão da literatura. Ciência \& Saúde Coletiva, Rio de Janeiro, v. 13, n. 1, p. 259-68, 2008.

BOUSQUAT, A. E. M. et al. Avaliação da Atenção Primária à Saúde. In: TANAKA, O.Y.; RIBEIRO, E.L.; ALMEIDA, C.A.L (Org.). Avaliação em Saúde: contribuições para incorporação no cotidiano. Rio de Janeiro: Atheneu, 2017. Cap. 9, p. 101-13.

BRASIL. Decreto no 78.307, de 24 de agosto de 1976. Aprova o Programa de Interiorização das Ações de Saúde e Saneamento no Nordeste e dá outras providências. Disponível em: < http://www2.camara.leg.br/legin/fed/decret/1970-1979/decreto-78307-24-agosto-1976427254-publicacaooriginal-1-pe.html>. Acesso em: 04 jan. 2018.

BRASIL. Constituição (1988). Constituição da República Federativa do Brasil. Promulgada em 5 de outubro de 1988. Disponível em: <http://www.planalto.gov.br/ccivil_03/constituicao/constituição.htm>. Acesso em: 20 set. 2017.

BRASIL. Ministério da Saúde. Norma Operacional Básica do Sistema Único de Saúde: NOB SUS 96. Brasília: Ministério da Saúde, 1997, p. 34. Disponível em: <http://www.redeblh.fiocruz.br/media/nob.pdf $>$. Acesso em: 06 jul. 2017.

BRASIL. Lei Complementar $\mathbf{n}^{\mathbf{0}}$ 101, de 04 de maio de 2000. Estabelece normas de finanças públicas voltadas para a responsabilidade na gestão fiscal e dá outras providências. Disponível em <http://www.planalto.gov.br/ccivil_03/leis/LCP/Lcp101.htm>. Acessado em: 12 nov. 2017.

BRASIL. Ministério da Saúde. Secretaria de Atenção à Saúde. Departamento de Atenção Básica. Programa de Expansão e Consolidação da Saúde da Família - PROESF. Brasília: Ministério da Saúde, 2003. Disponível em: <http://bvsms.saude.gov.br/bvs/publicacoes/PROESF.pdf>. Acesso em: 17 dez. 2017.

BRASIL. Ministério da Saúde. Secretaria Executiva. Departamento de Apoio à Descentralização. Diretrizes operacionais dos Pactos pela Vida, em Defesa do SUS e de Gestão. Brasília: Ministério da Saúde, 2006.76 p. - (Série A. Normas e Manuais Técnicos).

BRASIL. Ministério da Saúde. Secretaria de Atenção à Saúde. Departamento de Atenção Básica. Política Nacional de Atenção Básica. 4. ed. Brasília: Ministério da Saúde, 2007. 68 p. - (Série E. Legislação de Saúde). Disponível em: $\langle$ http://bvsms.saude.gov.br/bvs/publicacoes/politica_nacional_atencao_basica_4ed.pdf $>$. Acesso em: 15 set. 2016. 
BRASIL. Ministério da Saúde. Secretaria de Atenção à Saúde. Departamento de Atenção Básica. Política Nacional de Atenção Básica. Brasília: Ministério da Saúde, 2012. 110 p: il. - (Série E. Legislação em Saúde).

BRASIL. Ministério da Saúde. Gabinete do Ministro. Portaria n ${ }^{\circ} 2.436$, de 21 de setembro de 2017. Aprova a Política Nacional de Atenção Básica, estabelecendo a revisão de diretrizes para a organização da Atenção Básica, no âmbito do Sistema Único de Saúde (SUS). Diário Oficial da União, Brasília, DF, 22 set. 2017, Seção 1, p. 68.

BRASIL. Ministério da Saúde. Departamento de Atenção Básica. Quais as mudanças da PNAB? 2017. Disponível em:

$\langle$ http://dab.saude.gov.br/portaldab/noticias.php? conteudo=_\&cod=2433 > . Acesso em: 10 out. 2017.

BRASIL. Ministério da Saúde. Conselho Nacional de Saúde. Apresentação. 2018a. Disponível em: <http://conselho.saude.gov.br/apresentacao-cns>. Acesso em: 11 maio 2018.

BRASIL. Ministério da Saúde. Gabinete do Ministro. Portaria ${ }^{\circ} 1.808$, de 28 de junho de 2018b. Altera a Portaria de Consolidação nº 6/GM/MS, de 27 de setembro de 2018, para dispor sobre o financiamento das Equipes de Atenção Básica - eAB e da Gerência da Atenção Básica, instituídos pela Política Nacional de Atenção Básica - PNAB. Disponível em: <http://bvsms.saude.gov.br/bvs/saudelegis/gm/2018/prt1808_29_06_2018.html >. Acesso em: 10 jul. 2019.

BRASIL. Ministério da Saúde. Gestão do SUS: Comissão Intergestores Tripartite.

Disponível em: 〈http://www.saude.gov.br/gestao-do-sus/articulacaointerfederativa/comissao-intergestores-tripartite>. Acesso em: 13 maio 2019.

BRASIL. Ministério da Saúde. Secretaria de Atenção à Saúde. Departamento de Atenção Básica. Nota técnica: Relatório de Cobertura na Atenção Básica. Disponível em: $\langle$ https://egestorab.saude.gov.br/paginas/acessoPublico/relatorios/nota_tecnica/nota_tecnica_r elatorio_de_cobertura_AB.pdf >. Acesso em: 04 jan. 2018.

BRASIL. Ministério da Saúde. Secretaria de Atenção à Saúde. Departamento de Atenção Básica. Novo método de cálculo do indicador Cobertura populacional estimada pelas equipes de Atenção Básica: Nota Metodológica. Disponível em:

$<$ https://egestorab.saude.gov.br/paginas/acessoPublico/relatorios/nota tecnica/nota metodolo gica_AB.pdf >. Acesso em: 04 jan. 2018.

CAMPOS, C. E. A. As origens da rede de serviços de atenção básica no Brasil: o Sistema Distrital de Administração Sanitária. História, Ciências, Saúde-Manguinhos, Rio de Janeiro, v. 14, n. 3, p. 877-906, 2007. Disponível em: $<$ http://www.scielo.br/scielo.php?script=sci_arttext\&pid=S010459702007000300011\&lng=en\&nrm=iso> . Acesso em: 03 maio 2017.

CAMPOS, C. E. A. et al. Trajetória histórica da organização sanitária da Cidade do Rio de Janeiro: 1916-2015. Cem anos de inovações e conquistas. Ciência \& Saúde Coletiva, Rio de Janeiro, v. 21, n. 5, p. 1351-64, 2016. Disponível em: <http://www.scielo.br/scielo.php?script=sci_arttext\&pid $=$ S1413$\underline{81232016000501351 \& \operatorname{lng}=\mathrm{en} \& n \mathrm{~nm}=\mathrm{iso}>}>$. Acesso em: 14 maio 2019.

CAMPOS, C. M. S. et al. Mudanças no capitalismo contemporâneo e seu impacto sobre as políticas estatais: o SUS em debate. Saúde e Sociedade, São Paulo, v. 24, supl. 1, p. 82-91, 
2015. Disponível em: $<$ http://www.scielo.br/scielo.php?script=sci_arttext\&pid=S010412902015000500082\&lng=en\&nrm=iso >. Acesso em: 07 fev. 2018.

CAPELLA, A. C. N. Perspectivas Teóricas sobre o Processo de Formulação de Políticas Públicas. In: HOCHMAN, G. et al. (Org.). Políticas públicas no Brasil, Rio de Janeiro: Fiocruz, 2007, p. 87-122.

CARVALHO, T. O (des)financiamento do SUS: O Sistema Único de Saúde enfrenta uma ameaça de colapso, Revista CONASEMS, Brasília, n. 64, p. 21-6, 2016. Disponível em: <https://www.conasems.org.br/orientacoes-ao-gestor/publicacoes/>. Acesso em: 10 set. 2017.

CASTRO, A. L. B.; MACHADO, C. V. A política federal de atenção básica à saúde no Brasil nos anos 2000. Physis, Rio de Janeiro, v. 22, n. 2, p. 477-506, 2012. Disponível em:

$<$ http://www.scielo.br/scielo.php?script=sci arttext\&pid=S0103-

73312012000200005\&lng=en\&nrm=iso > . Acesso em: 14 ago. 2017.

CECILIO, L. C. O.; REIS, A. A. C. Apontamentos sobre os desafios (ainda) atuais da atenção básica à saúde. Cadernos de Saúde Pública, Rio de Janeiro, v. 34, n. 8, 2018. Disponível em: <http://www.scielo.br/scielo.php?script=sci_arttext\&pid=S0102-

$\underline{311 X 2018000800501 \& \operatorname{lng}=\text { pt\&nrm=iso }>\text {. Acesso em: } 21 \mathrm{dez} .2018 .}$

COHEN, M. et al. A Garbage Can Model of Organizational Choice. Administrative Science Quarterley, v. 17, n. 1, p. 1-25, 1972.

CONSELHO NACIONAL DE SECRETARIAS MUNICIPAIS DE SAÚDE (CONASEMS); CONSELHO NACIONAL DE SECRETÁRIOS DE SAÚDE (CONASS). Nota Conjunta

CONASEMS e CONASS sobre a reformulação PNAB. 2017. Disponível em:

<http://www.conass.org.br/nota-conjunta-conasems-e-conass-sobre-reformulacao-pnab/>. Acesso em: 15 ago. 2017.

CONASS. A queda da imunização no Brasil. CONSENSUS - Revista do Conselho Nacional de Secretários de Saúde. Brasília, ano 7, n. 25, p. 20-9, 2017. Disponível em:

$<$ https://www.conass.org.br/biblioteca/pdf/revistaconsensus_25.pdf $>$. Acesso em: $04 \mathrm{abr}$. 2019.

CONILL, E. M. Ensaio histórico-conceitual sobre a Atenção Primária à Saúde: desafios para a organização de serviços básicos e da estratégia saúde da família em centros urbanos no Brasil. Cadernos de Saúde Pública, Rio de Janeiro, v. 24, supl. 1, p. 7-16, 2008.

DURÃO, A. V. et al. Os agentes comunitários de saúde e o conceito de comunidade na configuração de sua qualificação. In: VIEIRA, M. et al. (Org.). Para além da comunidade: trabalho e qualificação dos agentes comunitários de saúde. Rio de Janeiro: Escola Politécnica de Saúde Joaquim Venâncio, 2011. p. 119-59.

FONSECA, H.L.P. A Reforma da Saúde de Brasília, Brasil. Ciência \& Saúde Coletiva, Rio de Janeiro, v. 24, n. 6, p. 1981-90, 2019. Disponível em:

$<$ http://www.scielo.br/scielo.php?script=sci_arttext\&pid=S1413-

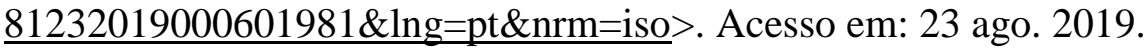

FONTENELLE, L. F. Mudanças recentes na Política Nacional de Atenção Básica: uma análise crítica. Revista Brasileira de Medicina de Família e Comunidade, Florianópolis, v. 7, n. 22, 2012. Disponível em: <https://www.rbmfc.org.br/rbmfc/article/view/417>. Acesso em: 15 set. 2017. 
FREY, K. Políticas Públicas: um debate conceitual e reflexões referentes à prática da análise de políticas públicas no Brasil. Planejamento e Políticas Públicas, n. 21, 2000. p. 211-59.

GIOVANELLA, L. A atenção primária à saúde nos países da União Europeia: configurações e reformas organizacionais na década de 1990. Cadernos de Saúde Pública, Rio de Janeiro, v. 22, n. 5, p. 951-63, 2006. Disponível em: $<$ http://www.scielo.br/scielo.php?script=sci_arttext\&pid=S0102311X2006000500008\&lng=en\&nrm=iso > . Acesso em: 09 out. 2017.

GIOVANELLA, L. et al. Saúde da família: limites e possibilidades para uma abordagem integral de atenção primária à saúde no Brasil. Ciência \& Saúde Coletiva, Rio de Janeiro, v. 14, n. 3, p. 783-94, 2009. Disponível em:

<http://www.scielo.br/scielo.php?script=sci_arttext\&pid=S141381232009000300014\&lng=en\&nrm=iso >. Acesso em: 14 out. 2019.

GIOVANELLA, L.; LOBATO, L. V. C. Sistemas de Saúde: origens, componentes e dinâmica. In: GIOVANELLA L. et al (Ed.). Políticas e Sistemas de Saúde no Brasil. 2. ed. Rio de Janeiro: Fiocruz/Centro Brasileiro de Estudos de Saúde, 2012. p. 107-40.

GODOY, A. S. Introdução à pesquisa qualitativa e suas possibilidades. Revista de Administração de. Empresas, São Paulo, v. 35, n. 2, p. 57-63, 1995.

GOLDENBERG, M. A arte de pesquisar: como fazer pesquisa qualitativa em ciências sociais. 12. ed. Rio de Janeiro: Record, 2011.

GOMES, K. de O. et al. O agente comunitário de saúde e a consolidação do Sistema Único de Saúde: reflexões contemporâneas. Physis, Rio de Janeiro, v. 20, n. 4, p. 1143-64, 2010.

GOTTEMS, L. B. D. et al. Os modelos dos múltiplos fluxos de Kingdon na análise de políticas públicas de saúde: aplicabilidades, contribuições e limites. Saúde e Sociedade, São Paulo, v. 22, n. 2, p.511-20, 2013.

GOUVEIA, R.; PALMA, J. J. SUS: na contramão do neoliberalismo e da exclusão social. Estudos Avançados, São Paulo, v. 13, n. 35, p. 139-46, 1999. Disponível em: $<$ http://www.scielo.br/scielo.php?script=sci_arttext\&pid=S0103-40141999000100014 >. Acesso em: 25 out. 2018.

GUIMARÃES, C. Ministro é vaiado na abertura da CNS ao propor parcerias públicoprivadas. $15^{\text {a }}$ edição da Conferência foi aberta nesta terça-feira em Brasília. EPSJV/Fiocruz. 2015. Disponível em: <http://www.epsjv.fiocruz.br/noticias/reportagem/ministro-e-vaiado-naabertura-da-cns-ao-propor-parcerias-publico-privadas>. Acesso em: 26 jul. 2017.

HALL, P. A.; TAYLOR, R. C. R. As três versões do neo-institucionalismo. Lua Nova, São Paulo, n. 58, p. 193-223, 2003. Disponível em:

$<$ http://www.scielo.br/scielo.php?script=sci_arttext\&pid=S010264452003000100010\&lng=en\&nrm=iso >. Acesso em: 15 abr. 2019.

KINGDON, J.W. Agendas, alternatives and public policies. 2. ed. Nova York: Harper Collins, 2003 [1984].

KINGDON, J. W. Como chega a hora de uma ideia? In: SARAVIA, E.; FERRAREZI, E (Org.). Políticas Públicas: Coletânea. Brasília: ENAP, 2007. p. 219-224.

KINGDON, J. W. Juntando as coisas In: SARAVIA, E.; FERRAREZI, E (Org.).

Políticas Públicas: Coletânea. Brasília: ENAP, 2007. p. 225-246. 
KUSCHNIR, R.; CHORNY, A.H. Redes de atenção à saúde: contextualizando o debate. Ciência \& Saúde Coletiva, Rio de Janeiro, v. 15, n. 5, p. 2307-16, 2010. Disponível em <http://www.scielosp.org/scielo.php?script=sci_arttext\&pid=S1413-

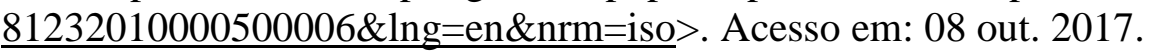

LAVRAS, C. Atenção primária à saúde e a organização de redes regionais de atenção à saúde no Brasil. Saúde e Sociedade, São Paulo, v. 20, n. 4, p. 867-74, jan. 2011. Disponível em: <http://www.revistas.usp.br/sausoc/article/view/29723 >. Acesso em: 30 jan. 2017.

LOTTA, G. O papel das burocracias do nível da rua na implementação de políticas públicas: entre o controle e a discricionariedade. In: FARIA, C. A (Org). Implementação de Políticas Públicas: Teoria e Prática. Belo Horizonte: PUCMINAS, 2012.

MAAS, L. W. D. et al. Segregação socioespacial e oferta de serviços de saúde na Região Metropolitana de Belo Horizonte em 2010. Cadernos Metrópoles, São Paulo, v. 21, n. 45, p. 597-618, 2019.

MACHADO, C. V. et al. Políticas de saúde no Brasil nos anos 2000: a agenda federal de prioridades. Cadernos de Saúde Pública, Rio de Janeiro, v. 27, n. 3, p. 521-32, 2011. Disponível em: <http://www.scielo.br/pdf/csp/v27n3/12.pdf > Acesso em: 12 nov. 2017.

MARQUES, E. As políticas públicas na ciência política. In: MARQUES, E.; FARIA, C. (Org.). A política pública como campo multidisciplinar. São Paulo: Unesp, 2013. Cap. 2, p. 23-46.

MATHIAS, M. ACS: um trabalhador inventado pelo SUS. Revista Poli: Saúde, Educação e Trabalho. Rio de Janeiro, ano I, n. 1, p.24, 2008. Disponível em: 〈http://www.epsjv.fiocruz.br/upload/EdicoesRevistaPoli/R1.pdf>. Acesso em: 23 out. 2017.

MATTOS, R. A.; BAPTISTA, T. W. F. Sobre a ciência e a política. In: MATTOS, R. A.; BAPTISTA, T. W. F. (Org.). Caminhos para análise das políticas de saúde. Porto Alegre: Rede Unida, 2015. p. 29-152.

MELLO, G. A.; et al. Atenção básica e atenção primária à saúde: origens e diferenças conceituais. Revista de APS, Juiz de Fora, v. 12, n. 2, p. 204-13, 2009.

MENDES, E.V. A construção social da atenção primária à saúde. Brasília: Conselho Nacional de Secretários Estaduais de Saúde - CONASS, 2015, p. 193.

MINAYO, M. C. S. Avaliação por triangulação de métodos: abordagem de programas sociais. Rio de janeiro: Fiocruz, 2005.

MOROSINI, M. V. G. C. et al. Política Nacional de Atenção Básica 2017: retrocessos e riscos para o Sistema Único de Saúde. Saúde Debate, Rio de Janeiro, v. 42, n. 116, p. 11-24, 2018. Disponível em: <http://www.scielo.br/scielo.php?script=sci_arttext\&pid=S010311042018000100011\&lng=en\&nrm=iso > . Acesso em: 10 jan. 2019.

NORONHA, J.C. de. Cobertura universal de saúde: como misturar conceitos, confundir objetivos, abandonar princípios. Cadernos de Saúde Pública, Rio de Janeiro, v. 29, n. 5, p. 847-9, 2013.

NUNES, M. de O. et al. O agente comunitário de saúde: construção desse personagem híbrido e polifônico. Cadernos de Saúde Pública, v. 18, n. 6, p. 1639-46, 2002.

OLIVEIRA, D. P. R. Sistemas de Informações Gerenciais. 5. ed. São Paulo: Atlas,1998. 
OLIVEIRA, F. P. de et al. Programa Mais Médicos: avaliando a implantação do Eixo Formação de 2013 a 2015. Interface - Comunicação, Saúde, Educação, Botucatu, v. 23, supl. 1, 2019. Disponível em:

<http://www.scielo.br/scielo.php?script=sci_arttext\&pid=S141432832019000600203\&lng=pt\&nrm=iso >. Acesso em: 17 maio 2019.

ORGANIZAÇÃO PAN-AMERICANA DA SAÚDE. Renovação da Atenção Primária nas Américas: documento de posicionamento da Organização Pan-Americana da Saúde/Organização Mundial da Saúde. 2007, p.44. Disponível em:

$<$ http://bvsms.saude.gov.br/bvs/publicacoes/renovacao_atencao_primaria_saude_americas.pdf >. Acesso em: 08 jan. 2018.

ORGANIZAÇÃO PAN-AMERICANA DA SAÚDE. Organização Mundial de Saúde. Informe Dawson sobre el futuro de lós servicios medicos y afines, 1920. Informe provisional presentado al Ministerio de Salud de la Gran Bretaña en 1920 por el Consejo Consultivo de Servicios Médicos y Afines. Publicación cientifica ${ }^{\circ}{ }^{9}$ 93. Washington, D.C.: OPAS, 1964.

ORGANIZAÇÃO MUNDIAL DE SAÚDE. Declaração de Alma-Ata: Relatório da Conferência Internacional sobre Cuidados Primários de Saúde. OMS/ONU, Alma-Ata, 1978. Disponível em: 〈http://apps.who.int/iris/bitstream/10665/39228/5/9241800011_por.pdf>. Acesso em: 20 ago. 2017.

PAIM. J. S.; ALMEIDA, N. F. Saúde Coletiva: uma "nova Saúde Pública" ou campo aberto a novos paradigmas? Revista de Saúde Pública, v. 32, n. 4, p. 299-316, 1998.

PAIM, J. S. Equidade e reforma em sistemas de serviços de saúde: o caso do SUS. Saúde e Sociedade, São Paulo, v. 15, n. 2, p. 34-46, 2006.

PAULA, L.F; PIRES, M. Crise e perspectivas para a economia brasileira. Estudos Avançados, v. 31, n. 89, p. 125-44, 2017. Disponível em: <http://www.scielo.br/pdf/ea/v31n89/0103-4014-ea-31-89-0125.pdf >. Acesso em: 20 ago. 2017.

PEREIRA, I. C.; OLIVEIRA, M. A. C. O trabalho do agente comunitário na promoção da saúde: revisão integrativa da literatura. Revista Brasileira de Enfermagem, Brasília, v. 66, n. 3, p. 412-9, 2013. Disponível em:

$<$ http://www.scielo.br/scielo.php?script=sci_arttext\&pid=S0034-

71672013000300017\&lng=en\&nrm=iso>. Acesso em: 03 ago. 2019.

PINTO, H. A. Análise da mudança da política nacional de atenção básica. Saúde em Redes, v. 4, n. 2, p. 191-217, 2018. Disponível em:

<http://revista.redeunida.org.br/ojs/index.php/rede-unida/article/view/1796/292 >. Acesso em: 25 fev. 2019.

PINTO, H. A. et al. Programa Mais Médicos: avaliando a implantação do Eixo Provimento de 2013 a 2015. Interface - Comunicação, Saúde, Educação, Botucatu, v. 21, supl. 1, p. 1087 101, 2017. Disponível em: <http://www.scielo.br/scielo.php?script=sci_arttext\&pid=S141432832017000501087\&lng=en\&nrm=iso>. Acesso em: 04 mar. 2018.

PRATES, M. L. et al. Desempenho da Atenção Primária à Saúde segundo o instrumento PCATool: uma revisão sistemática. Ciência \& Saúde Coletiva, Rio de Janeiro, v. 22, n. 6, p. 1881-93, 2017. Disponível em: 
$<$ http://www.scielo.br/scielo.php?script=sci_arttext\&pid=S1413-

81232017002601881\&lng=pt\&nrm=iso >. Acesso em: 05 abr. 2019.

QUEIROS, A. A. L.; LIMA, L. P. A institucionalização do trabalho do agente comunitário de saúde. Trabalho, Educação e Saúde, Rio de Janeiro, v. 10, n. 2, p. 257-81, 2012.

Disponível em: <http://www.scielo.br/scielo.php?script=sci_arttext\&pid=S198177462012000200005\&lng=en\&nrm=iso >. Acesso em: 10 jun. 2019.

REIS, J.G. et al. Criação da Secretaria de Atenção Primária à Saúde e suas implicações para o SUS. Ciência \& Saúde Coletiva [internet], 2019. Disponível em:

$<$ http://www.cienciaesaudecoletiva.com.br/artigos/criacao-da-secretaria-de-atencao-primariaa-saude-e-suas-implicacoes-para-o-sus/17305?id=17305 >. Acesso em: 20 ago. 2019.

ROUSSEF, D. Dilma anuncia reforma administrativa com redução de oito ministérios. 2015. Disponível em: <http://www.casacivil.gov.br/central-deconteudos/noticias/2015/outubro/dilma-anuncia-reforma-administrativa-com-reducao-de-8ministerios >. Acesso em: 23 abr. 2019.

RUA, M. G. Políticas Públicas. 2. ed. Florianópolis: Departamento de Ciências da Administração, Universidade Federal de Santa Catarina, 2012. 128 p.

SÁ-SILVA, J.R; ALMEIDA, C.D.; GUINDANI, J.F. Pesquisa documental: pistas teóricas e metodológicas. Revista Brasileira de História \& Ciências Sociais, São Leopoldo, ano I, n. I, 2009. 15 p.

SECRETARIA DE POLITICAS DE SAUDE. Departamento de Atenção Básica. Programa Saúde da Família. Revista de Saúde Pública, v. 34, n. 3, p. 316-9, 2000. Disponível em: $<$ http://www.scielo.br/scielo.php?script=sci_arttext\&pid=S0034-

89102000000300018\&lng=en\&nrm=iso>. Acesso em: 08 jan. 2018

SICSÚ, J. O que é que produz o ajuste fiscal? Carta Capital, 2015. Disponível em: <https://www.cartacapital.com.br/opiniao/o-que-e-e-o-que-produz-o-ajuste-fiscal-2903$\underline{\mathrm{html} />}$. Acesso em: 29 maio 2019.

SILVA, S. F. Municipalização da saúde e poder local: sujeitos, atores e políticas. São Paulo: Hucitec, 2001. 293 p.

SILVEIRA, L. B. A produção teórica da Saúde Coletiva brasileira na década de 90: texto, contexto e mudança social. 2015. Dissertação (Mestrado em Saúde Pública) - Escola Nacional de Saúde Pública, Fundação Oswaldo Cruz, Rio de Janeiro, 2015.

SOUZA, C. Políticas públicas: uma revisão de literatura. Sociologias, Porto Alegre, v. 8, n. 16, p. 20-45, 2006.

STARFIELD, B. Atenção Primária: equilíbrio entre necessidades de saúde, serviços e tecnologia. Brasília: UNESCO, Ministério da Saúde, 2002, 726 p.

TEIXEIRA, L.A. Comentário: Rodolfo Mascarenhas e a história da saúde pública em São Paulo. Revista de Saúde Pública, São Paulo, v. 40, n. 1, p. 3-19, 2006. Disponível em: <http://www.scielo.br/pdf/rsp/v40n1/27110.pdf $>$. Acesso em: 17 out. 2017.

VIANA, A. L. Abordagens metodológicas em políticas públicas. Revista de Administração Pública, Rio de Janeiro, v. 30, n. 2, p. 5-43, 1996.

VIOMUNDO. Deputados protocolam projeto que anula nova política de assistência do Ministério da Saúde: Prejudicial a usuários e profissionais. 2017. Disponível em: 
$<$ http://www.viomundo.com.br/denuncias/deputados-protocolam-projeto-que-anula-novapolitica-de-assistencia-do-ministerio-de-saude-graves-prejuizos-a-usuarios-eprofissionais.html> Acesso em: 03 jan. 2018.

VUORI, H. Health for all, primary health care and general practitioners. Journal of the Royal College of General Practitioners, v. 36, p. 398-402, 1986. 


\section{ANEXOS \\ Anexo 1 - Termo de Consentimento Livre e Esclarecido}

Você está sendo convidado(a) a participar da pesquisa: "Contexto, problemas e alternativas: análise da configuração da agenda de revisão da política nacional de atenção básica".

No Brasil, Atenção Básica (AB) aparece na agenda de governo como política prioritária e a Política Nacional de Atenção Básica (PNAB) tem importante papel na condução dos esforços governamentais para a garantia do acesso à saúde e organização do sistema de saúde.

Esta pesquisa propõe analisar o processo decisório sobre as alterações nas diretrizes para composição da equipe de atenção básica, levando em consideração as motivações técnicas e políticas, a atuação dos atores, o processo de negociação e possíveis repercussões no desenvolvimento da PNAB.

Para isso será realizada análise de documentos normativos e institucionais, relacionados ao processo de revisão das diretrizes da PNAB de 2017. Também serão realizadas entrevistas com sujeitos que participaram do processo de discussão da proposta de revisão da PNAB 2017. As entrevistas serão gravadas e transcritas exclusivamente como material de análise nesta pesquisa. Os dados coletados serão categorizados e analisados conforme o fluxo político, de problemas e soluções, que são elementos do modelo de análise chamado de Múltiplos Fluxos, bastante utilizado para se estudar como uma determinada demanda ganha a agenda de governo, dando origem a formulação de Políticas Públicas.

Você tem o direito de receber resposta a qualquer pergunta ou esclarecimento de qualquer dúvida a respeito dos procedimentos, riscos, benefícios e outras situações relacionadas com a pesquisa e divulgação dos resultados.

Tem a liberdade de retirar o seu consentimento e deixar de participar do estudo, a qualquer momento, sem que isso lhe traga quaisquer prejuízos.

Os potenciais riscos e desconfortos da sua participação na pesquisa podem decorrer de alguma situação em que não se sinta confortável em falar sobre algum assunto, entretanto esclarecemos que você poderá a qualquer momento se negar a responder qualquer questão, ou até mesmo se retirar da pesquisa, sem nenhuma repercussão para si ou instituição a que pertence.

Enquanto participante do estudo poderá se beneficiar com a discussão sobre a revisão da PNAB durante a entrevista. Indiretamente as pessoas podem se beneficiar à medida que a maior compreensão dos processos de definição da agenda auxilia na produção de políticas públicas mais eficientes e efetivas.

As informações obtidas através dessa pesquisa serão confidencias, asseguramos que os dados serão trabalhados de forma a manter o caráter confidencial das informações relacionadas à sua privacidade. No entanto, esclarecemos que pela natureza da pesquisa, é possível que sejam nomeadas instituições ou movimentos que se posicionaram publicamente com relação a revisão da PNAB e que porventura você pode fazer parte.

Você receberá uma cópia deste termo onde consta o telefone e o endereço do pesquisador, podendo tirar suas dúvidas sobre o projeto e sua participação, agora ou a qualquer momento. participar.

Declaro que entendi os objetivos, riscos e benefícios de minha participação na pesquisa e concordo em

O pesquisador me informou que o projeto foi aprovado pelo Comitê de Ética em Pesquisa em Seres Humanos da Faculdade de Saúde Pública da Universidade de São Paulo, localizada na Av. Dr. Arnaldo, 715, Cerqueira César - CEP 01246-904 - São Paulo - SP - Brasil. Fone (11) 3061-7779. Endereço eletrônico: coep@fsp.usp.br.

de de 
Anexo 2 - Consentimento para Gravação de Voz

$\mathrm{Eu}$, portador(a) do CPF: permito que o pesquisador Américo Yuiti Mori, grave em áudio a entrevista concedida por mim para fins de pesquisa.

A gravação visa registro do material a ser utilizado como fonte de dados da pesquisa intitulada "Contexto, problemas e alternativas: análise da agenda de revisão da Política Nacional de Atenção Básica". As informações obtidas têm como única finalidade de compor os dados da pesquisa e observará a confidencialidade e privacidade do entrevistado, conforme informado no Termo de Consentimento Livre Esclarecido.

Assinatura do Participante

Pesquisador Américo Yuiti Mori

de de 